Débora Maria Barbosa Salvador de Souza

\title{
Abordagem Baseada em Lógica Fuzzy para Alocação de Indicadores de Faltas em Sistemas de Distribuição de Energia Elétrica
}

Dissertação apresentada à Escola de Engenharia de São Carlos da Universidade de São Paulo, sendo parte dos requisitos para obtenção do título de Mestre em Engenharia Elétrica.

Orientador: Prof. Dr. Ivan Nunes da Silva

São Carlos 

"A felicidade não está em viver, mas em saber viver. Não vive mais o que mais vive, mas o que melhor vive." 



\section{Agradecimentos}

Agradeço primeiramente ao meu orientador Prof. Ivan Nunes da Silva que me incentivou a iniciar esta etapa da minha carreira e por suas orientações nos trabalhos que realizamos.

Aos professores pelos ensinamentos que me proporcionaram, aprimorando meus conhecimentos para o desempenho de minhas atividades.

Ao meu marido Luiz Henrique e minhas filhas Amanda e Maria Luiza pelo incentivo, apoio e carinho em todos os momentos em que me dediquei aos estudos.

Aos meus pais pelas suas orações e incentivo.

Aos amigos Rogério Flauzino, Danilo Spatti, Wesley Usida e Valmir Ziolkowski pela amizade e suporte que tem me fornecido.

Ao Luis Eduardo Oliveira Pinheiro, Luis Porta, Dirceu Camargo e Marcelo Vilarino da Elektro, pelo apoio e incentivo para que eu conseguisse chegar até aqui. 



\section{Resumo}

SOUZA, D. M. B. S. (2009). Abordagem Baseada em Lógica Fuzzy para Alocação de Indicadores de Faltas em Sistemas de Distribuição de Energia Elétrica. Dissertação (Mestrado) - Escola de Engenharia de São Carlos, Universidade de São Paulo, 2009.

Este trabalho apresenta uma metodologia para alocação eficiente de dispositivos indicadores de faltas em sistemas de distribuição de energia elétrica. São avaliadas como as principais variáveis que influenciam na quantificação da potencialidade para instalação de dispositivos indicadores de faltas se comportam ao longo do tronco principal dos alimentadores de distribuição de energia elétrica. Como metodologia, empregou-se sistemas de inferência fuzzy para quantificar a referida potencialidade a partir das variáveis avaliadas. Resultados com dados reais destacam também a eficiência da metodologia proposta para quantificar e avaliar a rede de dispositivos indicadores já existentes em alimentadores.

Palavras chave: Indicador de faltas, sistemas de distribuição, sistemas fuzzy, restabelecimento de energia. 



\begin{abstract}
SOUZA, D. M. B. S. (2009). Approach Based on Fuzzy Logic for Fault Indicator Allocation in Power Distribution Systems. Dissertation (Master's Degree) - Escola de Engenharia de São Carlos, Universidade de São Paulo, 2009.

This work presents a methodology for efficient allocation of fault indicator devices in electric power distribution systems. The behavior of the main variables that influence in the quantification of the potentiality for installation of fault indicator devices were analyzed taking into account the feeder length. In methodology terms, fuzzy inference systems were used to quantify this potentiality from the analyzed variables. Results with real data have also highlighted the efficiency of the proposed methodology to quantify and to evaluate the fault indicator device network already existent in power distribution feeders.
\end{abstract}

Keywords: Fault indicators, power distribution system, fuzzy systems, system reestablishment. 



\section{Lista de Siglas e Abreviaturas}
ANEEL Agência Nacional de Energia Elétrica
COD Centro de Operação da Distribuição
DEC Duração Equivalente de Interrupção por Unidade Consumidora
FEC Freqüência Equivalente de Interrupção por Unidade Consumidora
IF Indicador de Faltas
SCADA Supervisory Control and Data Acquisition
PRODIST Procedimentos de Distribuição
ELEKTRO Elektro Eletricidade e Serviço S.A. 



\section{Lista de Figuras}

FIGURA 2.2 - Pontos de instalação de indicadores de faltas. .............................19

FIGURA 2.3 - Modelos de indicadores de faltas..............................................20

FIGURA 2.4 - Diferentes modelos de indicadores de faltas de cabo......................22

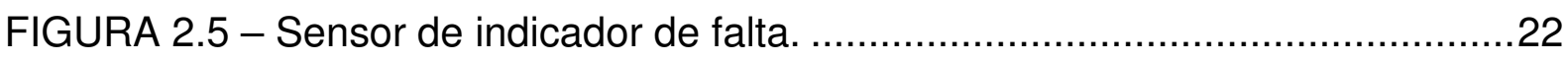

FIGURA 2.6 - Indicadores de faltas instalados nas três fases..........................23

FIGURA 2.7 - Esquema do indicador de faltas instalado no poste......................26

FIGURA 2.8 - Indicador de faltas de poste. .............................................27

FIGURA 3.1 - Funções de pertinência.................................................... 32

FIGURA 3.2 - Representação da variável lingüística corrente. ..........................36

FIGURA 3.3 - Mecanismo de inferência fuzzy.......................................... 38

FIGURA 3.4 - Diagrama típico de um modelo de sistemas fuzzy........................39

FIGURA 4.1 - llustração de sistema de distribuição visando delineamento do método

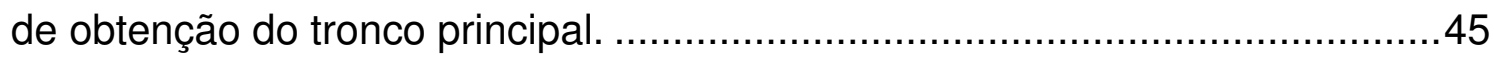

FIGURA 4.2 - Sistema de distribuição com destaque para o tronco principal. ........48

FIGURA 4.3 - Alimentador AL-1 com destaque para o tronco principal. ................49

FIGURA 4.4 - Comportamento da carga e do número de clientes ao longo do tronco

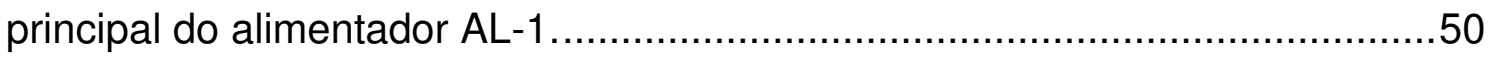

FIGURA 4.5 - Comportamento da corrente de curto-circuito mínima ao longo do

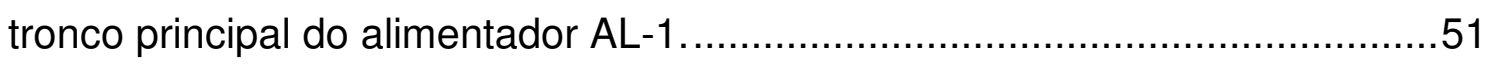

FIGURA 4.6 - Alimentador AL-2 com destaque para o tronco principal. .................51

FIGURA 4.7 - Comportamento da carga e do número de clientes ao longo do tronco principal do alimentador AL-2. 
FIGURA 4.8 - Comportamento da corrente de curto-circuito mínima ao longo do tronco principal do alimentador AL-2.

FIGURA 4.9 - Distância normalizada até os dispositivos indicadores de faltas ao longo do tronco principal do alimentador AL-1.

FIGURA 4.10 - Distância normalizada até os dispositivos indicadores de faltas ao longo do tronco principal do alimentador AL-2. 55

FIGURA 4.11 - Diagrama esquemático do sistema fuzzy empregado para o cálculo do potencial de instalação de dispositivos indicadores falta.

FIGURA 4.12 - Ilustração de função de pertinência normalizada para o cálculo do potencial de instalação de dispositivos indicadores de falta.

FIGURA 4.13 - Potencial para instalação de dispositivos indicadores de faltas ao longo do tronco principal do alimentador AL-1 60

FIGURA 4.14 - Potencial para instalação de dispositivos indicadores de faltas ao longo do tronco principal do alimentador AL-2.

FIGURA 5.1 - Estratégia de software em Matlab para automatização das simulações. 63

FIGURA 5.2 - Alimentador IGU04 com destaque para o tronco principal 65

FIGURA 5.3 - Comportamento da carga e do número de clientes ao longo do tronco principal do alimentador IGU04. 66

FIGURA 5.4 - Comportamento da corrente de curto-circuito mínima ao longo do tronco principal do alimentador IGU04.

FIGURA 5.7 - Alimentador TTD18 com destaque para o tronco principal. 71

FIGURA 5.8 - Comportamento da carga e do número de clientes ao longo do tronco principal do alimentador TTD18 72 
FIGURA 5.9 - Comportamento da corrente de curto-circuito mínima ao longo do tronco principal do alimentador TTD18.

FIGURA 5.10 - Distância normalizada até os dispositivos indicadores de faltas ao longo do tronco principal do alimentador TTD18.

FIGURA 5.11 - Potencial para instalação de dispositivos indicadores de faltas ao longo do tronco principal do alimentador TTD18. 75

FIGURA 5.12 - Alimentador RCA42 com destaque para o tronco principal. 76

FIGURA 5.13 - Comportamento da carga e do número de clientes ao longo do tronco principal do alimentador RCA42.

FIGURA 5.14 - Comportamento da corrente de curto-circuito mínima ao longo do tronco principal do alimentador RCA42. 78

FIGURA 5.15 - Distância normalizada até os dispositivos indicadores de faltas ao longo do tronco principal do alimentador RCA42.

FIGURA 5.16 - Potencial para instalação de dispositivos indicadores de faltas ao longo do tronco principal do alimentador RCA42.

FIGURA 5.17 - Alimentador IGU05 com destaque para o tronco principal.

FIGURA 5.18 - Comportamento da carga e do número de clientes ao longo do tronco principal do alimentador IGU05.

FIGURA 5.19 - Comportamento da corrente de curto-circuito mínima ao longo do tronco principal do alimentador IGU05.

FIGURA 5.20 - Distância normalizada até os dispositivos indicadores de faltas ao longo do tronco principal do alimentador IGU05.

FIGURA 5.21 - Potencial para instalação de dispositivos indicadores de faltas ao longo do tronco principal do alimentador IGU05.

FIGURA 5.22 - Alimentador IGU03 com destaque para o tronco principal. 
FIGURA 5.23 - Comportamento da carga e do número de clientes ao longo do tronco principal do alimentador IGU03.

FIGURA 5.24 - Comportamento da corrente de curto-circuito mínima ao longo do tronco principal do alimentador IGU03.

FIGURA 5.25 - Distância normalizada até os dispositivos indicadores de faltas ao longo do tronco principal do alimentador IGU03. 90

FIGURA 5.26 - Potencial para instalação de dispositivos indicadores de faltas ao longo do tronco principal do alimentador IGU03 


\section{Lista de Tabelas}

TABELA 2.1 - Comparação entre alguns fabricantes de Indicadores de faltas instalados em cabo. 24

TABELA 2.2 - Comparação entre alguns fabricantes de Indicadores de faltas instalados em poste .25

TABELA 4.1 - Regras para o sistema fuzzy ..... 58 



\section{SUMÁRIO}

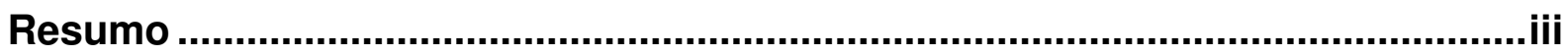

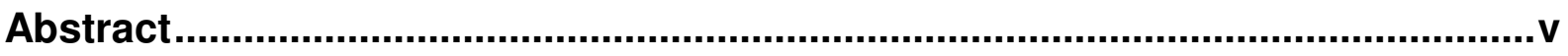

Lista de Siglas e Abreviaturas .............................................................................. vii

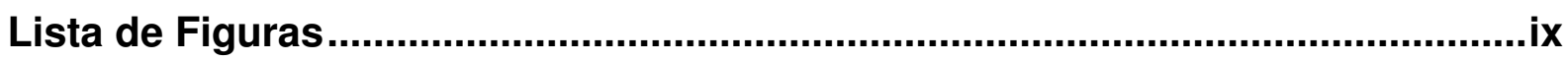

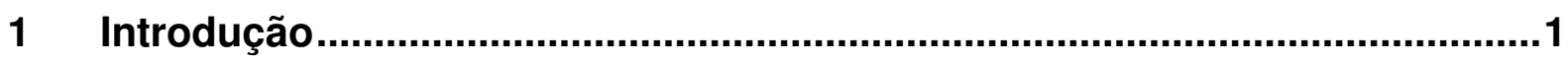

1.1 Motivação e Relevância do Trabalho …………..................................

1.2 Proposta e Justificativa do Trabalho …............................................. 4

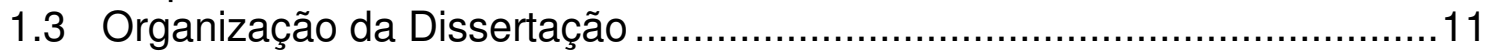

2 Aspectos Técnicos Relacionados aos Indicadores de Faltas em Sistemas de Distribuição de Energia Elétrica ..........................................................13

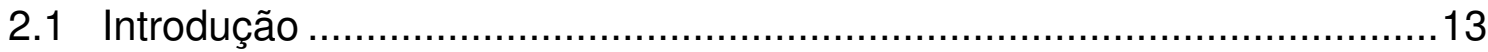

2.2 Aspectos Gerais dos Indicadores de Falta ........................................16

2.2.1 Descrição Funcional .......................................................... 16

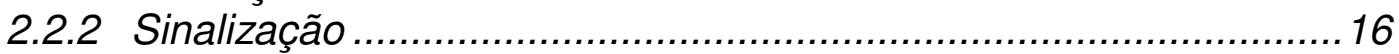

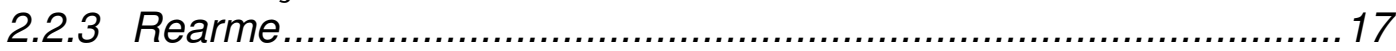

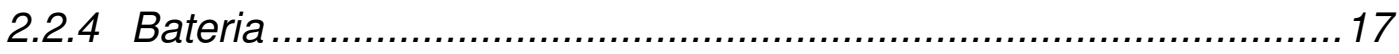

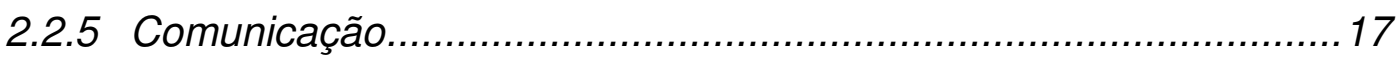

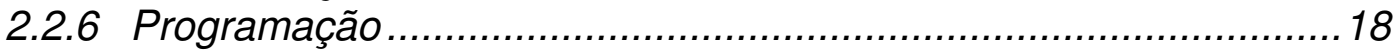

2.2.7 Pontos de Aplicação de Indicadores de Falta...............................18

2.2.8 Manutenção.....................................................................20

2.3 Indicadores de Faltas Instalados no Cabo Condutor-Fase ......................20

2.4 Indicadores de Faltas Instalados em Poste.........................................25

2.5 Novas Tecnologias Construtivas para Indicadores de Faltas...................27

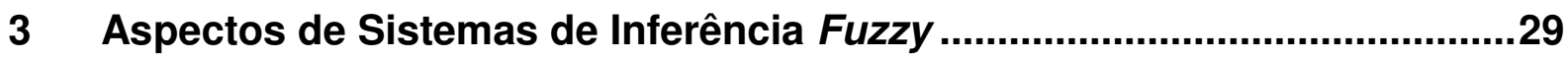

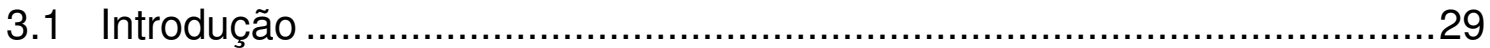

3.2 Conceitos sobre Conjuntos e Lógica Fuzzy ….....................................31

3.3 Definição de Operações e Operadores da Lógica Fuzzy ...........................34

3.4 Regras Fuzzy e Agregação de Regras ................................................35

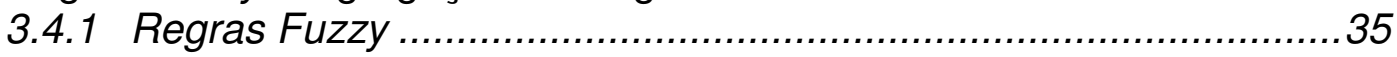

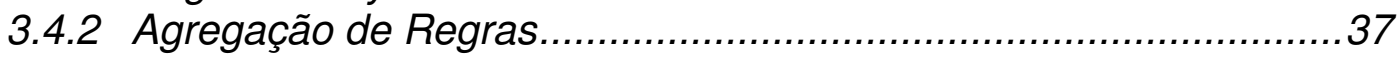

4 Método de Alocação de Indicadores de Faltas Usando Lógica Fuzzy .......41

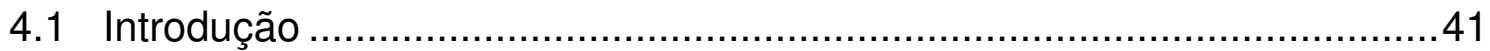

4.2 Descrição do Método Proposto ……………......................................42 
4.2.1 Variáveis Pertinentes ao Cálculo do Potencial Para Instalação de Dispositivos Indicadores de Falta ..................................................... 42

4.2.2 Determinação do Tronco Principal............................................... 44

4.2.3 Comportamento da Carga e do Número de Clientes à Jusante do Tronco Principal de Alimentadores de Distribuição ................................ 48

4.2.4 Distância aos Dispositivos Indicadores de Faltas Adjacentes........ 53

4.3 Sistema Fuzzy Para o Cálculo do Potencial de Instalação de Dispositivos

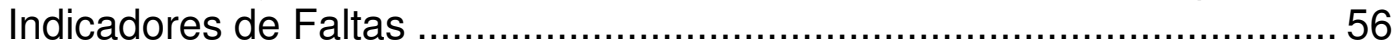

5 Resultados de Aplicação em Alimentadores Reais .....................................63

5.1 Resultados Para Alimentador IGU04 ……......................................... 64

5.2 Resultados Para Alimentador TTD18 ………….............................. 70

5.3 Resultados Para Alimentador RCA42 ………….............................. 75

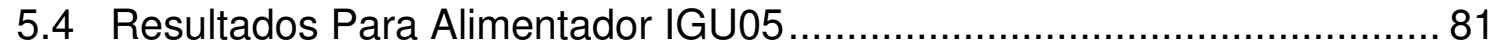

5.5 Resultados Para Alimentador IGU03 ……….................................... 87

6 Conclusões e Trabalhos Futuros ........................................................... 93

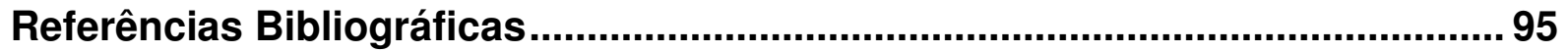




\section{Introdução}

\subsection{Motivação e Relevância do Trabalho}

A demanda por energia elétrica é cada vez maior em nossa sociedade. Juntamente com uma grande procura por energia elétrica, torna-se necessário o constante investimento no setor, tendo sempre como objetivo primeiro que a qualidade do serviço oferecido não seja comprometida.

Em um contexto atual a qualidade da energia está intimamente ligada ao fornecimento ininterrupto dessa. Indicadores da qualidade da energia elétrica fornecida, tais como o DEC (Duração Equivalente de Interrupção por Unidade Consumidora) e o FEC (Freqüência Equivalente de Interrupção por Unidade Consumidora), relacionam energia de boa qualidade como àquela fornecida ininterruptamente. Nos sistemas elétricos de potência, um dos principais fatores para a interrupção do serviço é a ocorrência de faltas. Estas demandam os maiores esforços das equipes de restabelecimento, pois exigem uma patrulha minuciosa, seja nos sistemas de distribuição ou de transmissão, para mitigar definitivamente o agente causador da falta.

Para que a energia elétrica entregue pelas concessionárias sofra menos abalos em conseqüência da ocorrência de uma falta, cada vez mais grupos de pesquisa estudam formas de modernizar os sistemas de proteção e melhorar 0 tempo de resposta dos mesmos diante de tal situação. Tanto isto é uma realidade que na literatura técnico-científica a presença de ferramentas inovadoras atuando na 
proteção dos sistemas elétricos de potência sempre é uma tônica em diversos trabalhos recentes, como pode ser observada nas referências bibliográficas, as quais envolvem automação da proteção e localização inteligente de uma falta. Essas linhas de pesquisa objetivam incrementar a confiabilidade e redundância do sistema visando reduzir o tempo em que o fornecimento de energia elétrica fica interrompido.

Os modernos sistemas elétricos de potência são caracterizados, dentre outros aspectos, pela alta disponibilidade temporal do fornecimento de energia elétrica com qualidade adequada ao correto funcionamento dos equipamentos supridos por esse sistema. A busca pela viabilidade técnico-financeira desse tipo de sistema guia o desenvolvimento de equipamentos e ferramentas computacionais que auxiliem no projeto, no estudo e no planejamento de expansão dedicada ao contexto dos sistemas elétricos de potência.

Preocupadas com a evolução da proteção dos sistemas elétricos de potência, as empresas do setor investem cada vez mais na inserção de dispositivos, tais como os indicadores de faltas, os quais são instalados nos sistemas de distribuição e são também os objetos principais deste estudo. Tais equipamentos já fazem parte do rol de proteção de um sistema elétrico de potência, tendo grande importância na identificação dos locais de falta, pois por meio de sua sinalização, quando da ocorrência dessas, seria possível percorrer e inspecionar o caminho que o distúrbio seguiu pelo sistema e assim mitigar sua origem.

Em virtude da complexidade decorrente do número e da diversidade topológica, verifica-se grande aporte de recursos especialmente atribuídos ao desenvolvimento de ferramentas de suporte para os sistemas de distribuição de energia elétrica. Dessas ferramentas, destaca-se o projeto automático de sistemas de proteção contra sobretensões de origem atmosférica (Santos et al., 2009), a 
avaliação do comportamento em freqüência para transformadores (Silva et al., 2005), bem como a especificação da melhor topologia de aterramento para os equipamentos inseridos no sistema de distribuição (Silva et al., 1999).

Além dessas linhas de pesquisas, outra tem merecido destaque no cenário compreendido pelas concessionárias de energia elétrica e diz respeito às ações que permitam uma proteção eficiente ao longo das linhas de distribuição. Um exemplo desse tipo de pesquisa é a busca dos melhores pontos para alocação de dispositivos de proteção em redes de distribuição de energia elétrica (Soudi \& Tomsovic, 1998, 1999, 2001; Wang \& Thorp, 2001). Nesses trabalhos a alocação dos dispositivos é realizada de maneira estratégica a garantir que, diante de uma condição de falta e da operação adequada do sistema de proteção, o menor número de consumidores ou de cargas ficará abstido do fornecimento de energia elétrica. Em outras palavras, esses dispositivos de proteção são alocados de forma a contribuir para a melhora dos índices de desempenho da concessionária de energia elétrica.

Nessa mesma linha de investigação, mais recentemente, destaca-se o estudo dos indicadores de faltas (Krajnak, 2000) e sua alocação ótima junto à rede de distribuição de energia elétrica (Duc-Pham et al., 2005). Os indicadores de faltas são dispositivos instalados ao longo do sistema de distribuição e possuem como funcionalidade a capacidade de indicar se o sistema experimentou algum tipo de falta à jusante de sua instalação (Angerer, 2001). Esses dispositivos vêm a contribuir com a redução do tempo necessário para que a equipe de manutenção consiga localizar o ponto de ocorrência da referida falta.

Em função dos ganhos promovidos pela alocação desses dispositivos nos sistemas de distribuição de energia elétrica, o número de indicadores de faltas 
instalados nos mesmos encontra-se em franco crescimento. Assim, em virtude desse crescimento expressivo e dos ganhos decorrentes de seu emprego, o interesse pelo desenvolvimento de metodologias e de ferramentas computacionais capazes de auxiliar no planejamento de sua instalação é latente, conforme se verifica por meio da comunidade especializada internacional (Tang et al., 2000).

Nesse contexto, aporte crescente pelos sistemas providos pela inteligência computacional é observado por meio do progressivo número de publicações relatando os resultados decorrentes de seu emprego. Assim, os indicadores de faltas também são objetos de estudos potenciais das ferramentas de sistemas inteligentes.

Um exemplo é a investigação do ponto ótimo de inserção desses equipamentos no sistema (Duc-Pham et al., 2005). Partindo-se do fato que o número de dispositivos indicadores de faltas é limitado, no referido trabalho foram empregados algoritmos genéticos para se determinar os pontos ótimos de inserção desses equipamentos, levando-se também em conta o histórico de ocorrências de faltas permanentes em pontos da rede de distribuição de energia elétrica.

\subsection{Proposta e Justificativa do Trabalho}

Se um equipamento de proteção não atuar de forma correta, toda uma cadeia de eventos pode ser disparada, culminando com a interrupção do fornecimento de energia elétrica. Como a mitigação de faltas requer conhecimento de todos os equipamentos envolvidos na proteção, considerando ainda como utilizálos em conjunto e aproveitando também suas características e minimizando suas limitações, além de um sem número de informações vindas do ambiente em estudo, deve-se então lançar mão de todas as ferramentas disponíveis visando enquadrar a solução mais factível para o problema. 
Como o setor de energia elétrica está em constante expansão e mudanças, um estudo sobre a inserção adequada de dispositivos de proteção como um indicador de faltas é deveras importante, já que não existem regras e metodologias definidas que melhor expliquem os pontos mais adequados de instalação desses dispositivos, assim como a sua quantidade. Deste modo, para a realização deste trabalho, foram levantadas informações sobre a ocorrência de faltas na empresa ELEKTRO, concessionária de distribuição de energia elétrica, bem como as características dessas e da rede onde os indicadores de faltas foram instalados.

De fato, o desenvolvimento dos sistemas elétricos de potência, desde seus primórdios, se deu de forma paralela e compassada à evolução dos sistemas de proteção dedicados aos mesmos (Zahra et al., 2000). Com o advento de novas tecnologias, diversas foram as filosofias de proteção que emergiram no escopo dos sistemas elétricos de potência. Porém, mesmo em face das diferenças conceituais entre tais filosofias, o objetivo primordial de cada uma dessas é a correta identificação de faltas e, em face de sua identificação, disponibilizar o controle adequado para os dispositivos de seccionamento responsáveis por isolarem o setor defeituoso do restante do sistema. Além disso, o sistema de proteção deve atuar de maneira seletiva, proporcionando a minimização do número de clientes que se encontrarão desprovidos do fornecimento de energia elétrica quando da ocorrência de uma falta (Cho \& Ha, 1998; Tang et al., 2000).

Assim, diante de uma falta no sistema elétrico de potência e mesmo frente à correta operação do sistema de proteção, existirá um determinado número de clientes que provisoriamente estarão sob uma condição de não fornecimento de energia elétrica. Esse cerceamento da energia elétrica, mesmo que por curtíssimos intervalos de tempo, podem decorrer em danos a equipamentos de consumidores, 
conduzir à situações de riscos e, de uma maneira geral, gerar prejuízos financeiros (Choi et al., 1999). Dessa forma, a localização rápida e precisa de uma falta torna-se imprescindível para a operação segura e econômica do sistema e, motivada por esses aspectos, a comunidade técnico-científica e especializada solidificaram linhas de pesquisas correlatas ao tema.

No entanto, mesmo diante de pesquisas voltadas ao tema de localização de faltas, o procedimento adotado, na maioria dos casos em sistemas de distribuição, para se identificar o ponto onde a falta ocorreu é baseado em inspeção visual. Procedendo segundo essa metodologia convencional, a equipe de restabelecimento responsável inspeciona visualmente a linha de distribuição a fim de identificar anomalias estruturais que possam ter desencadeado a falta. Esta técnica, dependendo da extensão da rede de distribuição, pode elevar o tempo em que o sistema fica sem energia elétrica a níveis capazes de depreciar significativamente os índices de desempenho da concessionária (Zhang \& Sang, 2004).

Contornando a precariedade da metodologia convencional para localização de faltas, inúmeros dispositivos, denominados por indicadores de faltas (ou ainda por identificadores de circuitos faltosos), foram desenvolvidos desde meados dos anos quarenta. Esses dispositivos, os quais são instalados ao longo da rede de distribuição de energia elétrica, têm por funcionalidade indicar se alguma condição de falta, identificada seja por corrente, ou por tensão, ocorreu à sua jusante. Assim, tais dispositivos objetivam agregar mais confiabilidade à proteção do sistema, pois sua correta operação proporcionaria uma redução do tempo de patrulha da equipe de restabelecimento responsável pela inspeção da linha após uma falta (Baker et al., 2001). 
O emprego de indicadores de faltas em sistema elétricos de potência tem nos seus primórdios a iniciativa da Companhia Horstmann, a qual em 1946 desenvolvera na Alemanha os primeiros indicadores de faltas (Angerer, 2001). Esses primeiros dispositivos possuíam sinalização mecânica, a qual era comandada pela rotação de um disco mediante a passagem de uma corrente elétrica acima do ajuste programado. Uma vez que esses dispositivos sinalizassem uma falta, a indicação da mesma permanecia até que, manualmente, o dispositivo indicador de faltas fosse rearmado.

Dessa forma, quando diante da ocorrência de uma falta no sistema de distribuição de energia elétrica, todos os indicadores de faltas à montante do ponto de incidência necessitavam ser rearmados, pois, em tese, todos esses dispositivos estavam em estado de indicação de falta. Esse tipo de operação de rearme manual decorre em um maior número de procedimentos para restabelecimento do sistema após a identificação da falta. Além desse inconveniente, esses dispositivos possuíam uma taxa de erros relativamente elevada, principalmente no que se refere à não identificação de faltas. Esse aspecto frustrou inicialmente as concessionárias quanto ao seu emprego em larga escala.

Mesmo diante das limitações observadas nos primeiros modelos de indicadores de falta, sua aplicação não caiu em desuso em função da demanda latente por esse tipo de dispositivo e os primeiros avanços logo se deram, iniciandose quando o rearme deixou de ser manual e passou a ser automático. O rearme automático se dava após um determinado tempo, contado a partir do momento em que a corrente voltava a patamares pré-ajustados ou após a normalização da tensão no sistema (Angerer, 2001). 
Outro avanço tecnológico de merecida citação se deu em meados dos anos setenta. A companhia Horstmann introduziu em 1976 uma bateria de lítio em seus indicadores de faltas. A utilização de uma fonte externa de energia permitiu aumentar a vida útil dos equipamentos, bem como testar os mecanismos de funcionamento, sem maiores intervenções físicas (Angerer, 2001). Além disso, um sistema de fornecimento de energia autônomo dedicado aos indicadores de faltas garantia o funcionamento desses mesmos quando, em virtude da atuação do sistema de proteção, a tensão no ponto de instalação do indicador fosse nula. Esse aspecto permitiu então melhorar a operação dos indicadores de faltas, reduzindo-se as condições nas quais as indicações de falta eram impossibilitadas pela ausência de alimentação.

Dessa forma, os indicadores de faltas poderiam ser rearmados e colocados em operação independentemente da intervenção humana. Esse avanço e a disponibilidade de novas tecnologias na área da eletrônica impulsionaram as empresas do setor a investirem em novos desenvolvimentos. Assim, com o advento de indicadores de faltas implementados por meio de circuitos eletrônicos, e não mais de forma eletromecânica, os erros de operação e as atuações indevidas foram minimizados significativamente e novos horizontes foram traçados para os dispositivos indicadores de faltas (Krajnak, 2000).

Atualmente, novos adventos científicos estão sendo propostos para a elaboração de indicadores de faltas que venham a contribuir para o aumento de sua sensibilidade e robustez de sua operação. Dentre as técnicas e metodologias citadas, destaque especial se verifica para aquelas inseridas no contexto da inteligência computacional, tais como as redes neurais artificiais e os sistemas de inferência fuzzy. Essas ferramentas computacionais possuem como características 
atraentes a possibilidade de generalização, a robustez de operação mesmo em face de um ambiente com incertezas e a capacidade de se adaptar, acompanhando-se as modificações que o sistema elétrico de potência venha por ventura a experimentar (Tang et al., 2000).

As ferramentas advindas da inteligência computacional estão sendo empregadas não apenas para elaboração de identificadores de faltas mais precisos, mas também para determinar em quais pontos do sistema de distribuição esses dispositivos devem ser inseridos a fim de possibilitar uma melhor operação global.

Diversos aspectos podem ser levados em consideração quando da localização ótima de identificadores de faltas como, por exemplo, o menor custo de instalação, ao mesmo tempo em que se garanta a total cobertura de monitoramento do sistema.

Portanto, frente ao desenvolvimento de metodologias e ferramentas computacionais que venham a auxiliar a concessionária de energia elétrica na alocação de dispositivos para identificação de faltas, almeja-se então uma redução significativa da duração das interrupções de fornecimento aos clientes do sistema e, conseqüentemente, melhorar o serviço oferecido. De fato, apenas fundamentado em informações seguras e confiáveis é que se pode atuar no restabelecimento da energia elétrica, sem comprometer toda uma série de entidades que dependem diretamente dos sistemas de distribuição e transmissão, desde a unidade geradora até o consumidor final.

Este trabalho tem suas justificativas embasadas na proposta de realizar um minucioso estudo do funcionamento dos indicadores de faltas e sua aplicação no sistema de distribuição de energia elétrica. 
Devido ao fato de muitos indicadores de faltas já se encontrarem instalados no sistema de distribuição de energia elétrica, torna-se ainda mais crucial que seja pesquisado o comportamento deste como equipamento do sistema de proteção, pois a busca por uma proteção eficiente, que seja capaz de restabelecer o serviço o mais rapidamente possível, sem danos para os clientes e para concessionária, envolve a operação de equipamentos distintos que devem atuar de forma coesa e complementar.

Corroborando ainda mais este fato, ressalta-se que a empresa de distribuição de energia elétrica estudada tem cerca de 2200 dispositivos indicadores de faltas instalados em seus sistemas, sendo que deste montante cerca de $40 \%$ deles não têm atuado de forma satisfatória. Dentre os motivos para a não atuação correta, podemos citar a falta de informações para ajuste do equipamento adequado ao ponto de instalação, falha de bateria, ajuste realizado de forma incorreta pelas equipes de campo. Considerando ainda que quando ocorre uma falta, a equipe de restabelecimento é orientada a verificar a sinalização do IF mais próximo e, a partir desta indicação, uma série de ações para o restabelecimento da energia e isolamento do trecho faltoso é iniciada. Uma indicação errônea do equipamento pode trazer como conseqüência a demora no restabelecimento e risco a segurança na operação do sistema elétrico.

Confrontando os dados de sinalização dos indicadores de faltas com os resultados advindos de simulações computacionais de situações de faltas, elaborouse então um sistema fuzzy que visa aumentar a precisão do local de instalação deste dispositivo, diminuindo-se, portanto, o tempo de inspeção das equipes de restabelecimento. 
Também, de posse dessas informações, foi possível realizar um mapeamento completo do histórico de ocorrência de faltas e de como os indicadores de faltas as sinalizaram, gerando assim subsídios para se analisar a eficácia do dispositivo para as condições do sistema de distribuição, o ponto mais apropriado de instalação, a quantidade de indicadores de faltas que devem ser instalados ao longo do sistema e o levantamento dos pontos que exijam maior necessidade desses equipamentos.

Assim sendo, o objetivo deste trabalho consiste em elaborar uma metodologia que contribua para a alocação eficiente de dispositivos indicadores de faltas em sistema de distribuição de energia elétrica. Além disso, a metodologia leva também em consideração a avaliação dos locais onde já existam indicadores de faltas instalados a fim de auxiliar nos processos de decisão quanto à sua possível realocação visando aumentar sua eficácia.

Por meio do desenvolvimento de algoritmos computacionais especialmente elaborados para a alocação eficiente de dispositivos indicadores de faltas, bem como por intermédio das características operacionais desses dispositivos e das particularidades dos sistemas de distribuição de energia elétrica, foi possível a disponibilização de um ferramental efetivo que auxiliará também na tomada de decisão que tange o planejamento da expansão da rede de dispositivos indicadores de faltas.

\subsection{Organização da Dissertação}

Esta dissertação será desenvolvida em 6 capítulos conforme se segue. 
O detalhamento dos indicadores de falta, pesquisas envolvendo o uso de indicadores de faltas e, também, a proposta de trabalho foram registrados neste Capítulo 1.

No Capítulo 2 serão apresentados os aspectos técnicos relacionados aos indicadores de faltas e sua aplicação nos sistemas de distribuição.

No Capítulo 3 serão apresentados os fundamentos básicos referentes aos sistemas de inferência fuzzy, os quais serão utilizados no mapeamento do problema de alocação eficiente de indicadores de faltas.

No Capítulo 4 se encontram as principais características do sistema inteligente proposto neste trabalho, destacando-se o método de alocação eficiente dos indicadores de falta.

No Capítulo 5 serão apresentados os resultados advindos da aplicabilidade da técnica proposta, a qual foi utilizada na alocação eficiente de indicadores de faltas em cinco alimentadores de distribuição.

No Capítulo 6 serão feitas as considerações finais a respeito deste trabalho, enfatizando quais os ganhos desta pesquisa para os sistemas de distribuição, ressaltando-se ainda as futuras frentes de pesquisa que podem ser conduzidas a partir das investigações realizadas nesta dissertação. 


\section{Aspectos Técnicos Relacionados aos Indicadores de Faltas em Sistemas de Distribuição de Energia Elétrica}

\subsection{Introdução}

A manutenção da continuidade no fornecimento pelas empresas distribuidoras de energia elétrica é de suma importância para todos os setores da sociedade. Porém, os sistemas de distribuição estão sujeitos a faltas causadas por uma variedade de situações, tais como condições climáticas, contato com vegetação, falhas de equipamentos, acidentes, etc. Se houverem informações sobre a falta, mais rápido é o processo de manutenção e, conseqüentemente, mais rápido é o restabelecimento de energia elétrica.

Assim, é muito importante que os elementos responsáveis em detectar faltas sejam sensibilizados por qualquer tipo de falta, imediatamente após a ocorrência desta, para que prejuízos humanos e financeiros não ocorram.

A aplicação de dispositivos indicadores de faltas na rede permite às empresas concessionárias de distribuição melhorar a confiabilidade e a qualidade no fornecimento de energia elétrica aos consumidores, uma vez que esses identificam e sinalizam a ocorrência de curtos-circuitos. Além disso, tais dispositivos permitem a redução do tempo de desligamento das redes elétricas, provenientes de faltas transitórias ou permanentes, pois diminui o tempo de patrulha das equipes de restabelecimento, facilitando o trabalho de isolamento da seção submetida a uma falta e restauração do sistema (Falaghi et al., 2005). 
Estudos apontam que as presenças de indicadores de faltas em sistemas de distribuição subterrâneos ou aéreos podem reduzir em até $60 \%$ o tempo de interrupção, pois uma vez que a equipe de restabelecimento consegue reparar rapidamente uma seção faltosa, diminuem-se os índices que contabilizam o tempo e a freqüência em que o consumidor fica sem energia elétrica (Krajnak, D. J., 2000). Além disso, existem índices que avaliam a continuidade no fornecimento de energia, como o DEC (Duração Equivalente de Interrupção por Unidade Consumidora) e FEC (Freqüência Equivalente de Interrupção por Unidade Consumidora), conforme estabelecido pela Resolução no 024/2000 da ANEEL (2000).

Na Figura 2.1 é ilustrada uma representação de um circuito de distribuição com um único indicador de faltas instalado.

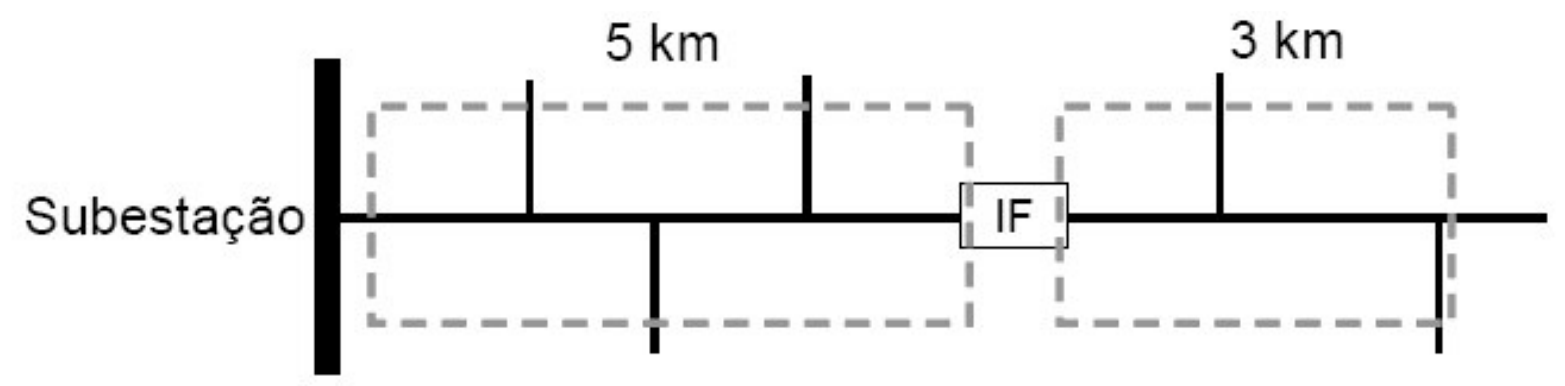

FIGURA 2.1 - Presença de indicador de faltas em um sistema de distribuição.

Em um sistema de distribuição como o da Figura 2.1 é possível de reduzir o tempo de busca pela falta utilizando-se o Indicador de Faltas (IF) como referencial. Supondo que o tempo médio para se localizar uma falta no alimentador da Figura 2.1 sem um indicador de faltas seja de 0,75 horas, o tempo para se localizar uma falta com a presença do indicador de faltas poderá ser reduzido, pois agora a equipe de restabelecimento pode percorrer antes do ponto de instalação do indicador, ou após, conforme as Expressões (2.1) e (2.2). 


$$
\begin{aligned}
& \text { Tempo }_{\text {DepoisDolF }}=\frac{3}{3+5} \times 0,75=0,28 \text { horas } \\
& \text { Tempo }_{\text {AntesDolF }}=\frac{5}{3+5} \times 0,75=0,47 \text { horas }
\end{aligned}
$$

Em certos casos, onde a ocorrência da falta foi severa, a ausência de um dispositivo de sinalização de faltas para orientar as equipes de restabelecimento requererá um tempo elevado para percorrer toda extensão da rede até encontrar e restaurar os pontos danificados. Esse procedimento geralmente ocasiona elevados custos operacionais à concessionária distribuidora, além de grandes dificuldades para o restabelecimento do sistema. Tal problema se torna mais crítico em redes rurais (devido a suas grandes extensões) e em alimentadores urbanos com elevado número de consumidores.

Como anteriormente apresentado, os indicadores de faltas foram produzidos pela primeira vez em 1946. A companhia Hortsmann foi a responsável pelo projeto dos primeiros dispositivos capazes de sinalizarem a passagem de uma corrente de falta em um circuito. Esses primeiros indicadores de faltas possuíam sinalização mecânica, promovida pela rotação de um disco mediante a passagem de uma corrente elevada. Tais dispositivos possuíam um rearme manual que necessitava de intervenção humana toda vez que a falta era sinalizada.

Os avanços tecnológicos em indicadores de faltas começaram quando o rearme passou a ser automático, seja pela restauração da corrente de carga ou pela tensão na rede no circuito de distribuição. Este avanço poupou inúmeras horas de serviço, no entanto, limitou a vida útil dos equipamentos que passaram a trabalhar de forma autônoma e sem manutenção. Em 1976, os indicadores passaram a ter vida útil e confiabilidade maior devido à presença de uma fonte externa de energia. 
Os dispositivos então poderiam ser armados e prontos para operar, independendo das características da rede elétrica.

Este avanço permitiu que os fabricantes investissem mais em tecnologia para dispositivos de indicação de falta, principalmente no campo da eletrônica de semicondutores. Em 1987, iniciou-se a produção de dispositivos indicadores de faltas para linhas aéreas com transmissão via radiofreqüência, enviando-se as informações via SCADA (Supervisory Control and Data Acquisition) para um centro de controle.

\subsection{Aspectos Gerais dos Indicadores de Falta}

Nas subseções seguintes serão detalhados os aspectos funcionais dos indicadores de falta.

\subsubsection{Descrição Funcional}

$\mathrm{Na}$ ocorrência de uma falta o dispositivo sinaliza se houver passagem de corrente de curto-circuito pelo circuito monitorado. A detecção da situação de falta é por meio de sensores que monitoram a passagem de corrente pela rede primária de distribuição, diferenciando situações de carga de uma falta, os quais são sensibilizados pelo campo magnético produzido pela corrente de carga fluindo através do sistema.

\subsubsection{Sinalização}

Se a corrente que flui pelo circuito monitorado excede o ajuste de disparo do indicador, o mesmo sinaliza, indicando-se a falta. Essa indicação ocorre de várias maneiras: por uma bandeirola colorida (geralmente sinalizados por lâmpadas de Gás 
Xenon), LED, ou uma combinação dos dois tipos, etc. Muitos fabricantes de IFs utilizam a sinalização para faltas transitórias diferente das permanentes.

\subsubsection{Rearme}

Uma vez localizado o defeito, reparado a linha e restaurado o fornecimento, o indicador precisa ser rearmado. Esse rearme pode ser automático ou manual. Os rearmes automáticos podem ser por tensão, por tempo, por corrente de carga, entre outros, variando de acordo com a aplicação e com a duração da falta.

\subsubsection{Bateria}

A alimentação do IF é feita por meio de bateria interna. A presença de uma fonte independente do circuito monitorado revolucionou a operação dos IFs, pois passaram a ter autonomia no seu funcionamento.

Alguns dispositivos IFs têm indicação de baixa capacidade de carga da bateria, ou seja, quando ela deve ser substituída. É importante lembrar que o correto funcionamento dos IFs depende do nível de carga da bateria. Geralmente, os fabricantes disponibilizam dados mais detalhados sobre a vida útil da bateria.

\subsubsection{Comunicação}

Atualmente no mercado existem IFs com possibilidade de comunicação remota, possibilitando a integração com o Centro de Operação da Distribuição (COD) e com outros equipamentos de proteção. Tal comunicação fornece o status operativo do IF no sistema SCADA do COD.

Existem modelos de IFs que emitem um sinal de radiofreqüência ou via GSM (Global System for Móbile Communication) quando há ocorrência de uma falta. Este 
sinal auxilia na alocação das equipes de manutenção através da identificação dos IFs que sinalizaram na ocorrência da falta.

\subsubsection{Programação}

O IF detecta curto-circuitos quando a corrente excede o nível de detecção ou o nível de limiar pré-estabelecido. As programações variam de acordo com o fabricante, mas geralmente os ajustes dos sensores e de rearme aparecem em todos eles.

Para evitar sinalizações em situações de manobra do sistema, como por exemplo, corrente de energização (inrush) da linha, o sensor de corrente $\frac{d i}{d t}$ é bloqueado durante um período de tempo suficiente para energização da rede. Enquanto o tempo de bloqueio transcorre, a corrente na linha se estabiliza e não há disparo do sensor. A programação é feita por meio de banco de chaves (switches) ou via software. Existem modelos que utilizam corrente de trip para sensibilizar os sensores de indicação de falta.

\subsubsection{Pontos de Aplicação de Indicadores de Falta}

Geralmente, os IFs são instalados em pontos estratégicos do sistema de distribuição. Tais pontos, como mostram a Figura 2.2, são derivações do alimentador e ao longo de grandes trechos de alimentadores rurais, pois quando estes possuem extensões elevadas a localização do defeito pelas equipes de restabelecimento pode demorar. Neste exemplo é evidenciado como o correto posicionamento dos IF em pontos estratégicos pode auxiliar a tomada de decisão para o rápido restabelecimento Outro ponto a ser observado no posicionamento dos IF é a característica dos equipamentos instalados à jusante e a contribuição para a 
corrente capacitiva, garantindo que esteja abaixo no nível de trip pré-definido para evitar que o indicador se ative indevidamente. Outra dificuldade é o posicionamento considerando pontos de deslocamento da equipe.

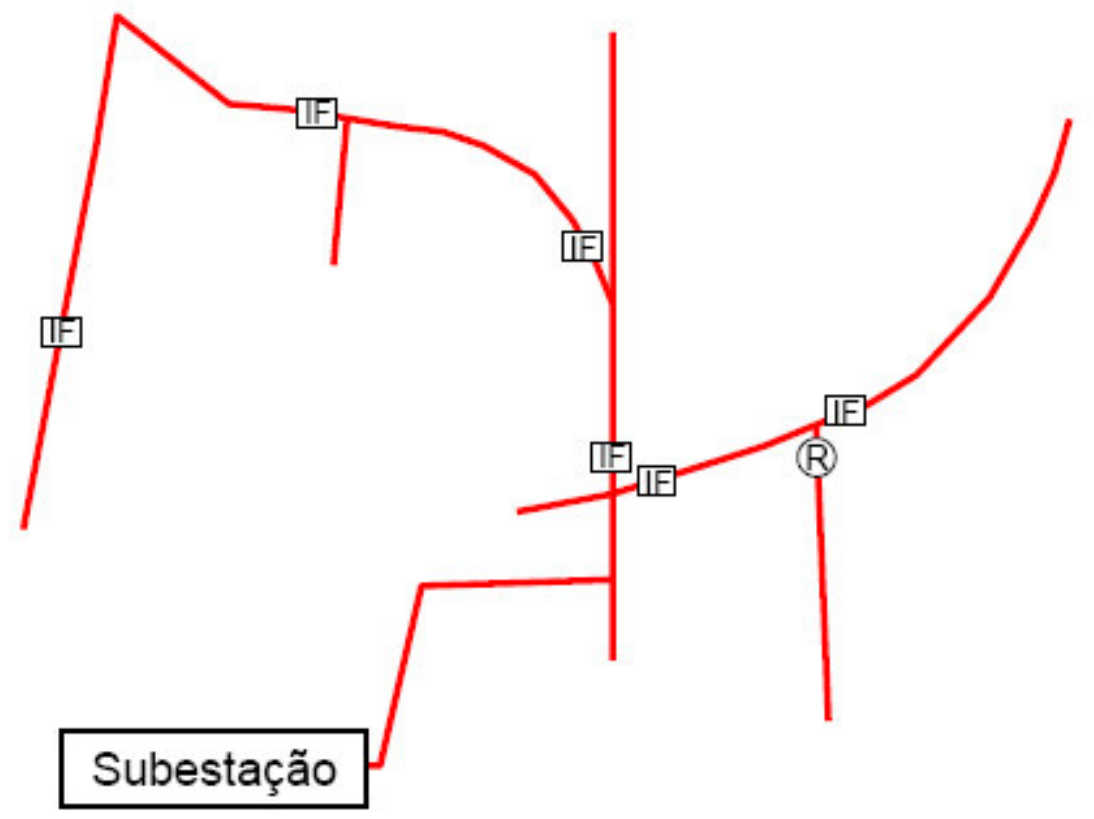

FIGURA 2.2 - Pontos de instalação de indicadores de faltas.

Os IFs podem ser aplicados em redes de distribuição subterrâneas ou aéreas. Nas redes aéreas, estes podem ser instalados de duas formas:

- Condutor-fase;

- Poste.

Na Figura 2.3 encontram-se representados estes dois tipos. 

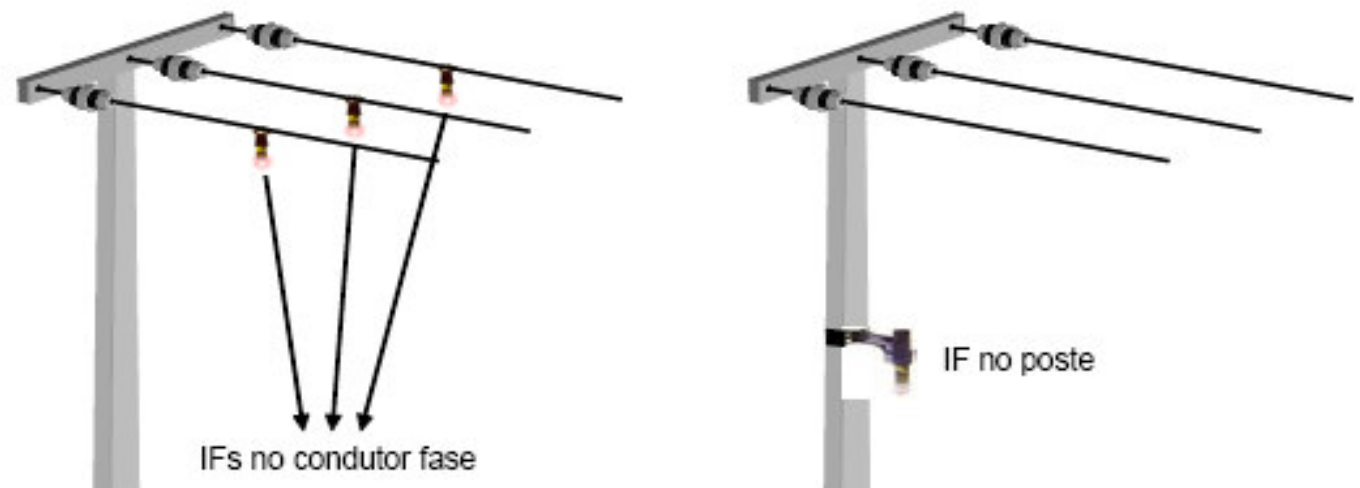

IFs no condutor fase

FIGURA 2.3 - Modelos de indicadores de faltas.

\subsubsection{Manutenção}

Quanto à manutenção dos IFs, os mesmos devem ser inspecionados periodicamente. Geralmente, os fabricantes recomendam a cada intervalo de um ano, com testes de verificação do funcionamento da bateria.

No entanto, este teste não garante seu funcionamento adequado. Foi observado que em alguns modelos podem ocorrer: alteração da posição das chaves de ajuste ao se fechar o equipamento, rompimento do cabo do sensor, problemas estes que somente serão observados quando esses IF forem retirados da rede para verificação.

\subsection{Indicadores de Faltas Instalados no Cabo Condutor-Fase}

Como já descrito anteriormente, os IFs não localizam o ponto de falha, sendo que os mesmos apenas sinalizam a seção da falta. Após ter identificado a seção faltosa, as equipes de restabelecimento se dirigem ao local para correção do 
defeito. Com isso, ajudam a restabelecer a energia de forma mais rápida e eficiente, diminuindo-se a duração e freqüência das interrupções. Portanto, os IFs são dispositivos eficazes não só para a melhoria dos índices de qualidade das distribuidoras, como também para o relacionamento da distribuidora junto a seus clientes, ou seja, interrupções de energia cada vez menos freqüentes e mais curtas significam consumidores mais satisfeitos e menos reclamações.

O IF instalado no condutor-fase de redes primárias de distribuição de energia elétrica tem papel fundamental nesse contexto. Tal dispositivo é instalado de forma fácil e segura diretamente no cabo energizado da linha de distribuição e tem por finalidade monitorar a corrente e a tensão da fase da linha e também identificar a passagem de uma corrente de curto-circuito por esse local, com conseqüente desligamento da tensão elétrica dessa linha pelos equipamentos automáticos de proteção. Isso caracteriza a chamada falta permanente e requer atuação da equipe de manutenção.

Identificada a falta permanente, o IF começa a piscar e pode ser facilmente visto de dia ou de noite pela equipe que percorre o alimentador buscando o defeito. Quando identificado um ramal do alimentador principal por onde circulou a corrente de curto-circuito, a equipe de restabelecimento tem a certeza de que é por ali que terá que seguir para localizar o ponto exato do defeito.

Os IFs instalados no cabo condutor-fase são também conhecidos por IFs de cabo ou IFs de linha, ou ainda, por sinalizadores de falta. Estes são pequenos dispositivos pinçados (presos) em torno de um cabo como ilustrado na Figura 2.4. 


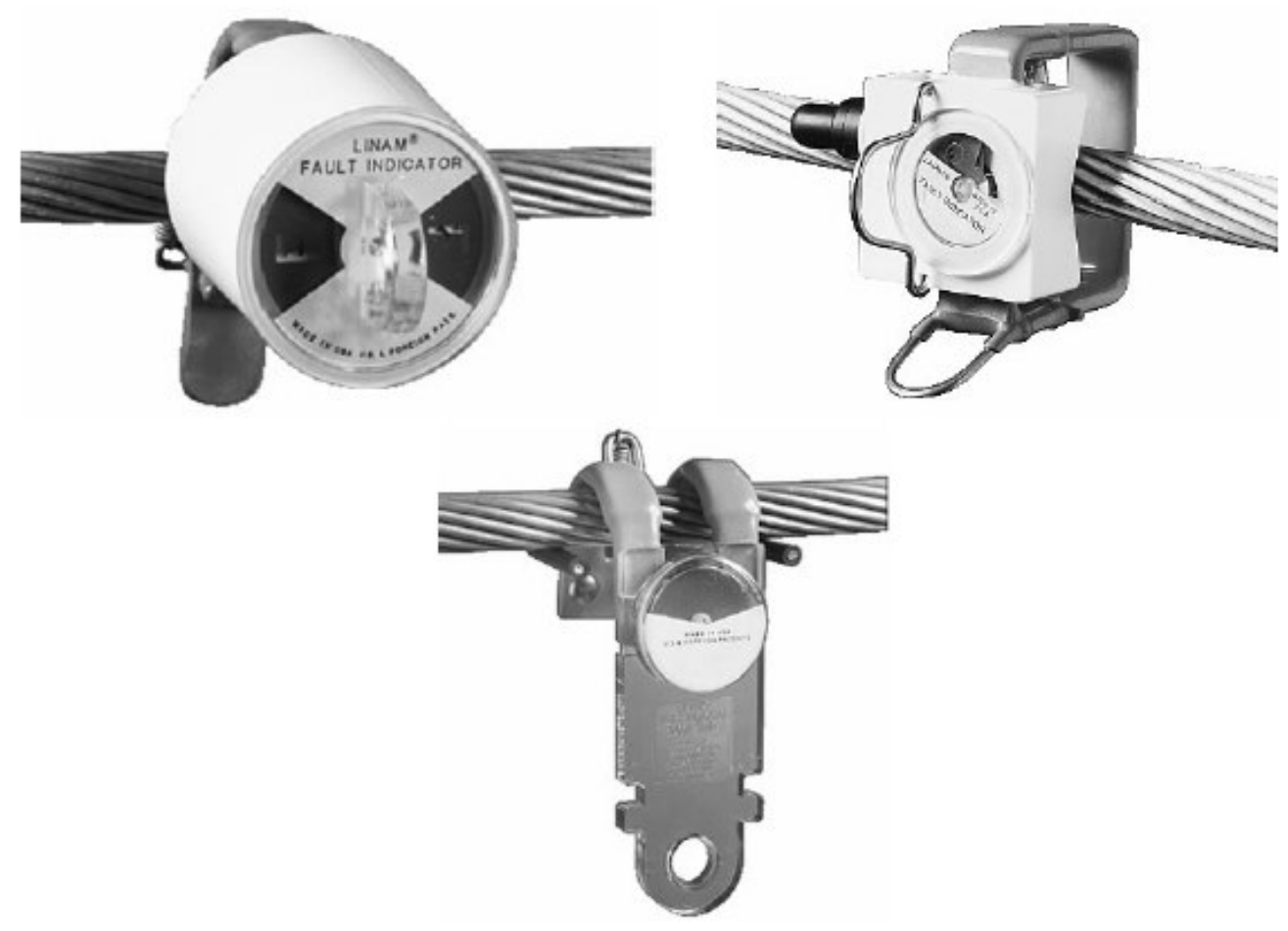

FIGURA 2.4 - Diferentes modelos de indicadores de faltas de cabo.

Na ocorrência de uma falta, o dispositivo sinaliza se houver passagem de corrente de curto-circuito pelo condutor monitorado. A detecção da corrente de falta é por meio de um sensor que monitora a variação da corrente no tempo, ou seja, $\frac{d i}{d t}$. Esse sensor diferencia uma corrente de carga fluindo através do condutor como mostra a Figura 2.5.

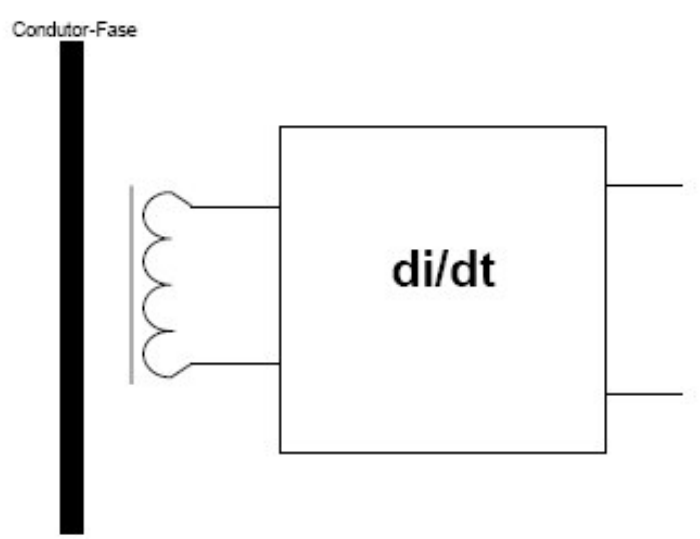

FIGURA 2.5 - Sensor de indicador de falta. 
A Figura 2.6 ilustra o esquema de instalação de IF na rede aérea. Geralmente, instala-se um IF para monitorar cada fase.

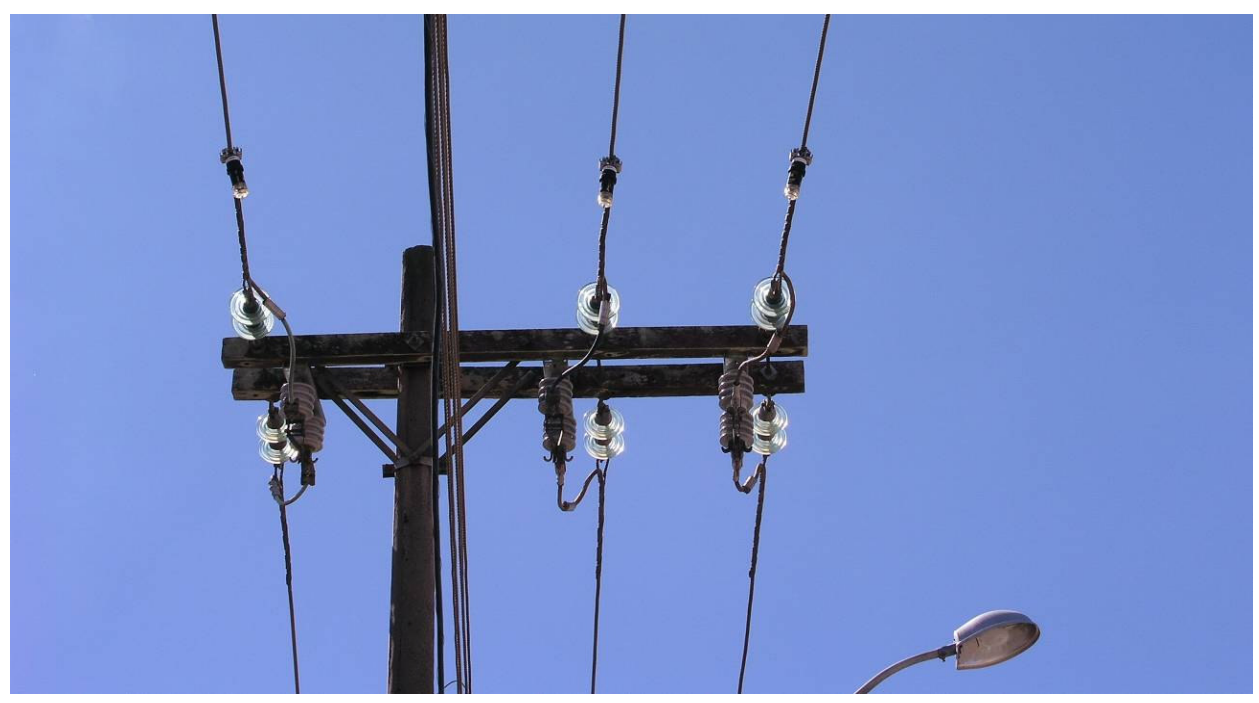

FIGURA 2.6 - Indicadores de faltas instalados nas três fases.

Os principais fabricantes de IFs de linha são:

- Schweitzer - www.selinc.com.br

- Schneider Electric - www.schneider-electric.com

- Nortroll - www.nortroll.com

- LOFA - www.lofa.net

- Bowden Bros - www.bowden-bros.com

$\mathrm{Na}$ Tabela 2.1, tem-se uma comparação entre os principais fornecedores de indicadores de falta para instalação em cabo com descrição dos seguintes ajustes: tipo de rearme, sinalização, bloqueio de corrente de inrush, faixa de trip, programação e tempo de vida útil da bateria. 
TABELA 2.1 - Comparação entre alguns fabricantes de Indicadores de faltas instalados em cabo.

\begin{tabular}{|c|c|c|c|c|c|c|c|c|c|c|}
\hline & $\begin{array}{c}\text { Indicadores } \\
\text { de Falta }\end{array}$ & 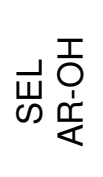 & ๗崩 & 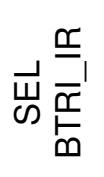 & 山 & 岀㟔 & 岀号 & 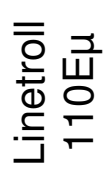 & 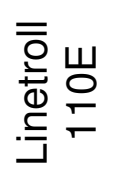 & 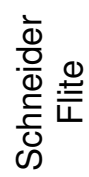 \\
\hline \multirow{4}{*}{ 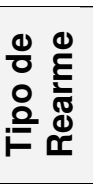 } & Eletrostático & & & & $X$ & $X$ & & & & \\
\hline & Corrente & & & & & & $x$ & & & \\
\hline & Tensão & & & & & & & $\mathrm{X}$ & $\mathrm{X}$ & $\mathrm{X}$ \\
\hline & Tempo & $x$ & $X$ & $x$ & & & & $\mathrm{X}$ & $\mathrm{X}$ & $X$ \\
\hline \multirow{2}{*}{ 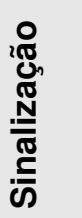 } & $\begin{array}{l}\text { Falta } \\
\text { Transitória }\end{array}$ & $x$ & & $x$ & & & & $x$ & $x$ & $x$ \\
\hline & $\begin{array}{l}\text { Falta } \\
\text { Permanente }\end{array}$ & $x$ & $x$ & $x$ & $x$ & & & $x$ & $x$ & $x$ \\
\hline \multicolumn{2}{|c|}{ Bloqueio de Inrush } & $x$ & $x$ & $x$ & $x$ & $x$ & $x$ & $x$ & $x$ & $x$ \\
\hline \multicolumn{2}{|c|}{ Faixa de Trip (A) } & $\begin{array}{l}50- \\
1.2 \mathrm{k}\end{array}$ & $\begin{array}{l}50- \\
1.2 \mathrm{k}\end{array}$ & $\begin{array}{l}50- \\
1.2 \mathrm{k}\end{array}$ & $\begin{array}{l}50- \\
1.2 \mathrm{k}\end{array}$ & $\begin{array}{l}50- \\
1.2 \mathrm{k}\end{array}$ & $\begin{array}{l}100- \\
1.2 \mathrm{k}\end{array}$ & $250-1 k$ & $250-1 \mathrm{k}$ & \\
\hline \multirow{2}{*}{ 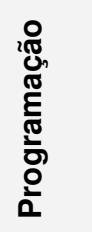 } & Switchs & \multirow{2}{*}{$\begin{array}{l}.0 \\
\frac{.0}{ \pm} \\
\frac{\pi}{E} \\
\frac{0}{0} \\
\frac{1}{2}\end{array}$} & $x$ & $x$ & & & & $x$ & $x$ & $x$ \\
\hline & Software & & & & & & & & & $x$ \\
\hline \multicolumn{2}{|c|}{$\begin{array}{l}\text { Tensão Nominal } \\
\text { de Operação (kV) }\end{array}$} & $\begin{array}{l}4.16- \\
69\end{array}$ & $\begin{array}{l}4.16- \\
69\end{array}$ & $\begin{array}{l}8.66- \\
38\end{array}$ & $\begin{array}{l}8.66- \\
69\end{array}$ & $\begin{array}{l}8.66- \\
69\end{array}$ & $>38$ & $6-66$ & $6-66$ & $5-25$ \\
\hline \multicolumn{2}{|c|}{$\begin{array}{l}\text { Vida Útil da Bateria } \\
\text { (anos) }\end{array}$} & 20 & 20 & & & 20 & & $5-10$ & $5-10$ & 10 \\
\hline
\end{tabular}

$\mathrm{Na}$ Tabela 2.2, tem-se uma comparação para os principais fornecedores para indicadores de falta para instalação em poste. 
TABELA 2.2 - Comparação entre alguns fabricantes de Indicadores de faltas instalados em poste.

\begin{tabular}{|c|c|c|c|c|c|c|}
\hline & $\begin{array}{c}\text { Indicadores } \\
\text { de Falta }\end{array}$ & 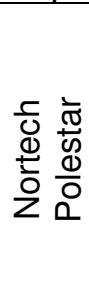 & 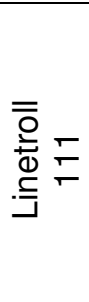 & 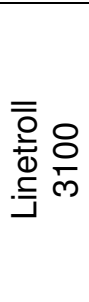 & 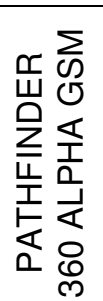 & 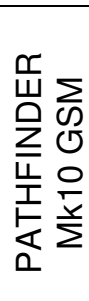 \\
\hline \multirow{4}{*}{ 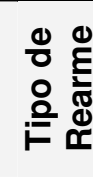 } & Manual & $X$ & $X$ & $\mathrm{X}$ & $\mathrm{X}$ & $\mathrm{X}$ \\
\hline & Corrente & & & & & \\
\hline & Tensão & $\mathrm{X}$ & $\mathrm{X}$ & $\mathrm{X}$ & $\mathrm{X}$ & \\
\hline & Tempo & $X$ & $X$ & $X$ & $X$ & \\
\hline \multirow{2}{*}{ 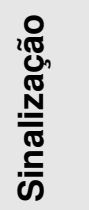 } & $\begin{array}{l}\text { Falta } \\
\text { Transitória }\end{array}$ & $X$ & $X$ & $x$ & $x$ & $x$ \\
\hline & $\begin{array}{l}\text { Falta } \\
\text { Permanente }\end{array}$ & $x$ & $x$ & $\mathrm{x}$ & $\mathrm{x}$ & $x$ \\
\hline \multicolumn{2}{|c|}{ Bloqueio de Inrush } & & $X$ & $x$ & $X$ & $x$ \\
\hline \multirow{2}{*}{ 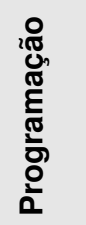 } & Switchs & & $x$ & $\mathrm{X}$ & & $x$ \\
\hline & Software & & & & & \\
\hline \multicolumn{2}{|c|}{$\begin{array}{l}\text { Tensão Nominal } \\
\text { de Operação (kV) }\end{array}$} & $\begin{array}{l}11- \\
275\end{array}$ & $6-66$ & $6-132$ & 6-132 & $6-132$ \\
\hline \multicolumn{2}{|c|}{$\begin{array}{l}\text { Vida Útil da Bateria } \\
\text { (anos) }\end{array}$} & 10 & 5-10 & $7-8$ & $\begin{array}{l}10- \\
15\end{array}$ & 6-10 \\
\hline \multicolumn{2}{|c|}{ Comunicação } & $x$ & & $\mathrm{X}$ & $\mathrm{X}$ & $\mathrm{X}$ \\
\hline
\end{tabular}

\subsection{Indicadores de Faltas Instalados em Poste}

Conforme pode ser observado na Figura 2.7, o IF instalado no poste monitora as 3 fases do sistema de distribuição. 


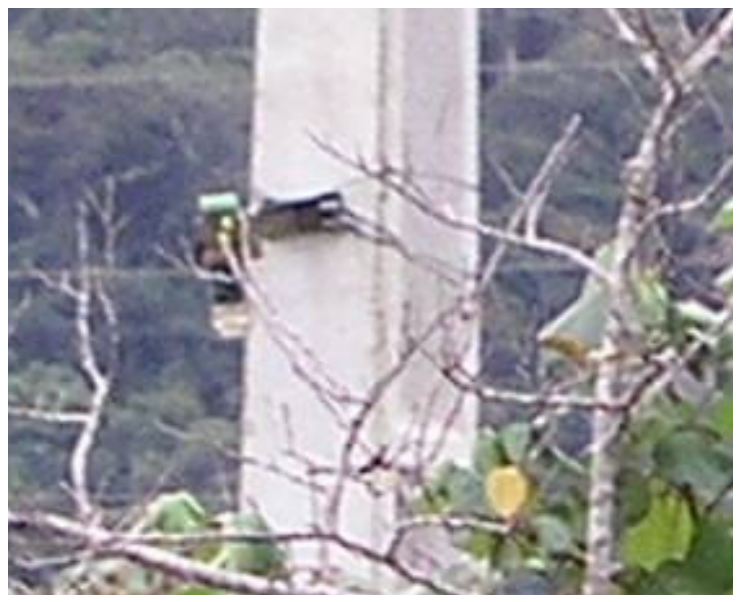

FIGURA 2.7 - Esquema do indicador de faltas instalado no poste.

Os indicadores de poste são empregados para detectar faltas Fase-Fase e Fase-Terra e também utilizam o princípio da variação da corrente para detectar uma falta. Há modelos que possuem sensores elétricos e magnéticos que monitoram constantemente a tensão e a corrente. Os sensores magnéticos $\frac{d i}{d t}$ se adaptam a presença de corrente na linha e são sensibilizados quando há um aumento abrupto de corrente quando ocorre uma falta. Já os sensores elétricos monitoram a presença de tensão na linha, por intermédio de uma antena localizada dentro do indicador.

Estes dispositivos podem sinalizar faltas permanentes, indicando iluminação de alerta principal, e também a passagem de faltas transitórias por intermédio de indicadores luminosos secundários. Na Figura 2.8, tem-se uma visualização de um IF instalado em um poste. 


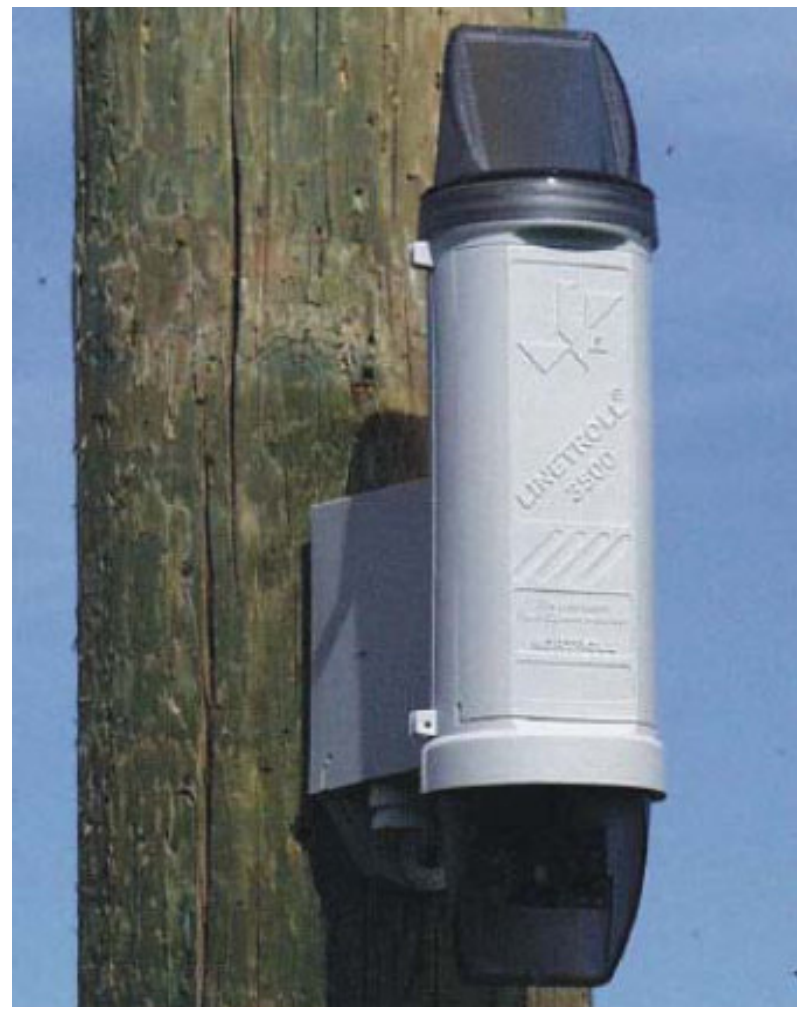

FIGURA 2.8 - Indicador de faltas de poste.

Como citado anteriormente, os indicadores de faltas instalados em postes monitoram as 3 fases simultaneamente com um único dispositivo. No entanto, estão sujeitos a interferências, tais como a presença da rede secundária no mesmo poste, o que torna o IF de linha mais adequado para esta situação.

Os principais fabricantes de IFs de poste são: Nortech, Nortroll e Bowden Bros.

\subsection{Novas Tecnologias Construtivas para Indicadores de Faltas}

Diversas linhas de pesquisa vêm sendo desenvolvidas com o intuito de melhorar o desempenho dos indicadores de faltas. Destaca-se uma grande tendência no uso de ferramentas inteligentes e de transformadas wavelet.

O crescimento de aplicações envolvendo a transformada wavelet na detecção e localização de faltas é devido às dificuldades em se detectar uma falta de alta impedância (Kim et al., 2002). 
A transformada wavelet tem um elevado poder de tratamento de sinais, pois permite realizar uma análise multiresolução considerando-se o domínio do tempo e da freqüência simultaneamente. Há também abordagens híbridas, que utilizam redes neurais artificiais combinadas com transformada wavelet, em que a decomposição do sinal é apresentada a uma estrutura neural para a tomada de decisão da sinalização de uma falta (Aravena \& Chowdhury, 1996).

As faltas de alta impedância representam um desafio para a proteção dos sistemas elétricos, principalmente devido às baixas magnitudes das correntes, que na maioria das vezes são menores que as de carga. Métodos para deixar os indicadores de faltas mais robustos com relação a este tipo de distúrbio, e que utilizam componentes fundamentais de correntes e tensões, estão também sendo investigados.

Nestes casos, utilizam-se as componentes de seqüência zero para distinguir as correntes de falta daquelas de carga. Este é o caso da proposta apresentada em Baldwin et al. (2003), que traz também um modelo para detectar a direção da falta por meio de técnicas de processamento de sinais. Essa proposta se mostra atraente pelo fato de empregar um único dispositivo (microprocessado) capaz de detectar a passagem de uma falta, bem como o seu sentido de propagação.

Os indicadores de faltas também poderiam ser sensibilizados por união dos ruídos de altas freqüências produzidos pela passagem de uma falta. A proposta apresentada em Tang et al. (2000) consiste de rejeitar ou deixar passar uma banda específica de freqüências, detectando-se apenas os sinais de faltas da rede. Este tipo de abordagem necessita de uma elevada taxa de aquisição para que as componentes de altas freqüências possam ser corretamente representadas. 


\section{Aspectos de Sistemas de Inferência Fuzzy}

\subsection{Introdução}

A aplicação crescente de técnicas de sistemas inteligentes, agregadas às técnicas convencionais, tem gerado resultados bem eficientes e cada vez mais convincentes quando utilizadas em problemas relacionados aos sistemas de distribuição de energia elétrica, pois o objetivo de destaque da aplicação dessas técnicas consiste no alcance de tratabilidade, robustez, baixo custo e altas taxas de eficiência.

Mais especificamente, a utilização de sistemas inteligentes, notadamente aqueles baseados nas redes neurais artificiais e na inferência fuzzy, possuem elevado potencial de aplicação em sistemas dedicados à distribuição de energia elétrica, pois as características mais atrativas desses sistemas consistem em sua elevada habilidade em mapear sistemas não-lineares e em tratar as eventuais incertezas associadas ao processo.

O termo fuzzy (em inglês) tem vários significados, porém, os conceitos mais utilizados passam por "vago", "difuso", "nebuloso", "incerto”, etc. Este capítulo tem por finalidade apresentar os conceitos fundamentais sobre sistemas de inferência fuzzy, os quais serão utilizados para mapear os procedimentos de alocação eficiente de IFs.

Os sistemas de inferência fuzzy são técnicas de inteligência computacional usadas para representação e processamento do conhecimento. Suas características baseiam-se na lógica fuzzy proposta por Zadeh (1965). 
Essa lógica é o ramo da matemática que suporta os modos de raciocínio que são aproximados ao invés de exatos, ou ainda, de forma mais abrangente, pode ser aceita como a melhor maneira de representação do raciocínio humano, que é parcial e aproximado em sua essência.

A modelagem e o controle fuzzy de sistemas são técnicas para o tratamento de informações qualitativas de uma forma rigorosa. Derivada do conceito de conjuntos fuzzy, a lógica fuzzy constitui a base para o desenvolvimento de métodos e algoritmos de modelagem e controle de processos, permitindo a redução da complexidade de projeto e implementação, tornando-se uma alternativa para a solução de problemas de controle e modelagem de sistemas.

Esta forma de estruturação do raciocínio é capaz de tomar decisões racionais mesmo estando em um ambiente de incertezas e imprecisões, onde os dados desta natureza e até mesmo os conflitantes são tratados (Lee, 1990)

A tecnologia advinda da teoria de conjuntos fuzzy e da lógica fuzzy tem permitido a aplicação destas técnicas em diversas áreas do conhecimento, tendo-se como exemplos os sistemas fuzzy de controle, os quais podem possibilitar um controle mais acurado, além de um desempenho estável e robusto; ou ainda, na modelagem de processos, onde por meio das técnicas de sistemas de inferência fuzzy é possível uma representação mais fiel do mesmo e inclusive a extração de informações qualitativas deste (Gomide \& Gudwin, 1994; Hirota, 1993).

Como mencionado anteriormente, a lógica fuzzy procura expressar o raciocínio aproximado, ou seja, por intermédio da representação do conhecimento por regras, pode-se então responder a um determinado estímulo. Na lógica fuzzy existe a opção adicional de se empregar possibilidades lingüísticas, como por exemplo "provável", "altamente provável" e "improvável", interpretados como 
números fuzzy e manipulados pela aritmética fuzzy. Também em contraste com a lógica modal clássica, o conceito de possibilidade é interpretado utilizando os subconjuntos fuzzy no universo dos reais.

Por meio da lógica fuzzy, um sistema pode ser representado através de conceitos imprecisos, tais como "rápido", "baixo" e "pequeno". Essas propriedades são responsáveis, entre outras, pela facilidade na extração do conhecimento a respeito de um sistema a partir de observações realizadas sobre o mesmo.

Em um sistema de inferência fuzzy, os valores de entrada são normalizados e convertidos para representação fuzzy. Este processo é denominado de fuzzificação das variáveis de entrada. As regras do sistema fuzzy serão executadas em paralelo, conseqüentemente, uma região fuzzy será produzida para cada variável. A produção desta região fuzzy a partir das regras ativas do sistema é conhecida por agregação. Depois do processamento das regras de inferência, as regiões fuzzy são convertidas em valores não fuzzy, também conhecidos como valores "crisp", determinando-se assim o valor de cada variável de saída do sistema. O processo de se converter tal região fuzzy em um valor real é conhecido por defuzzificação.

\subsection{Conceitos sobre Conjuntos e Lógica Fuzzy}

Nesta seção serão apresentados os conceitos básicos relacionados aos conjuntos e à lógica fuzzy, tendo-se como foco a modelagem de sistemas. Apesar de existir uma complexa base formal sustentando seu uso na modelagem e controle de sistemas, serão evidenciados somente os fundamentos necessários para o entendimento da teoria básica de modelagem fuzzy. 
Assim, na teoria clássica de conjuntos, um elemento ou pertence a uma classe ou não. Dado um universo de discurso $U$ e um elemento particular $x \in U$, o grau de pertinência $\mu_{A}(x)$ com relação a um conjunto $A \subseteq U$ é dado por:

$$
\mu_{A}(x)=\left\{\begin{array}{l}
1, \text { se } x \in A \\
0, \text { se } x \notin A
\end{array}\right.
$$

A função $\mu_{A}(x): U \rightarrow\{0,1\}$ é chamada de função característica na teoria clássica de conjuntos. Pode-se observar por meio de (3.1) que a função característica, assim definida, pode assumir apenas valores discretos.

Freqüentemente, uma generalização desta idéia é utilizada, por exemplo, para manipulação de dados com erros limitados. Todos os números pertencentes a um intervalo pré-definido terão um grau de pertinência 1, ao passo que os números que não pertencerem a este intervalo possuirão um grau de pertinência nulo, como pode ser observado na Figura 3.1(a). Na Figura 3.1(b), o caso preciso é apresentado e, a partir deste, tem-se que o grau de pertinência recebe o valor unitário somente em determinado ponto $x$, sendo nulo para os demais valores.
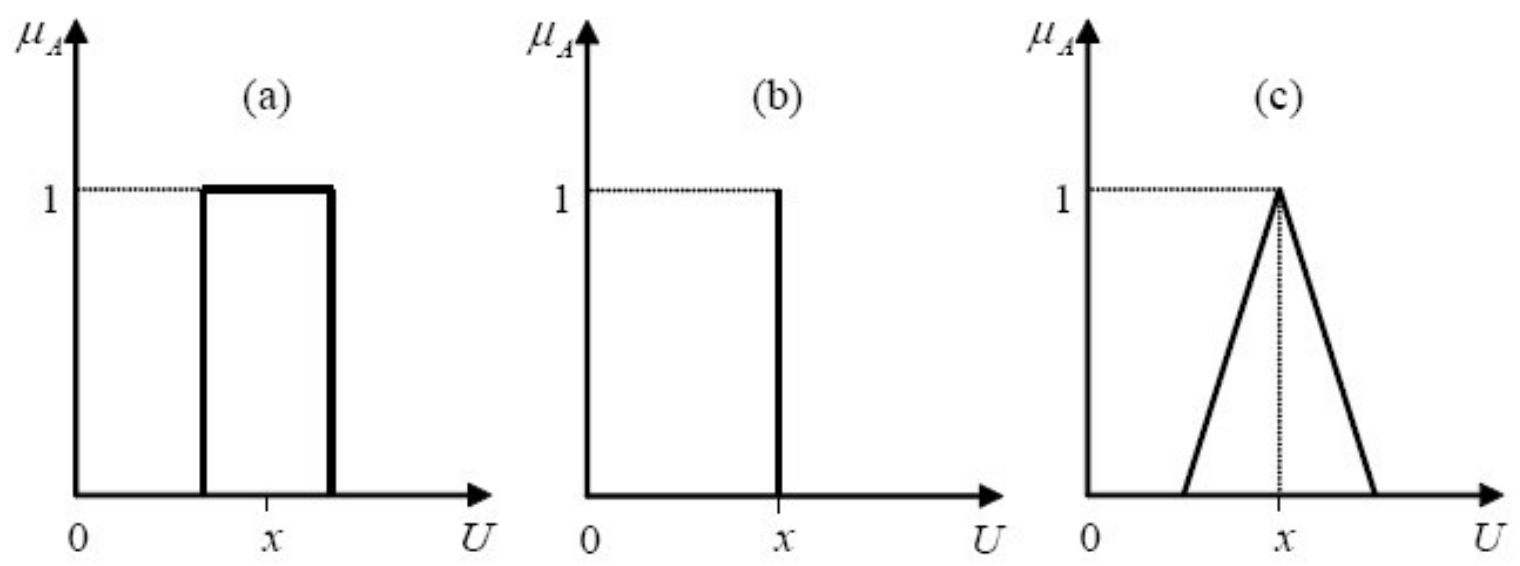

FIGURA 3.1 - Funções de pertinência. 
Zadeh (1973) propôs uma caracterização mais ampla, na medida em que sugere que alguns elementos são mais pertencentes a um conjunto do que outros. $\mathrm{O}$ grau de pertinência pode então assumir qualquer valor entre o intervalo [0, 1], sendo que o valor 0 indica uma completa exclusão e um valor 1 representa completa pertinência, ou seja, a função característica passa a ser contínua no seu domínio. Esta generalização aumenta o poder de expressão da função característica. $\mathrm{Na}$ Figura 3.1(c) representa-se esta abordagem na forma de uma função de pertinência triangular com pico em $x$, sugerindo-se a idéia de que quanto mais próximo de $x$, mais o elemento se identifica com o conceito representado por $x$ (Zadeh, 1973).

A partir desta definição, o conceito de elemento e o conceito de conjunto podem ser expandidos e novas denominações mais amplas assumidas, como apresentado a seguir.

Formalmente, seja $U$ uma coleção de objetos denominados genericamente por $\{u\}$. O domínio $U$ é chamado de universo de discurso, podendo ser contínuo ou discreto.

Um conjunto fuzzy $A$ em um universo de discurso $U$ é definido por uma função de pertinência $\mu_{A}$ que assume valores em um intervalo [0, 1], ou seja:

$$
\mu_{A}: U \rightarrow[0,1]
$$

O conjunto suporte de um conjunto fuzzy $A$ é o subconjunto dos pontos de $u$ em $U$, tal que $\mu_{A}(u)>0$. Um conjunto fuzzy, cujo conjunto suporte é um único ponto de $U$, com $\mu_{A}=1$, é chamado de um conjunto fuzzy unitário. A partir desta definição, os conjuntos clássicos passam a ser um caso específico na teoria de conjuntos fuzzy. Na Figura 3.1(c), tem-se uma função de pertinência do tipo triangular, no 
entanto, pode-se utilizar qualquer função $f: \Re \rightarrow[0,1]$ para representação de um determinado conjunto fuzzy.

\subsection{Definição de Operações e Operadores da Lógica Fuzzy}

Sejam $A$ e $B$ dois conjuntos fuzzy definidos em um universo de discurso $U$ com funções de pertinência $\mu_{A}$ e $\mu_{B}$, respectivamente. As operações envolvendo estes conjuntos fuzzy, tais como a união $(A \cup B)$, a intersecção $(A \cap B)$ e 0 complemento $(\bar{A})$ são definidas, respectivamente, de maneira formal pelas Expressões (3.3), (3.4) e (3.5).

$$
\begin{aligned}
& \mu_{A \cup B}(u)=\mu_{A}(u) \& \mu_{B}(u) \\
& \mu_{A \cap B}(u)=\mu_{A}(u) \Gamma \mu_{B}(u) \\
& \mu_{\bar{A}}(u)=1-\mu_{A}(u)
\end{aligned}
$$

onde $\Gamma$ é uma norma triangular (t-norma) e \& é uma co-norma triangular (s - norma).

Como exemplo de $s$-norma, tem-se a Expressão (3.6) e, como exemplo de $t$ - norma, tem-se a Expressão (3.7).

$$
\begin{aligned}
& \mu_{A \cup B}=\max \left\{\mu_{A}(u), \mu_{B}(u)\right\} \\
& \mu_{A \cap B}=\min \left\{\mu_{A}(u), \mu_{B}(u)\right\}
\end{aligned}
$$

O emprego do operador máximo ("max") representando a $s$-norma e o operador mínimo ("min") representando a $t$-norma foi proposto inicialmente em Zadeh (1965). No entanto, inúmeras outras $s$-normas e $t$-normas podem ser empregadas na definição dos sistemas fuzzy (Pedrycz \& Gomide, 1998). 


\subsection{Regras Fuzzy e Agregação de Regras}

\subsubsection{Regras Fuzzy}

Para expressar conceitos ou relacionamentos por meio de elementos de linguagem natural é muito comum o uso de elementos qualitativos ao invés de valores quantitativos. Elementos lingüísticos típicos incluem expressões do tipo "mais ou menos", "alto", "não muitos", "médios", etc. Estas idéias são capturadas pela definição de variáveis lingüísticas. Uma variável lingüística tem por característica assumir valores dentro de um conjunto de termos lingüísticos, ou seja, palavras ou frases.

Assim, ao invés de assumir instâncias numéricas, estas variáveis assumem instâncias lingüísticas. Por exemplo, uma variável lingüística "Corrente Elétrica" poderá assumir como valor um dos termos do conjunto \{"muito baixa", "baixa", "média", "alta", "muito alta"\}. Para se atribuir um significado aos termos lingüísticos, associa-se a cada um destes termos um conjunto fuzzy definido sobre um universo de discurso comum, que neste exemplo será a "Corrente Elétrica". A Figura 3.2 ilustra cinco possíveis termos lingüísticos para a variável lingüística representando a corrente elétrica. 


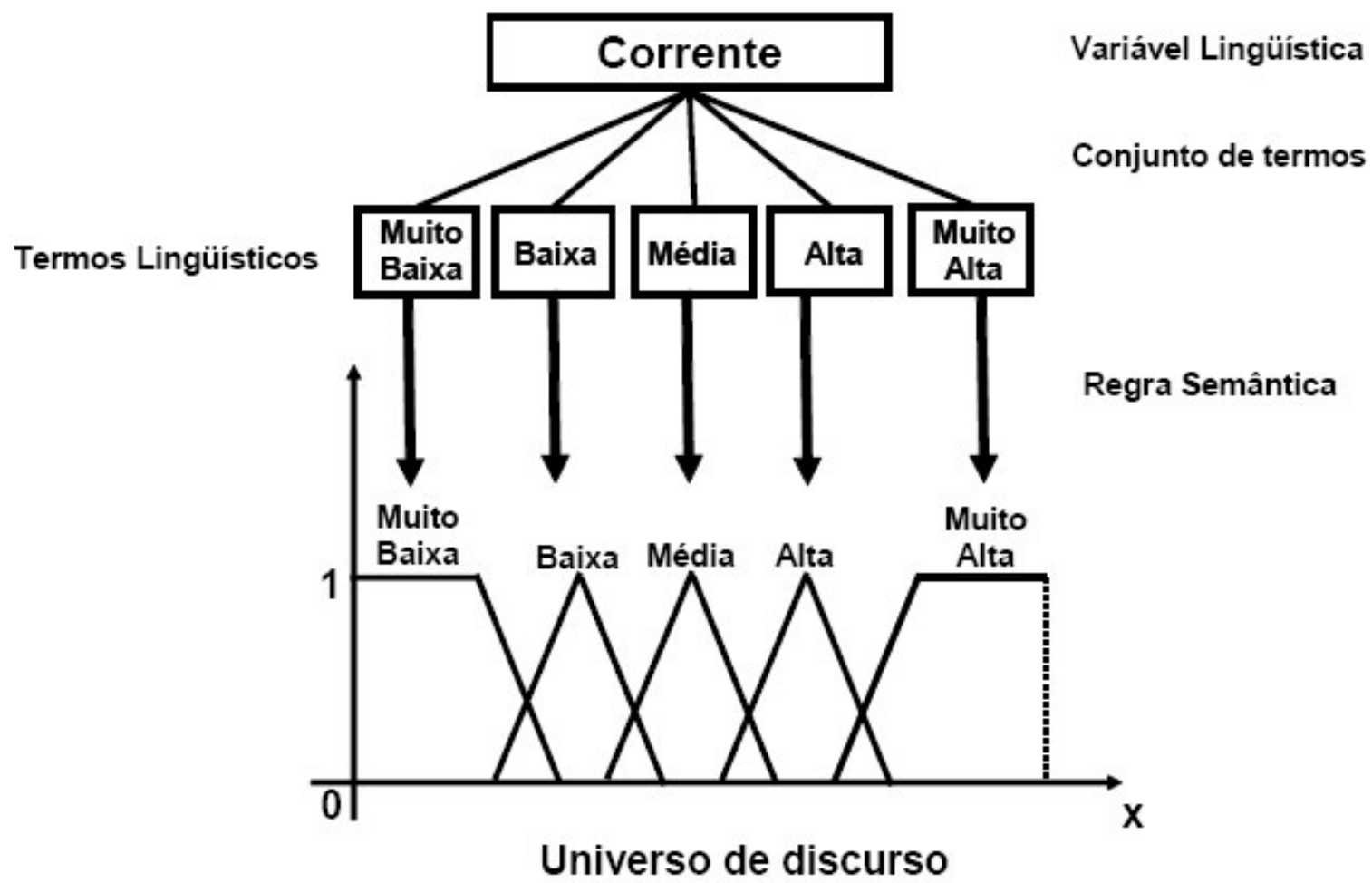

FIGURA 3.2 - Representação da variável lingüística corrente.

A forma mais comum de expressar o conhecimento é por meio de regras do tipo condição-ação. Neste tipo de regra, um conjunto de condições descrevendo uma parcela observável das entradas do processo é associado com uma ação de saída que irá manter ou levar o sistema às condições desejadas, ou ainda, expressar o conhecimento especialista associado a um processo e permitir que a modelagem seja mais flexível por admitir que informações qualitativas possam ser usadas para mapear o seu comportamento.

Tipicamente, uma condição é uma proposição lingüística (envolvendo variáveis lingüísticas) sobre o valor de algumas das variáveis de entrada, como por exemplo, "o erro é grande e positivo". Da mesma maneira, uma ação típica de controle é uma descrição lingüística, como por exemplo, "aumente um pouco a vazão". A idéia embutida junto às regras fuzzy de representar o conhecimento por meio de um conjunto de termos lingüísticos associados às variáveis de saída e 
entrada do processo é absorvida pelos sistemas de inferência fuzzy. As ações de controle ou as saídas do modelo são expressas de forma similar para cada variável de controle (saídas). Regras do tipo "se-então" são freqüentemente chamadas de declarações condicionais fuzzy ou simplesmente regras fuzzy. Dependendo do propósito, controle ou modelagem, podem ser chamadas ainda de regras de controle fuzzy ou regras de modelagem fuzzy. Uma regra fuzzy típica pode ser dada por:

$$
\begin{aligned}
& \mu_{R_{i}}=\mu_{\left(A_{i} \text { and } B_{i} \rightarrow C_{i}\right)}(u, v, w) \\
& \mu_{R_{i}}=\left[\mu_{A_{i}}(u) \text { and } \mu_{B_{i}}(v)\right] \rightarrow \mu_{C_{i}}(w)
\end{aligned}
$$

onde $A_{i}, B_{i}$ e $C_{i}$ são conjuntos fuzzy pertencentes respectivamente aos universos de discurso $U, V$ e $W$ e o operador $(\rightarrow)$ denota uma função de implicação fuzzy. Utilizando a regra max-mim de inferência composicional de Zadeh (Zadeh, 1973), para uma relação do tipo $R_{A \rightarrow B}$, onde $A \in U$ e $B \in V$, e dado um conjunto fuzzy de $U$ denotado por $A^{\prime}$ e um conjunto fuzzy $B^{\prime}$ de $V$, a inferência de $A^{\prime}$ é dada pela seguinte função de pertinência:

$$
\mu_{B^{\prime}}(v)=\max _{u}\left\{\min \left(\mu_{A^{\prime}}(u), \mu_{R}(u, v)\right)\right\} ; u \in U, v \in V
$$

A ação de controle ou de estimação consistirá então da união de todas as funções fuzzy ativadas. O valor final, ou seja, aquele que será apresentado pelas saídas do sistema fuzzy, será determinado pelo processo de defuzzificação.

\subsubsection{Agregação de Regras}

Em uma base de regras, quando mais de uma regra é acionada, as contribuições das diversas regras após a inferência são combinadas pelo operador de agregação. Por exemplo, supondo-se que $B_{1}^{\prime}, \ldots, B_{n}^{\prime}$ são todos os resultados 
derivados das diversas regras acionadas, todos relacionados a uma mesma variável lingüística, o resultado da implicação de todas as regras $B^{\prime}$ será:

$$
B^{\prime}=\bigcup_{i}^{n} B_{i}^{\prime}
$$

onde o símbolo U representa o operador de agregação. Um exemplo de função para o operador agregação é o próprio operador união.

A Figura 3.3 ilustra o processo de inferência max-min quando existem duas regras, $A_{i} \rightarrow B_{i}$ e $A_{j} \rightarrow B_{j}$, onde $A^{\prime}$ é o fato (sinal) de entrada, representado como um conjunto fuzzy.
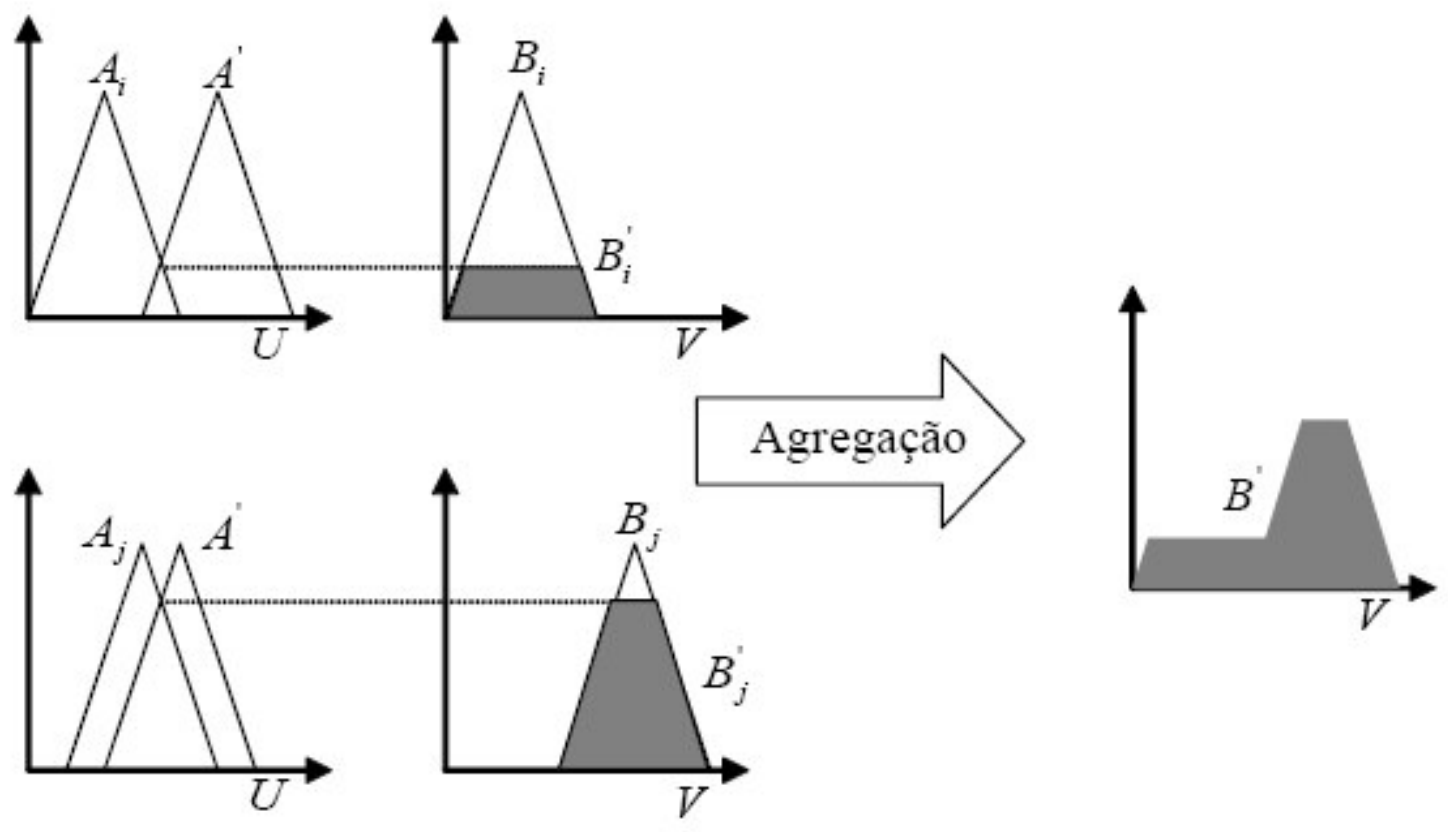

FIGURA 3.3 - Mecanismo de inferência fuzzy.

Todo processo envolvido em um sistema fuzzy é mostrado resumidamente pela Figura 3.4. Os valores numéricos provenientes da medição passam pelo processo de fuzzificação, passando então a serem representadas por valores lingüísticos. A base de conhecimento do sistema fuzzy encontra-se armazenado nas regras fuzzy do tipo "Se-Então". 


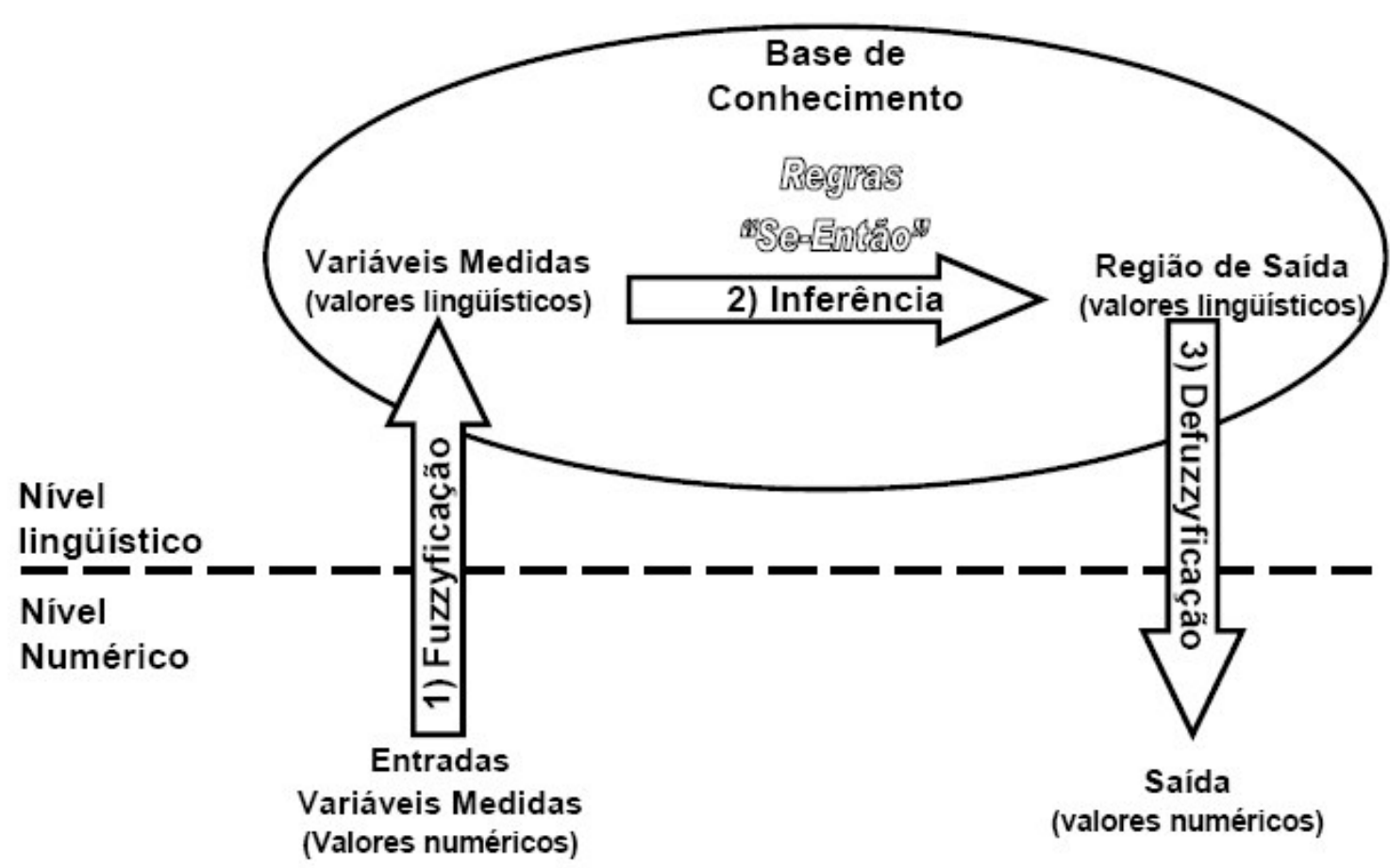

FIGURA 3.4 - Diagrama típico de um modelo de sistemas fuzzy.

Assim, o processo de inferência aplicado em valores lingüísticos de entrada resulta então em uma região de saída, também em valores lingüísticos. Para que estes possam realmente ser utilizados é necessário o processo de defuzzificação, que retorna um valor numérico pontual para a respectiva região de saída fuzzy representada por termos lingüísticos.

Esses conceitos foram utilizados para estabelecer a metodologia para aplicação dos indicadores de falta no sistema elétrico, conforme descrito no próximo capítulo. 



\section{Método de Alocação de Indicadores de Faltas Usando Lógica Fuzzy}

\subsection{Introdução}

Uma das principais dificuldades encontradas para utilização maciça de dispositivos IFs está justamente na ausência de metodologias eficientes que visam apontar quais os potenciais pontos do sistema de distribuição seriam mais apropriados para instalação destes dispositivos. De fato, os principais trabalhos apresentados na literatura correlata tratam dos IFs como elementos direcionadores para automatizar o restabelecimento de setores faltosos (Lehtonen et al., 2000). Porém, se o IF estiver posicionado em locais inapropriados, a eficiência global do processo de automatização do restabelecimento pode então ser substancialmente comprometida (Falaghi et al., 2005).

Baseado em tal contexto, apresenta-se neste capítulo uma abordagem baseada em sistemas de inferência fuzzy que quantifica os potenciais locais do sistema de distribuição que serão os mais apropriados para instalação de dispositivos IF. Resultados de análises com dados reais obtidos do banco de dados da Elektro serão apresentados para propósitos de validação do método desenvolvido. 


\subsection{Descrição do Método Proposto}

\subsubsection{Variáveis Pertinentes ao Cálculo do Potencial Para Instalação de Dispositivos Indicadores de Falta}

Assim como apresentado anteriormente, para que se possa ter uma avaliação dos prováveis pontos candidatos à instalação de dispositivos IF, torna-se necessário quantificar a potencialidade do respectivo ponto. Dessa forma, considerando a aplicação prática da técnica apresentada, torna-se também fundamental atentar, para a referida ponderação, aspectos como a carga, o número de clientes, a distância até os IFs adjacentes, bem como o nível de curto-circuito mínimo do ponto.

A alocação dos IFs feita por meio do especialista leva em consideração basicamente a distância que o ponto escolhido se encontrará das proteções tripolares à montante, justificando-se o uso dessa variável como parâmetro de entrada do sistema fuzzy. Além disso, a distância foi selecionada devido a necessidade de alocação em pontos estratégicos do sistema elétrico e em trechos com equipamentos de proteção tripolares.

A variável curto-circuito foi selecionada devido à sinalização do IF em função dessa corrente, sendo que o nível da corrente de curto-circuito ao longo do alimentador determina o melhor local de instalação e também os pontos onde a instalação do IF não é possível. Nas simulações foi considerada a corrente de curto fase-terra, com resistência de $40 \Omega$, considerada corrente de curto-circuito mínima.

As variáveis carga e clientes foram selecionadas devido à sua distribuição não-linear ao longo do alimentador. Quando ocorre uma falta no sistema elétrico, procura-se restabelecer rapidamente o maior número de clientes possível. Com a aprovação do PRODIST (Procedimentos de Distribuição) pela ANEEL, as 
concessionárias não mais são penalizadas por ultrapassagem das metas de indicadores coletivos, mas as compensações por descumprimento do padrão de qualidade são pagas diretamente ao cliente. Neste contexto, a variável carga tem uma importância muito grande na priorização do restabelecimento, possibilitando-se identificar trechos mais significativos e, conseqüentemente, aqueles que devem ser prioritários quando da instalação de IF.

Aspectos como a carga e o número de clientes à jusante do ponto sob análise permitem auferir sobre a importância de se ter um dispositivo IF instalado no mesmo. Intuitivamente, tem-se que, se à jusante do ponto tanto a carga alimentada como o número de clientes forem expressivos, o ponto, por sua vez, possuirá um grande potencial. Por outro lado, caso já exista instalado um dispositivo IF nas adjacências, o potencial, ora tido como elevado, deixa de possuir tanta expressão. Observações semelhantes podem ser conferidas para pontos do sistema de distribuição onde a corrente de curto-circuito mínima possuir níveis que impeçam a sensibilização dos dispositivos IF.

Em outras palavras, assim como o potencial de instalação decai para pontos próximos a outros dispositivos IF, o mesmo se faz para pontos onde a corrente de curto-circuito mínima pode comprometer o funcionamento dos mesmos. Empregando a corrente de curto-circuito mínima para ponderação do potencial de instalação de dispositivos IFs em um alimentador, tem-se que a probabilidade dos mesmos apresentarem índices expressivos de não-atuação é reduzida.

O emprego desses indicadores de desempenho para consubstanciar o uso das variáveis citadas no cálculo do potencial de instalação de IF, considerando um determinado ponto, pode também ser feito quando se levam em conta as variáveis relativas à carga e aos clientes atendidos. Para tanto, pode-se citar o tempo médio 
de restabelecimento, ou seja, supondo que um IF operou devidamente, é então sabido que as cargas à montante poderão ser restabelecidas, pois o ponto de falta não se encontra nos trechos de rede que as alimentam.

Ainda, há de se considerar também para fins de análise e de aplicações práticas, o uso de IF no tronco principal do alimentador. Essa consideração se justifica, pois, diante da interrupção do fornecimento de energia elétrica desencadeada por uma falta, o restabelecimento do serviço poderá ser feito gradualmente conforme as equipes de manutenção percorrem o tronco principal e verifiquem que o ponto de falta ocorrera à jusante do último indicador inspecionado.

Assim sendo, visando a formulação do método proposto, nas subseções seguintes serão apresentadas como as variáveis consideradas relevantes para avaliação do potencial para instalação de dispositivos IFs se comportam ao longo do tronco principal, ou seja, desde a barra secundária da subestação até o ponto mais distante em termos de comprimento de rede.

\subsubsection{Determinação do Tronco Principal}

Para se conduzir o delineamento do algoritmo responsável pela determinação dos trechos compondo o tronco principal do alimentador, considerarse-á inicialmente o diagrama unifilar de um sistema de distribuição ilustrado pela Figura 4.1. 


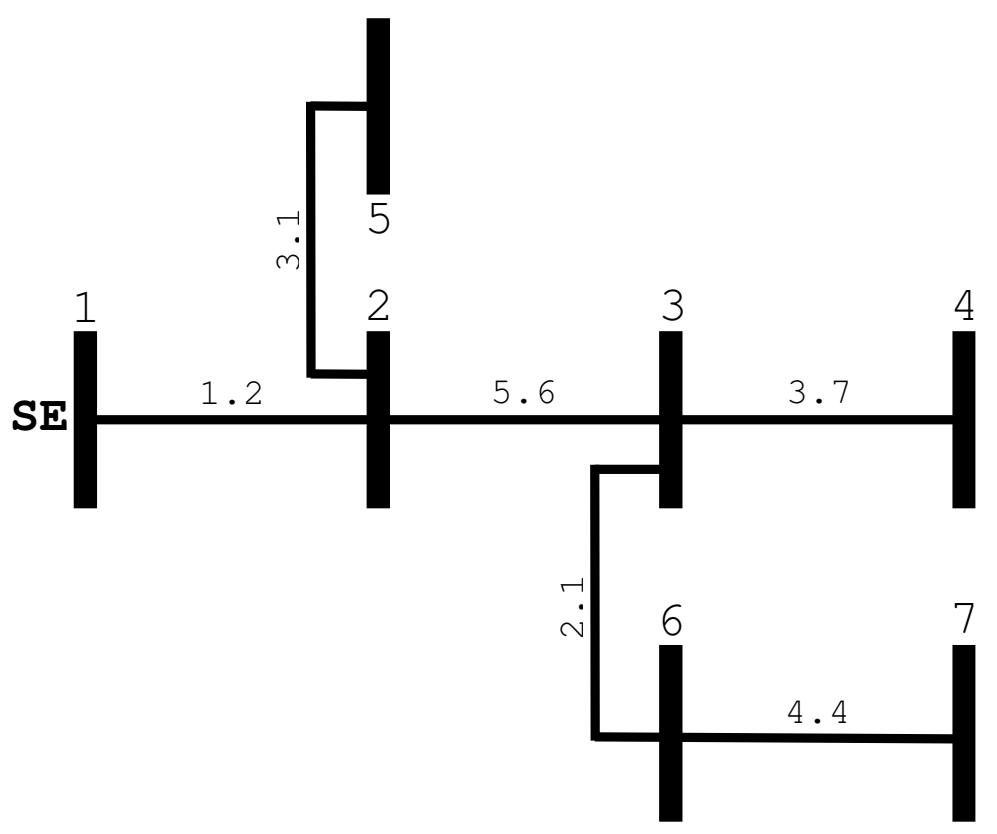

FIGURA 4.1 - Ilustração de sistema de distribuição visando delineamento do método de obtenção do tronco principal.

A determinação do tronco principal não é realizada de forma direta, requerendo o cálculo da distância, em relação à subestação, em que cada barra se encontra. Considera-se nesta simulação que cada trecho primário compreende a distância entre postes cadastrados no banco de dados da Elektro.

Esse cálculo se torna necessário visto que adotar-se-á o critério da mais distante barra para definir o tronco principal. Por meio desse princípio, o conjunto de trechos primários que conduzirem, a partir da subestação, à barra mais distante se constituirá o tronco principal do alimentador. Assim, considerando-se os comprimentos dos trechos primários indicados na Figura 4.1, o seguinte sistema de equações lineares pode ser escrito: 


$$
\left\{\begin{array}{l}
x_{1}=0 \\
x_{2}-x_{1}=1.2 \\
x_{3}-x_{2}=5.6 \\
x_{4}-x_{3}=3.7 \\
x_{5}-x_{2}=3.1 \\
x_{6}-x_{3}=2.1 \\
x_{7}-x_{6}=4.4
\end{array}\right.
$$

Expressando (4.1) em forma matricial, tem-se:

$$
A \cdot x=b
$$

onde:

$$
A=\left[\begin{array}{cccccccc}
1 & & & & & & \\
-1 & 1 & & & & & \\
& -1 & 1 & & & & \\
& & -1 & 1 & & & \\
& -1 & & & 1 & & \\
& & -1 & & 1 & \\
& & & & & -1 & 1
\end{array}\right]
$$

$$
\begin{aligned}
& b=\left(\begin{array}{lllllll}
0 & 1.2 & 5.6 & 3.7 & 3.1 & 2.1 & 4.4
\end{array}\right)^{T} \\
& x=\left(\begin{array}{lllllll}
x_{1} & x_{2} & x_{3} & x_{4} & x_{5} & x_{6} & x_{7}
\end{array}\right)^{T}
\end{aligned}
$$

onde $x_{i}$ representa a distância, em relação à subestação, da $i$-ésima barra do sistema de energia elétrica. Supondo um típico sistema de distribuição radial, é possível afirmar que não existirá redundância de caminhos para uma mesma barra.

Assim, dado um sistema com $n$ barras, haverá então $(n-1)$ equações de trechos primários para determinação da distância das barras até a subestação. Somando-se a esse conjunto de equações a referência de distância nula para a barra representativa da subestação, totalizar-se-ão então $n$ equações. Posto isso, torna-se possível afirmar que a matriz $A$ será quadrada quando se referir a sistemas 
de energia inteiramente radiais, tais como os de distribuição. Em função dessa constatação, a solução de (4.2) pode ser obtida da seguinte maneira:

$$
x=A^{-1} \cdot b
$$

Para o exemplo abordado, a matriz $A^{-1}$ pode ser expressa conforme se faz em (4.7), ou seja:

$$
A^{-1}=\left[\begin{array}{llllllll}
1 & & & & & & \\
1 & 1 & & & & & \\
1 & 1 & 1 & & & & \\
1 & 1 & 1 & 1 & & & \\
1 & 1 & & & 1 & & \\
1 & 1 & 1 & & & 1 & \\
1 & 1 & 1 & & & 1 & 1
\end{array}\right]
$$

Conseqüentemente, o vetor de distâncias será dado por:

$$
x=\left(\begin{array}{lllllll}
0 & 1.2 & 6.8 & 10.5 & 4.3 & 8.9 & 13.3
\end{array}\right)^{T}
$$

Por inspeção, verifica-se que a barra que está mais distante da subestação é aquela de número 7, posicionando-se à 13.3 unidades de comprimento da subestação representada pela barra de número 1 . Retomando-se à matriz $A^{-1}$, temse que a linha correspondente à barra mais distante é constituída da seguinte forma:

$$
A_{7,1 . .7}^{-1.7}=\left(\begin{array}{lllllll}
1 & 1 & 1 & 0 & 0 & 1 & 1
\end{array}\right)
$$

Lembrando-se de que as linhas de $A$ foram constituídas pelo conjunto de equações expresso em (4.1), a mesma inferência pode ser feita para as colunas de $A^{-1}$. Portanto, os conjuntos de trechos primários que constitui o tronco principal são aqueles entre as barras 1 e 2, 2 e 3, 3 e 6 , e as barras 6 e 7. A Figura 4.2 ilustra o tronco principal do alimentador empregado como exemplo. 


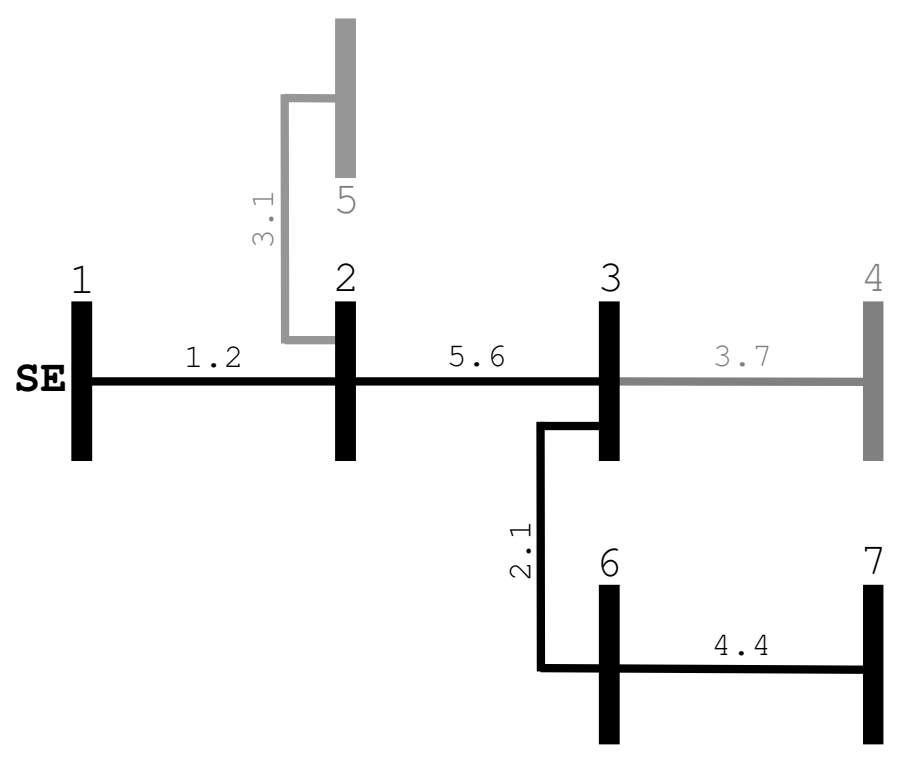

FIGURA 4.2 - Sistema de distribuição com destaque para o tronco principal.

Assim, em termos de aplicação prática, o emprego de técnicas numéricas dedicadas às matrizes esparsas deve ser também considerado para a determinação do tronco principal mediante o uso do algoritmo proposto. Tal observação torna-se pertinente quando se calcula o grau de esparsidade $\Phi$ em relação à matriz $A$, ou seja:

$$
\Phi=\frac{n^{2}-2 n+1}{n^{2}}
$$

Considerando-se a forma como as matrizes esparsas são computacionalmente representadas, e valendo-se de (4.10), verifica-se que se torna vantajosa o emprego da álgebra de matrizes esparsas para sistemas compostos inclusivamente por mais de 6 barras.

\subsubsection{Comportamento da Carga e do Número de Clientes à Jusante do Tronco Principal de Alimentadores de Distribuição}

Assim como posto no início dessa seção, o potencial de inclusão de dispositivos IFs em um determinado ponto ou trecho deve ser função, dentre outras variáveis, da carga e do número de clientes à jusante do ponto ou trecho sob 
análise. Como o objetivo dessa dissertação é apresentar como esse potencial para instalação se comporta ao longo do tronco principal de alimentadores de distribuição, torna-se então conveniente apresentar como as referidas grandezas também se comportam ao longo do referido tronco. Para tanto, dois alimentadores reais de distribuição que são nomeados por AL-1 e AL-2 foram eleitos e analisados segundo os critérios aqui expostos.

Assim, apresenta-se na Figura 4.3 o alimentador AL-1 com destaque para o tronco principal obtido por meio do algoritmo exposto na subseção anterior.

Fazendo-se uso dos dados disponíveis para o alimentador AL-1 (Figura 4.3), torna-se possível calcular como a carga instalada à jusante de cada uma das barras constituintes do tronco principal, em um total de 335, se comporta. Além da carga instalada à jusante, calcula-se também o número de clientes à jusante das barras do tronco principal.

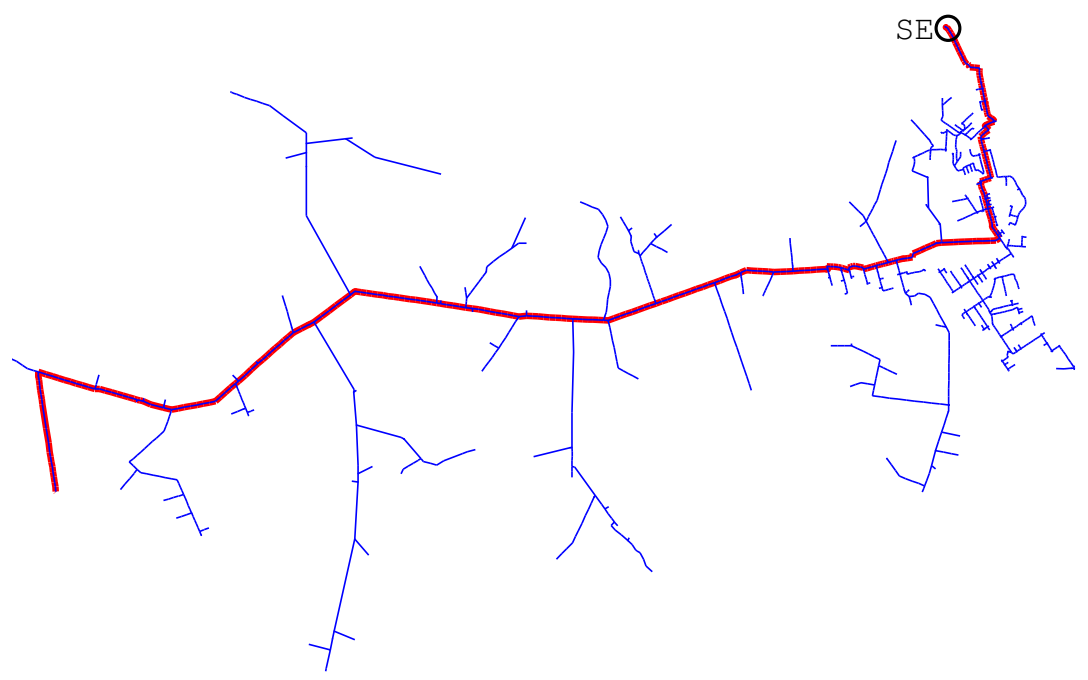

FIGURA 4.3 - Alimentador AL-1 com destaque para o tronco principal.

Assim, por meio da Figura 4.4, apresenta-se como a carga e o número de clientes se comportam ao longo da extensão do tronco principal do alimentador AL-1. 


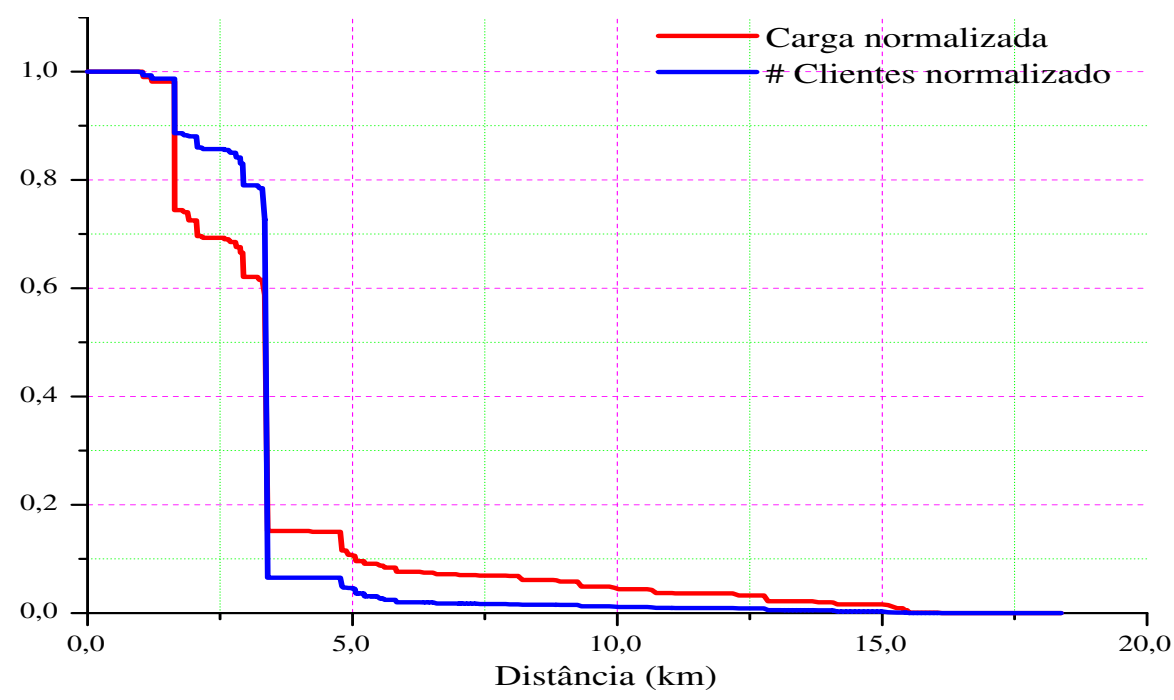

FIGURA 4.4 - Comportamento da carga e do número de clientes ao longo do tronco principal do alimentador $A L-1$.

Por meio dos gráficos da Figura 4.4 é possível verificar que o alimentador apresenta uma sensível mudança da carga e do número de clientes à jusante do ponto com distância de 3,35 km contados da subestação. Em termos reais, tem-se que esse alimentador possui seus primeiros $3 \mathrm{~km}$, aproximadamente, destinados à alimentação de cargas urbanas e o restante (mais de $15 \mathrm{~km}$ ) destinado à alimentação de cargas rurais.

Mesmo possuindo esta sensível variação, a mesma não se observa para a corrente de curto-circuito mínima ao longo do tronco principal. Essa observação se justifica em função da uniformidade dos cabos empregados para constituição do tronco principal de alimentadores de distribuição. A Figura 4.5 ilustra o comportamento da corrente de curto-circuito mínima ao longo do tronco principal do alimentador AL-1. 


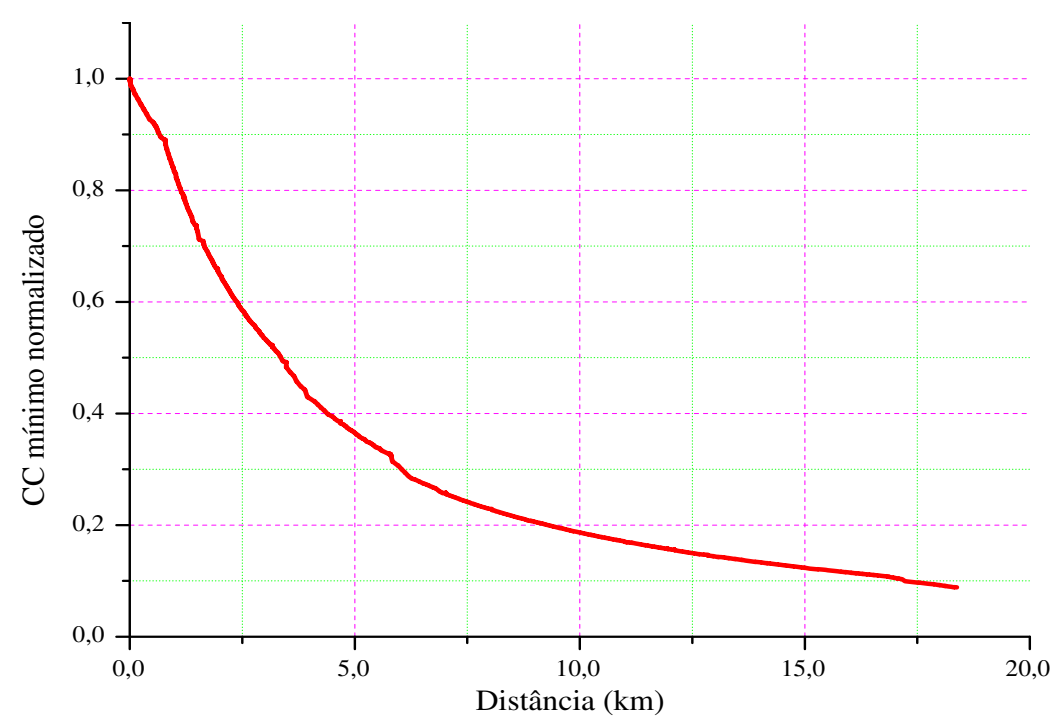

FIGURA 4.5 - Comportamento da corrente de curto-circuito mínima ao longo do tronco principal do alimentador $A L-1$.

Complementando a apresentação dos dados da pesquisa, tem-se por meio da Figura 4.6 a disposição geográfica do alimentador AL-2, onde se destacam tanto a localização da subestação (SE) como também do tronco principal do mesmo.

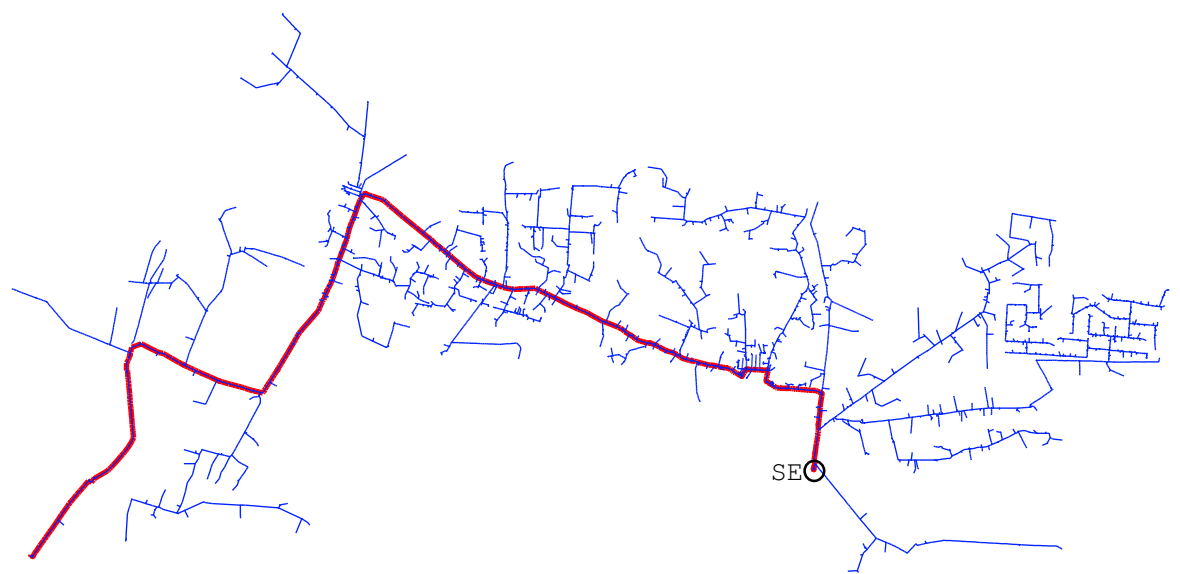

FIGURA 4.6 - Alimentador AL-2 com destaque para o tronco principal.

O comportamento da carga e do número de clientes à jusante de cada uma das barras constituintes do tronco principal do alimentador AL-2 é ilustrado por meio da Figura 4.7. 


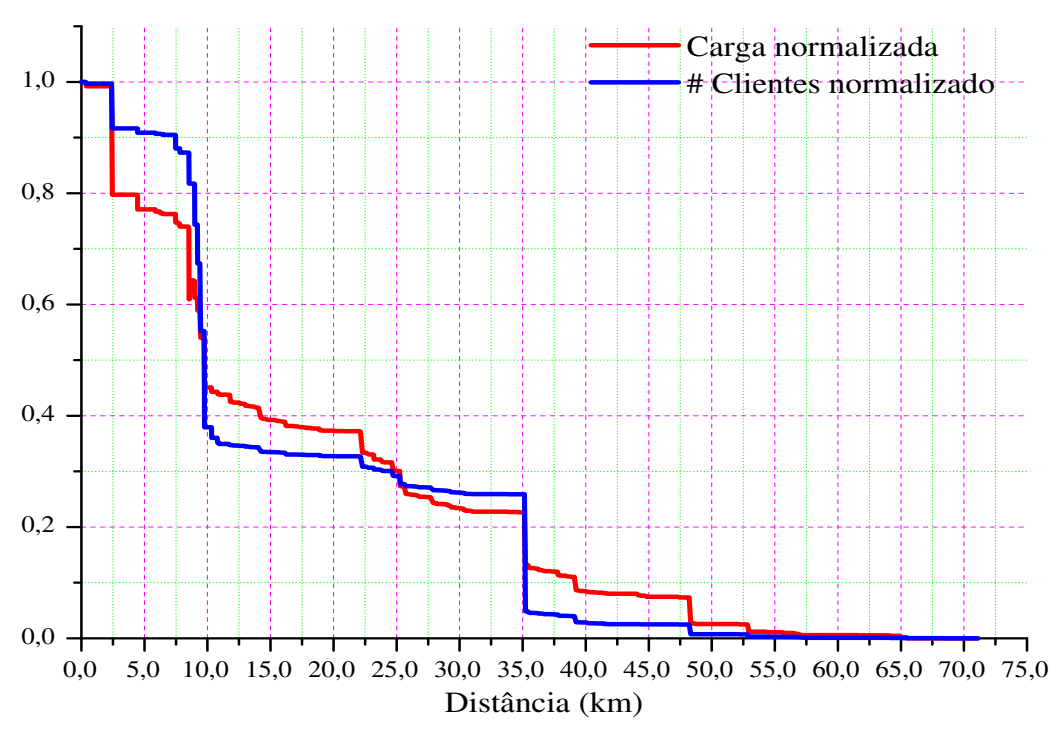

FIGURA 4.7 - Comportamento da carga e do número de clientes ao longo do tronco principal do alimentador AL-2.

A partir da Figura 4.7, além de se verificar como a carga e o número de clientes variam ao longo do tronco principal do alimentador AL-2 sob estudo, constata-se também a sua grande extensão, aproximadamente $72 \mathrm{~km}$. Tal fato motiva ainda mais a investigação de técnicas que visam a determinação dos potenciais pontos de instalação de dispositivos IF, pois, diante de uma configuração não otimizada de alocação desses dispositivos, o tempo de restabelecimento do serviço poderá ser substancialmente afetado, refletindo-se conseqüentemente nos indicadores de qualidade da concessionária.

Em complemento, por meio da Figura 4.8, tem-se como a corrente de curtocircuito mínima varia ao longo de toda a extensão do tronco principal do alimentador AL-2. 


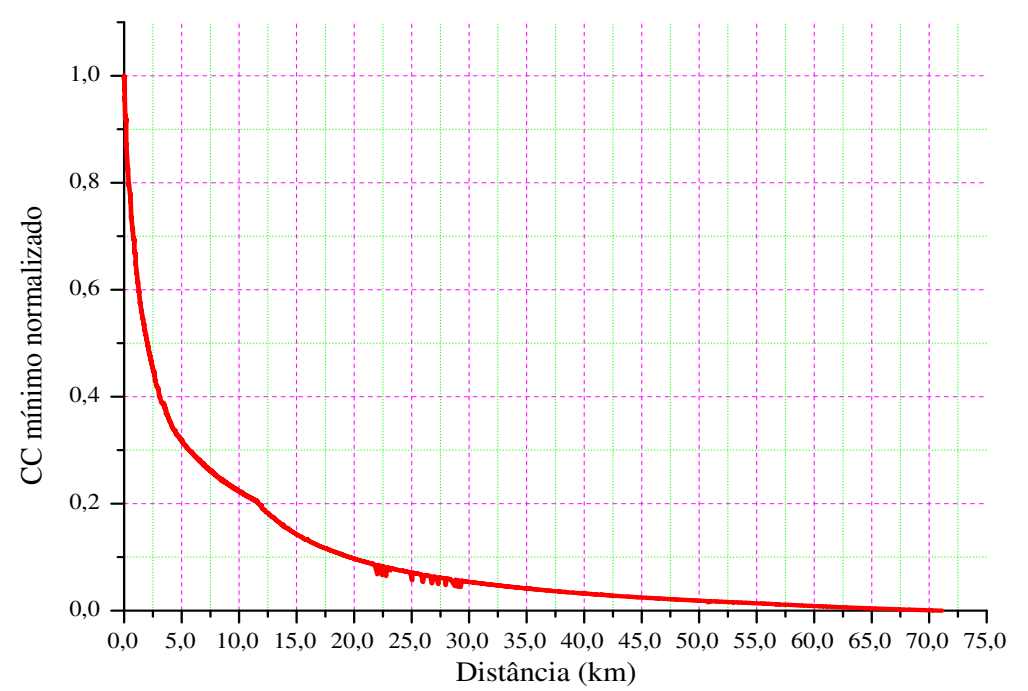

FIGURA 4.8 - Comportamento da corrente de curto-circuito mínima ao longo do tronco principal do alimentador AL-2.

Assim como observado para o alimentador AL-1, verifica-se que a corrente de curto-circuito mínima possui decréscimo uniforme, sendo reflexo direto da uniformidade dos condutores constituintes do seu tronco principal.

\subsubsection{Distância aos Dispositivos Indicadores de Faltas Adjacentes}

Não apenas a carga, o número de clientes e a corrente de curto-circuito mínima devem ser variáveis consideradas no cálculo do potencial dos pontos ou trechos do tronco principal para receber dispositivos IF. Há de se considerar também, com igual importância, a distância do potencial ponto em relação aos dispositivos IFs adjacentes.

O cálculo da distância até os dispositivos IFs adjacentes pode ser conduzido de maneira semelhante ao exposto na Subseção 4.2.2. A adaptação necessária ao referido cálculo deve ser feita sobre a primeira linha de $A$, correspondente à equação da referência nula para a distância, mantendo-se o vetor $b$ constante.

No exemplo conduzido na Subseção 4.2.2 a referência fora posta sobre a barra número 1, a qual correspondia à barra da subestação. Assim, considerando-se que na barra número 3 exista um dispositivo indicador de falta, a matriz $A$ deve ser 
modificada, conforme apresentado em (4.11), de forma que a solução (vetor $x$ ) forneça a distância de cada uma das barras até o dispositivo instalado na barra de número 3.

$$
A=\left[\begin{array}{ccccccc} 
& & 1 & & & & \\
-1 & 1 & & & & & \\
& -1 & 1 & & & & \\
& & -1 & 1 & & & \\
& -1 & & & 1 & & \\
& & -1 & & & 1 & \\
& & & & & -1 & 1
\end{array}\right]
$$

Vale a pena ressaltar que o emprego de algoritmos próprios para tratamento de matrizes esparsas se torna novamente conveniente para a condução dos inúmeros cálculos que possam se fazer pertinentes à determinação da distância de cada barra em relação aos dispositivos IFs adjacentes mais próximos. Ressalta-se que os cálculos serão repetidos para cada uma das $n$ barras existentes. Para ilustrar como a distância até os dispositivos adjacentes mais próximos se procede, apresenta-se por meio da Figura 4.9 o comportamento dessa variável ao longo do tronco principal do alimentador AL-1. 


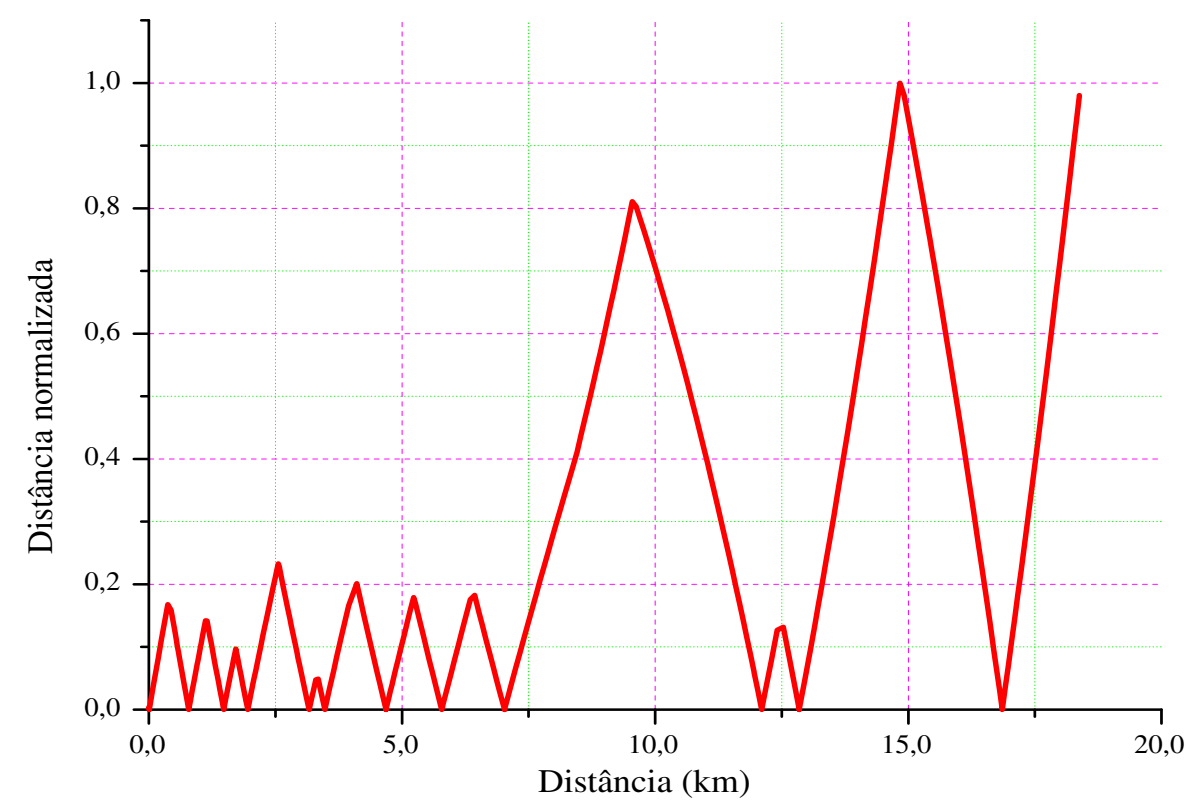

FIGURA 4.9 - Distância normalizada até os dispositivos indicadores de faltas ao longo do tronco principal do alimentador AL-1.

Por meio da Figura 4.9 verifica-se que, aproximadamente, nos pontos distantes em torno de 10 e $15 \mathrm{~km}$ do tronco principal do alimentador AL-1 a distância entre dispositivos IFs apresentam seus maiores valores. Da mesma maneira, por meio da Figura 4.10, destaca-se o comportamento da distância aos dispositivos IFs para o alimentador AL-2.

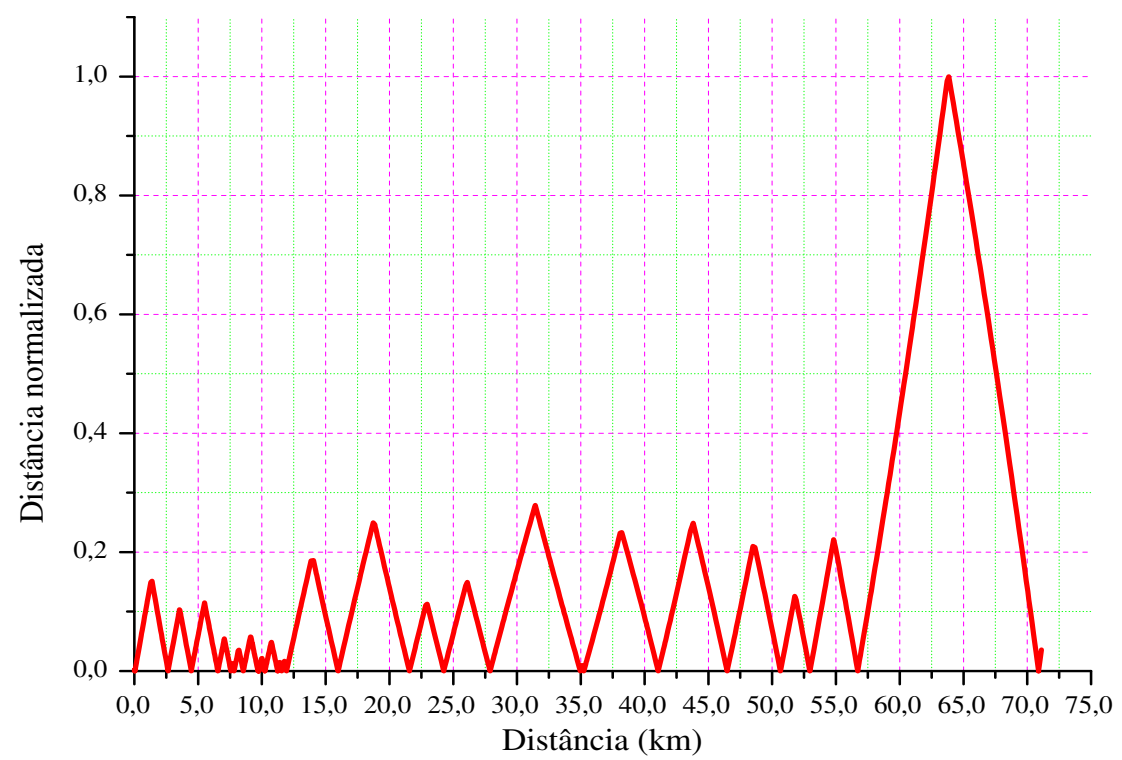

FIGURA 4.10 - Distância normalizada até os dispositivos indicadores de faltas ao longo do tronco principal do alimentador AL-2. 
Diferente do que ocorre com o alimentador AL-1, no alimentador AL-2 se observa uma maior uniformidade das distâncias aos dispositivos IF, com exceção do entorno da distância de $63 \mathrm{~km}$.

\subsection{Sistema Fuzzy Para o Cálculo do Potencial de Instalação de Dispositivos Indicadores de Faltas}

Por meio da análise realizada nas subseções anteriores, torna-se possível extrair, conforme apresentado, as informações pertinentes para a quantificação da importância da instalação de indicadores de faltas ao longo do tronco principal de um alimentador de sistema de distribuição de energia elétrica. Além de operar tendo como referência as informações fornecidas explicitamente pela respectiva base de dados da concessionária, desenvolveram-se também algoritmos computacionais para se calcular parâmetros adicionais e que contribuíssem para uma precisa especificação dos pontos de instalação de dispositivos indicadores de falta.

Dentre as informações calculadas para tal propósito destaca-se a distância que uma determinada barra encontra-se dos dispositivos de proteção adjacentes. Essa informação é de relevante importância quando se almeja inferir os possíveis pontos de instalação, tendo-se como meta a otimização dos índices de qualidade que refletem o tempo de restabelecimento do sistema após a ocorrência de uma falta no mesmo.

No entanto, não se atendo apenas a essa métrica, conforme destacado nas subseções anteriores, o sistema responsável pela estimação do potencial de instalação de IF deve ser sensível à carga, aos clientes e aos níveis de curto-circuito da rede à jusante do respectivo ponto potencial.

Dessa forma, formulou-se um sistema de inferência fuzzy dedicado ao cálculo do potencial de instalação de dispositivos indicadores de faltas que uma 
determinada barra ou trecho primário possui. Para tanto, consideraram-se como entradas os quatro parâmetros anteriormente listados, ou seja, as cargas, os clientes, os níveis de curto-circuito e as distâncias até os dispositivos IFs adjacentes ao ponto em questão, sendo que a saída do sistema fornece uma resposta entre 0 e 1 que representa o valor do potencial de instalação ao longo do tronco principal do alimentador. Quanto mais altos forem esses valores, maiores então serão as chances de determinados pontos receberem indicadores de faltas. A Figura 4.11 ilustra esquematicamente o sistema fuzzy desenvolvido.

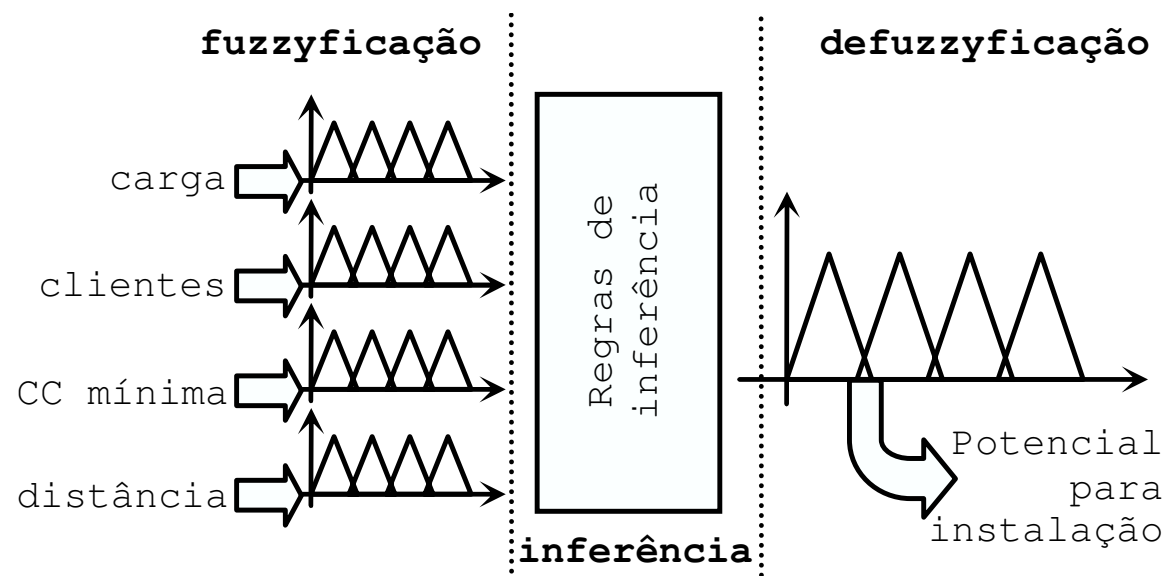

FIGURA 4.11 - Diagrama esquemático do sistema fuzzy empregado para o cálculo do potencial de instalação de dispositivos indicadores falta.

O sistema de inferência fuzzy esquematicamente representado por meio da Figura 4.11 fora constituído por um total de 28 regras, possuindo nas entradas e na saída um conjunto de funções de pertinência constituídas de 5 termos.

Os termos para as funções de pertinência para o sistema fuzzy são os seguintes:

- MP: Muito Pequeno

- PE: Pequeno

- ME: Médio

- GR: Grande

- MG: Muito Grande 
As regras compostas para o sistema fuzzy estão descritas na Tabela 4.1. Os fatores de ponderação (1.0) e (0.5) em cada regra são determinados em função do impacto para o cálculo. Pode-se observar na Tabela 4.1 que as regras referentes a variável distância são as que receberam a maior ponderação, representadas pelas regras de 1 a 5 . Essa variável é que determinará prioritariamente se o ponto em estudo possui potencial para a instalação do IF.

TABELA 4.1 - Regras para o sistema fuzzy.

\begin{tabular}{|c|c|}
\hline № & Regra Sistema Fuzzy \\
\hline 1 & Se Distância é MP Então Potencial é MP (1.0) \\
\hline 2 & Se Distância é PE Então Potencial é PE (1.0) \\
\hline 3 & Se Distância é ME Então Potencial é ME (1.0) \\
\hline 4 & Se Distância é GR Então Potencial é GR (1.0) \\
\hline 5 & Se Distância é MG Então Potencial é MG (1.0) \\
\hline 6 & Se Carga é MP ou Clientes é MP Então Potencial é MP (0.5) \\
\hline 7 & Se Carga é PE ou Clientes é PE Então Potencial é PE (0.5) \\
\hline 8 & Se Carga é ME ou Clientes é ME Então Potencial é ME (0.5) \\
\hline 9 & Se Carga é GR ou Clientes é GR Então Potencial é GR (0.5) \\
\hline 10 & Se Carga é MG ou Clientes é MG Então Potencial é MG (0.5) \\
\hline 11 & Se Distância é MP e Icc é MP Então Potencial é MP (0.5) \\
\hline 12 & Se Distância é PE e Icc é PE Então Potencial é PE (0.5) \\
\hline 13 & Se Distância é ME e Icc é ME Então Potencial é ME (0.5) \\
\hline 14 & Se Distância é GR e Icc é GR Então Potencial é GR (0.5) \\
\hline 15 & Se Distância é MG e Icc é MG Então Potencial é MG (0.5) \\
\hline 16 & Se Distância é MG e Icc é GR Então Potencial é GR (0.5) \\
\hline 17 & Se Distância é MG e Icc é ME Então Potencial é ME (0.5) \\
\hline 18 & Se Distância é MG e Icc é PE Então Potencial é PE (0.5) \\
\hline 19 & Se Distância é MG e Icc é MP Então Potencial é MP (0.5) \\
\hline 20 & Se Distância é GR e Icc é MG Então Potencial é GR (0.5) \\
\hline 21 & Se Distância é GR e Icc é ME Então Potencial é ME (0.5) \\
\hline 22 & Se Distância é GR e Icc é ME Então Potencial é PE (0.5) \\
\hline 23 & Se Distância é GR e Icc é PE Então Potencial é MP (0.5) \\
\hline 24 & Se Distância é ME e Icc é MG Então Potencial é ME (0.5) \\
\hline 25 & Se Distância é ME e Icc é GR Então Potencial é PE (0.5) \\
\hline 26 & Se Distância é ME e Icc é ME Então Potencial é MP (0.5) \\
\hline 27 & Se Distância é ME e Icc é PE Então Potencial é MP (0.5) \\
\hline 28 & Se Distância é ME e Icc é MP Então Potencial é MP (0.5) \\
\hline
\end{tabular}


Cada uma dessas funções de pertinência possui formatos normalizados como aqueles apresentados na Figura 4.12.

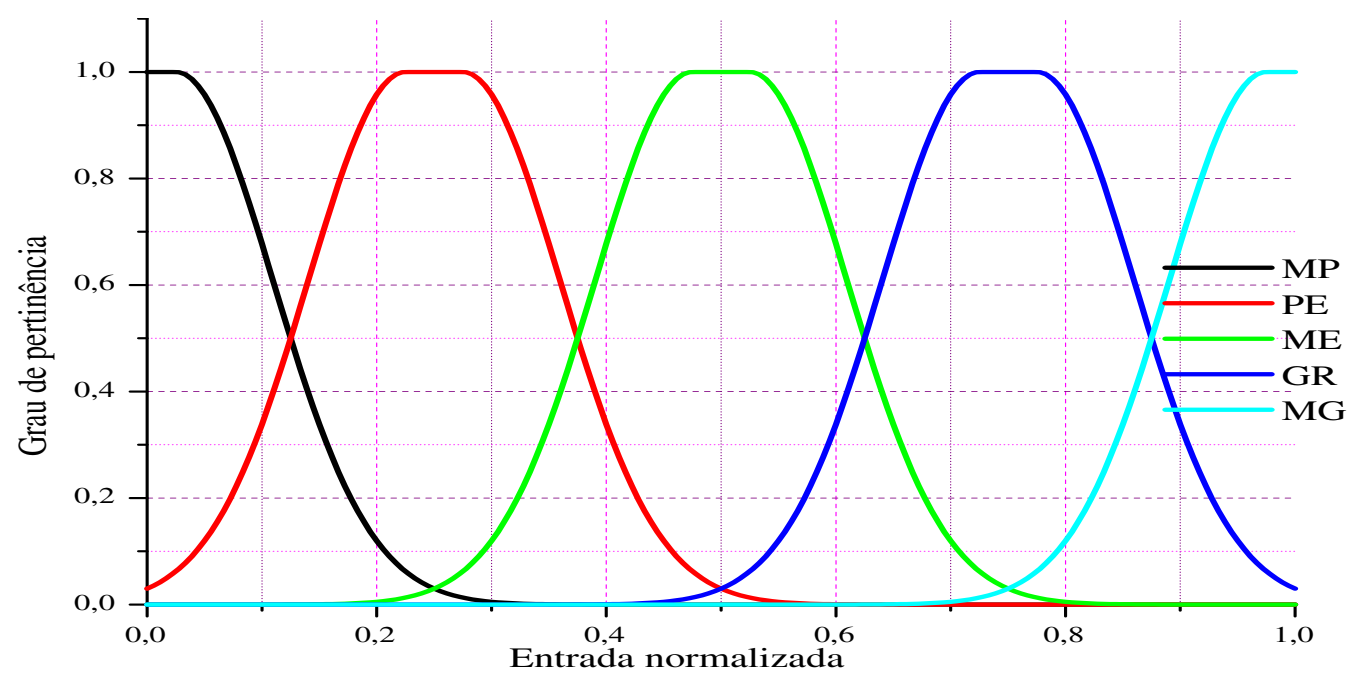

FIGURA 4.12 - Ilustração de função de pertinência normalizada para o cálculo do potencial de instalação de dispositivos indicadores de falta.

Fazendo uso dos dados apresentados na Subseção 4.2.1 e do sistema fuzzy destacado nos parágrafos anteriores, calculou-se então os potenciais pontos para instalação de dispositivos IFs ao longo dos troncos principais dos alimentadores $\mathrm{AL}-1$ e AL-2.

Assim, por meio da Figura 4.13, destaca-se como o potencial para instalação se comporta ao longo do tronco principal do alimentador AL-1. 


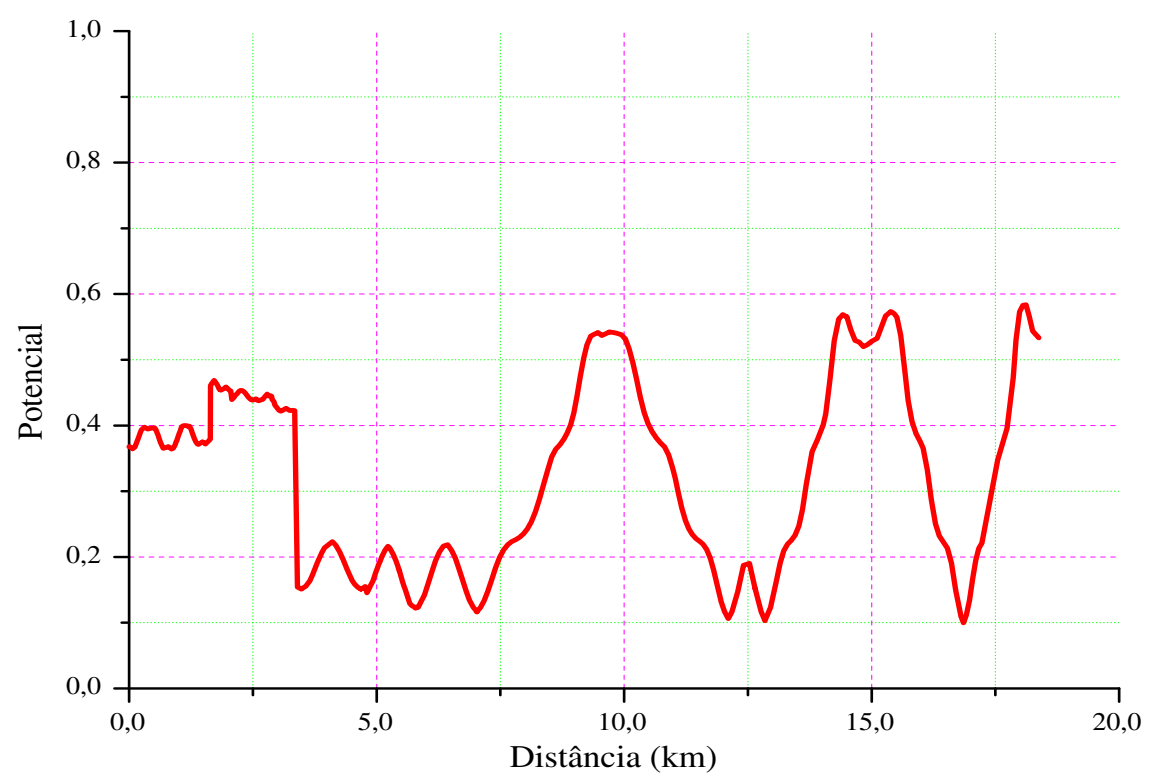

FIGURA 4.13 - Potencial para instalação de dispositivos indicadores de faltas ao longo do tronco principal do alimentador AL-1.

O gráfico da Figura 4.13 fornece o potencial que os trechos constituintes do tronco principal possuem para instalação de dispositivos IF. É possível observar que, mesmo possuindo a maior carga à jusante, os principais pontos para a referida instalação não se encontram na região urbana do alimentador $A L-1$. Em função do maior espaçamento entre dispositivos IFs se encontrar na região rural (Figura 4.9), tem-se que esses seriam inicialmente os principais pontos para instalação. Entretanto, os principais potenciais pontos de instalação estariam há uma distância aproximada entre 1,5 e 3,0 km da subestação no caso de se priorizar as cargas urbanas (Figura 4.4) ao invés das rurais.

Na Figura 4.14 destaca-se o potencial que os trechos do tronco principal do alimentador AL-2 possuem para instalação de dispositivos IF. Com exceção dos trechos finais no alimentador AL-2, o potencial para instalação dos dispositivos IFs possui a tendência de se reduzir conforme aumenta a distância em relação à subestação. Essa observação é um indicativo que a atual rede de dispositivos IFs 
existente no referido alimentador está coerente, necessitando apenas de uma avaliação nos seus trechos terminais.

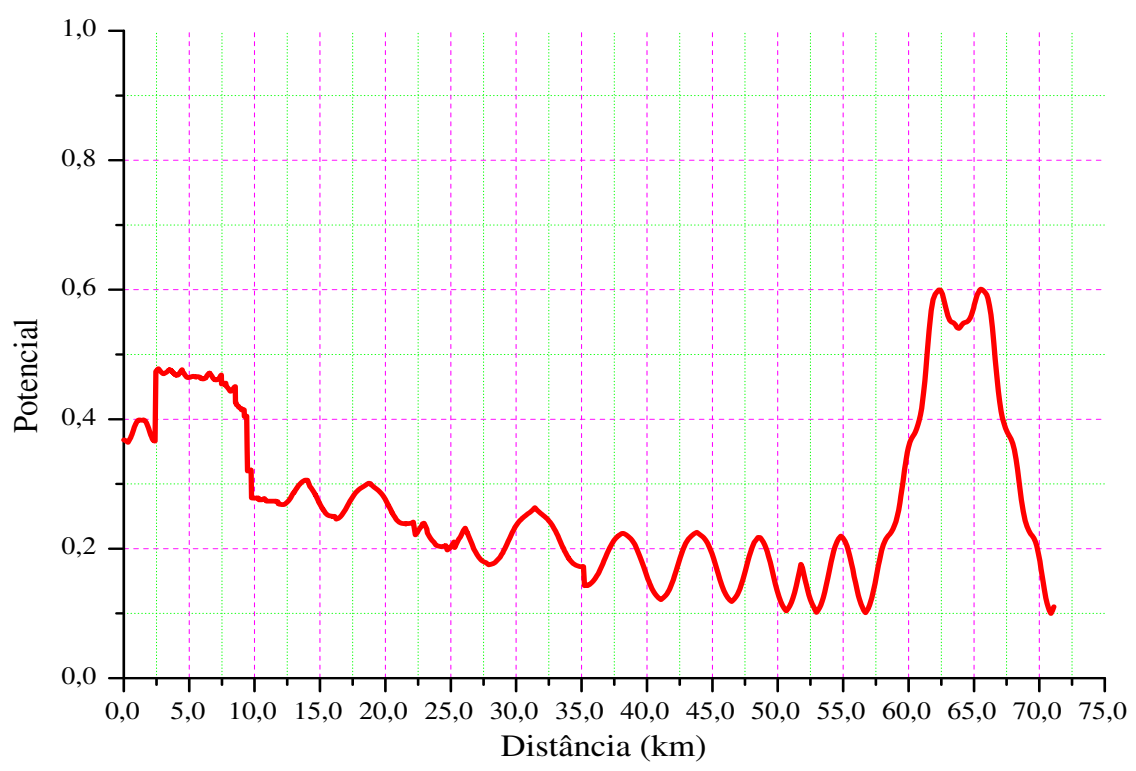

FIGURA 4.14 - Potencial para instalação de dispositivos indicadores de faltas ao longo do tronco principal do alimentador AL-2.

Entretanto, no caso de se priorizar a carga e o número de clientes (Figura 4.7), os principais pontos de instalação estaria há uma distância aproximada entre 3 e 8 km da subestação. 



\section{Resultados de Aplicação em Alimentadores Reais}

Para propósitos de validação, a abordagem proposta nesta dissertação foi aplicada no cálculo do potencial de instalação em diversos alimentadores do sistema de distribuição da concessionária ELEKTRO. Todas as variáveis foram diretamente extraídas das bases de dados da concessionária com o intuito de se garantir uma maior fidelidade dos procedimentos computacionais.

A representação dos alimentadores por meio de modelos deve ser a mais fiel possível à realidade, tendo-se como objetivo de que as simulações computacionais estejam em conformidade com o comportamento real do sistema de distribuição. A riqueza de detalhes disponíveis nos bancos de dados da concessionária, referentes aos alimentadores, permite tal representação, o que propicia um elevado nível de detalhamento dos circuitos de distribuição que serão utilizados neste capítulo.

Para tanto, utilizou-se software em Matlab que, a partir do banco de dados de alimentadores da concessionária, extraem-se as informações necessárias para se realizar as simulações, conforme pode ser observado na Figura 5.1.

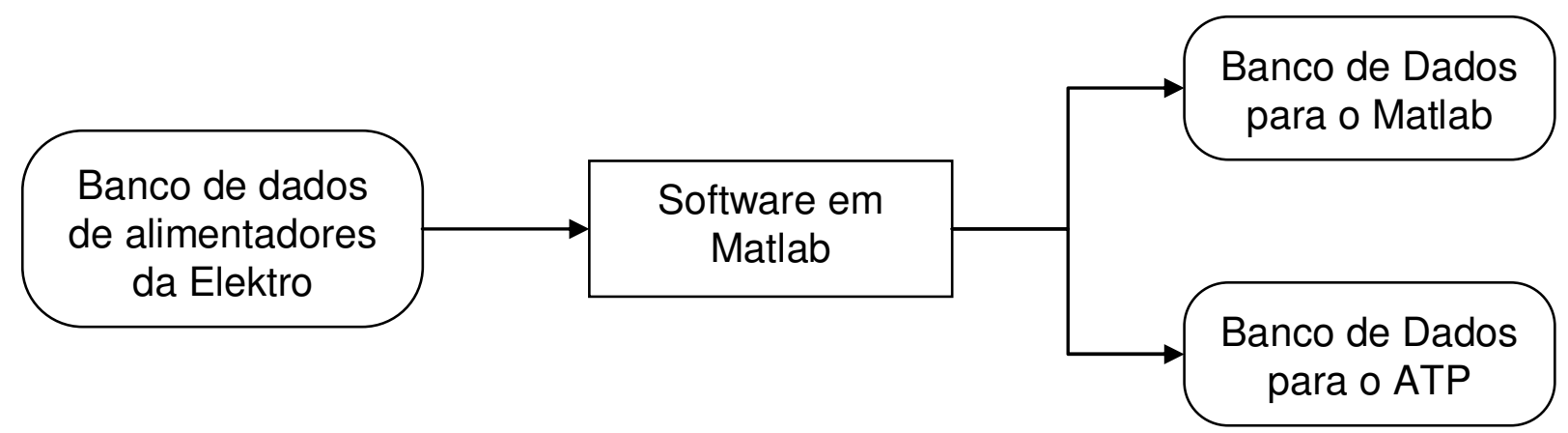

FIGURA 5.1 - Estratégia de software em Matlab para automatização das simulações. 
O programa computacional em linguagem Matlab realiza a leitura do banco de dados de alimentadores em formato utilizado pela concessionária e extrai as informações necessárias para a confecção dos arquivos utilizados pelo SimPowerSystems do Matlab e também no ATP. A partir de tais informações, tornase então possível se reconstruir de maneira automática, por intermédio dos modelos que o Matlab e o ATP operam, os alimentadores pilotos que serão utilizados pela estratégia fuzzy visando o cálculo do potencial de instalação de indicadores de falta.

\subsection{Resultados Para Alimentador IGU04}

O primeiro estudo de caso será realizado sobre o Alimentador IGU04, o qual está situado na cidade de lguape (Subestação Iguape 01). O alimentador é derivado do Transformador 2 da referida SE, com potência de 10/12,5 MVA, tensão de transformação de 69/13,8 kV, esquema de ligação $\mathrm{D} / \mathrm{Y}$ aterrado, tendo uma extensão de aproximadamente $43,4 \mathrm{~km}$ no tronco principal.

Este alimentador é caracterizado tipicamente por atender cargas residenciais, com $90 \%$ do total de 5.900 clientes. Do total de 14,2 MVA de carga suprida por esse alimentador, 14 MVA é atendida na área urbana e 0,2 MVA na área rural, atendendo também a localidade de llha Comprida. A Figura 5.2 apresenta a representação gráfica da disposição geográfica deste alimentador. 


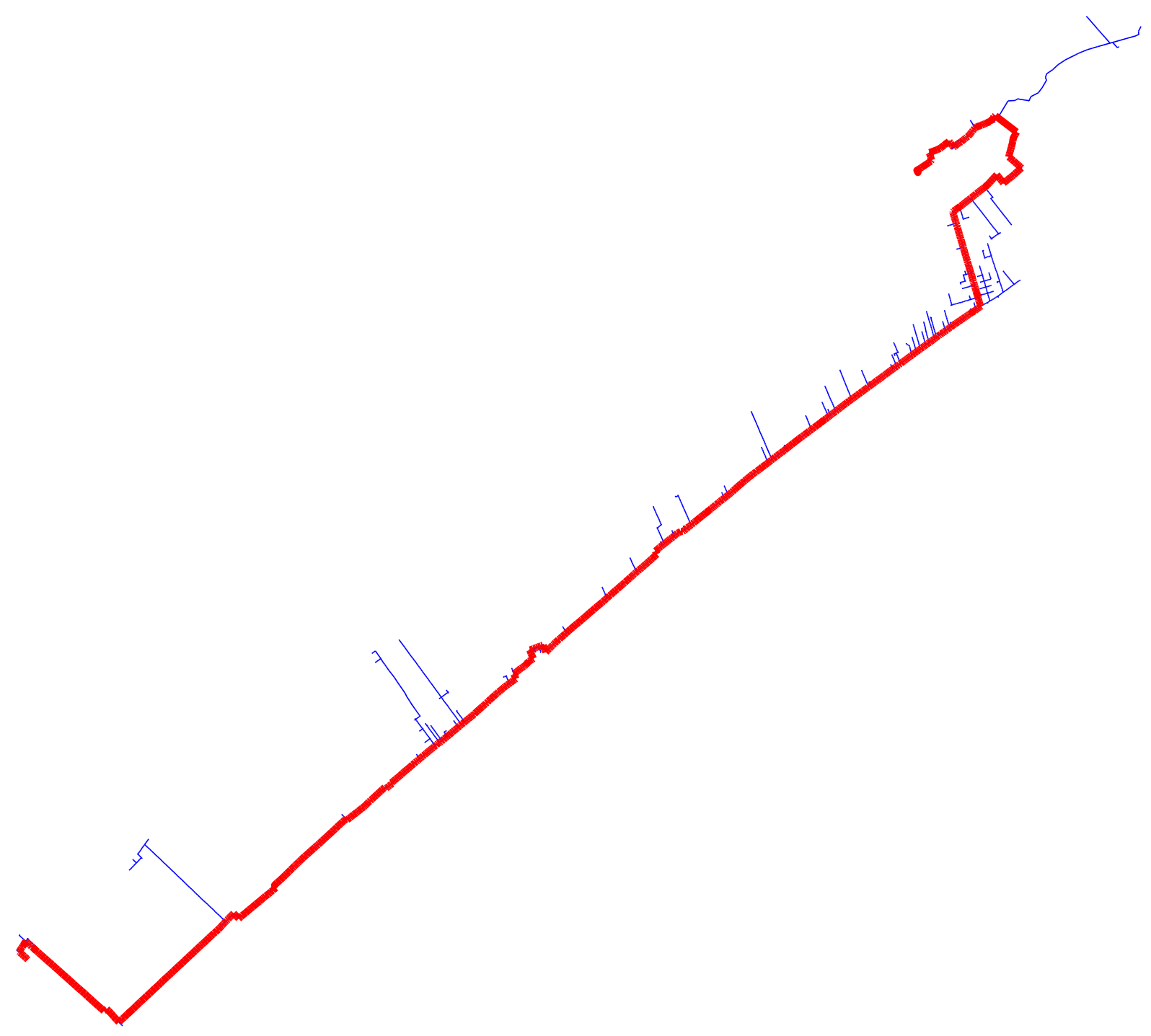

FIGURA 5.2 - Alimentador IGU04 com destaque para o tronco principal

Assim, por meio da Figura 5.3, apresenta-se como a carga e o número de clientes se comportam ao longo da extensão do tronco principal do alimentador IGU04. 


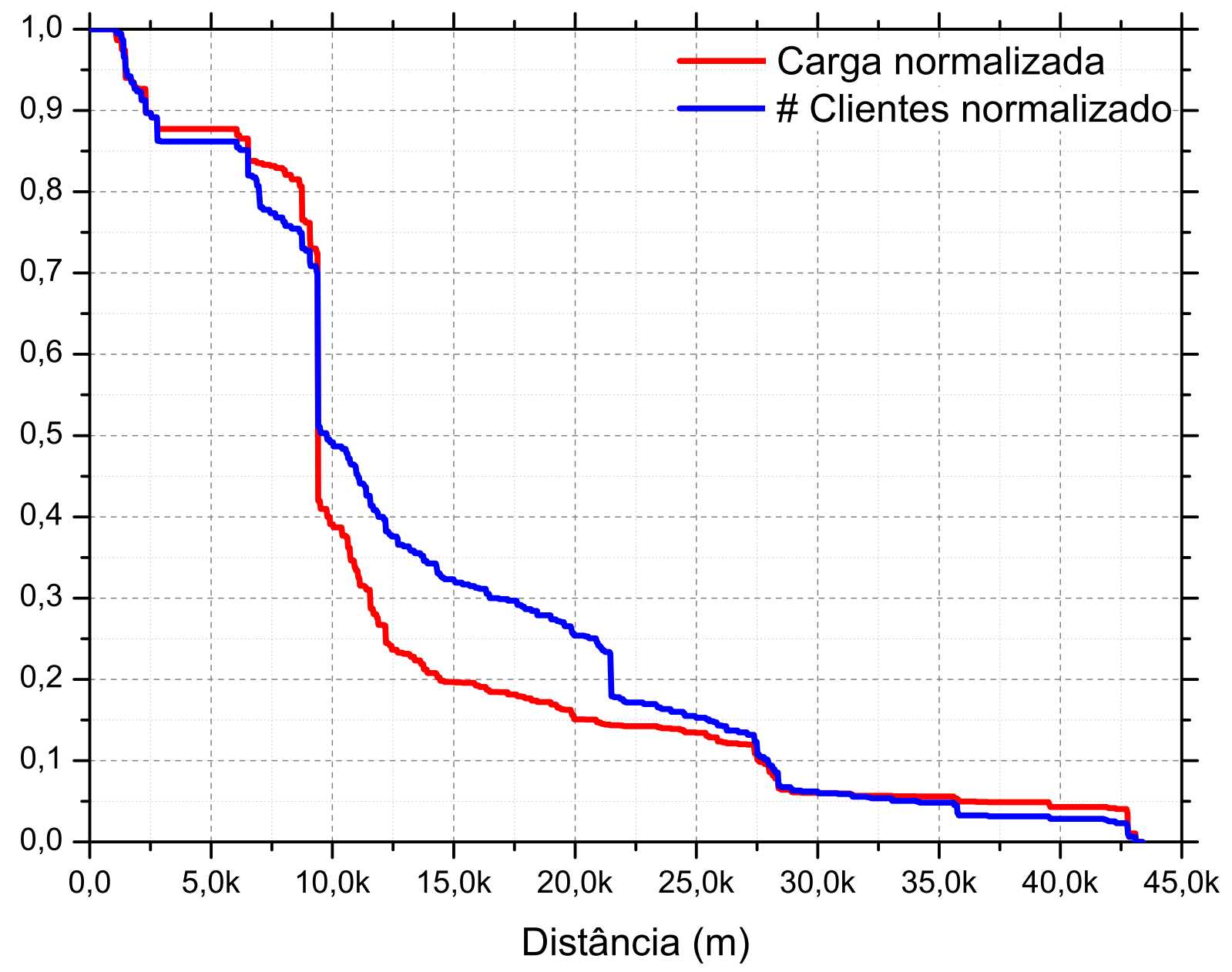

FIGURA 5.3 - Comportamento da carga e do número de clientes ao longo do tronco principal do alimentador IGU04.

Por meio dos gráficos da Figura 5.3 é possível verificar que o alimentador apresenta uma sensível mudança da carga e do número de clientes à jusante do ponto com distância de 9,5 km contados da subestação. Em termos reais, tem-se que esse alimentador possui seus primeiros $10 \mathrm{~km}$, aproximadamente, destinados à alimentação de cargas urbanas e o restante (mais de $35 \mathrm{~km}$ ) destinado à alimentação de cargas rurais.

Pode-se observar esta mesma variação para a corrente de curto-circuito mínima ao longo do tronco principal. Essa observação se justifica em função da uniformidade dos cabos empregados para constituição do tronco principal de 
alimentadores de distribuição. A Figura 5.4 ilustra o comportamento da corrente de curto-circuito mínima ao longo do tronco principal do alimentador IGU04.

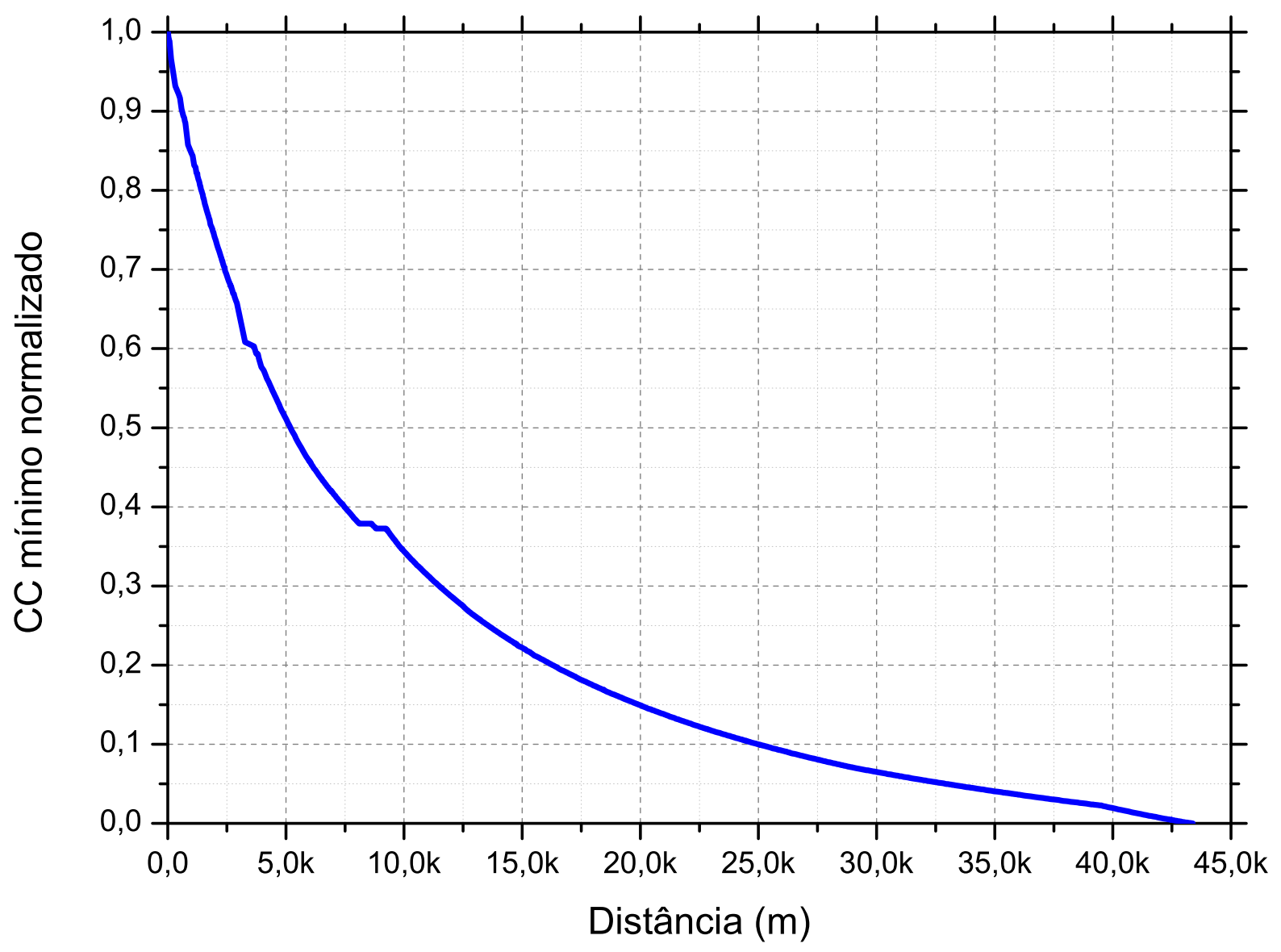

FIGURA 5.4 - Comportamento da corrente de curto-circuito mínima ao longo do tronco principal do alimentador IGU04.

Na Figura 5.5 ilustra como a distância até os dispositivos adjacentes mais próximos tem se procedido ao longo do tronco principal do alimentador IGU04. 


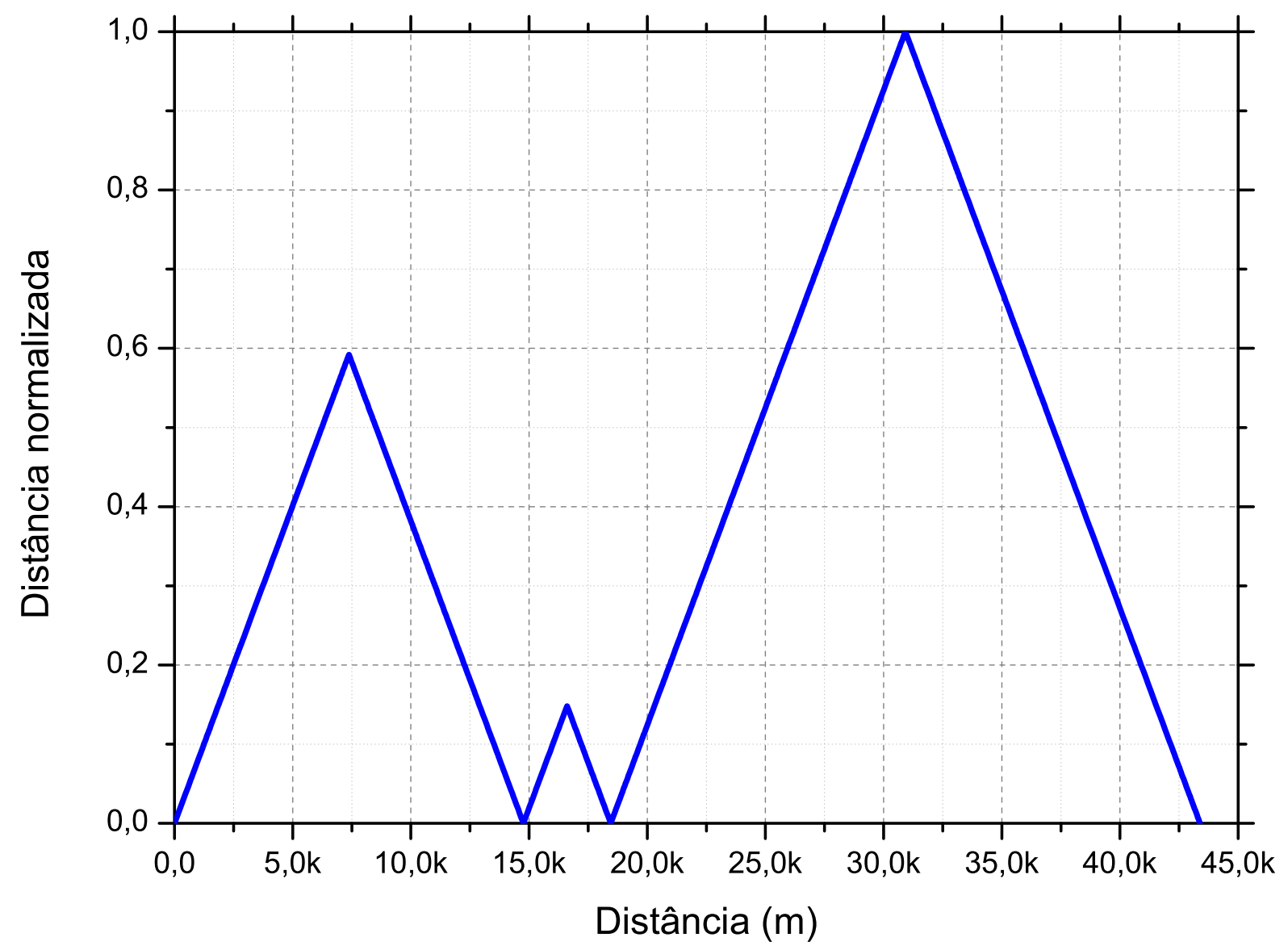

FIGURA 5.5 - Distância normalizada até os dispositivos indicadores de faltas ao longo do tronco principal do alimentador IGU04.

Por meio da Figura 5.5 verifica-se que, aproximadamente, nos pontos distantes em torno de 7,5 e $32 \mathrm{~km}$ do tronco principal do alimentador IGU04, a distância entre dispositivos IFs apresentam seus maiores valores.

Assim, a partir da aplicação do sistema de inferência fuzzy apresentado na Seção 4.3, ilustra-se por meio da Figura 5.6 como o potencial para instalação de dispositivos IFs se comporta ao longo do tronco principal do alimentador IGU04. 


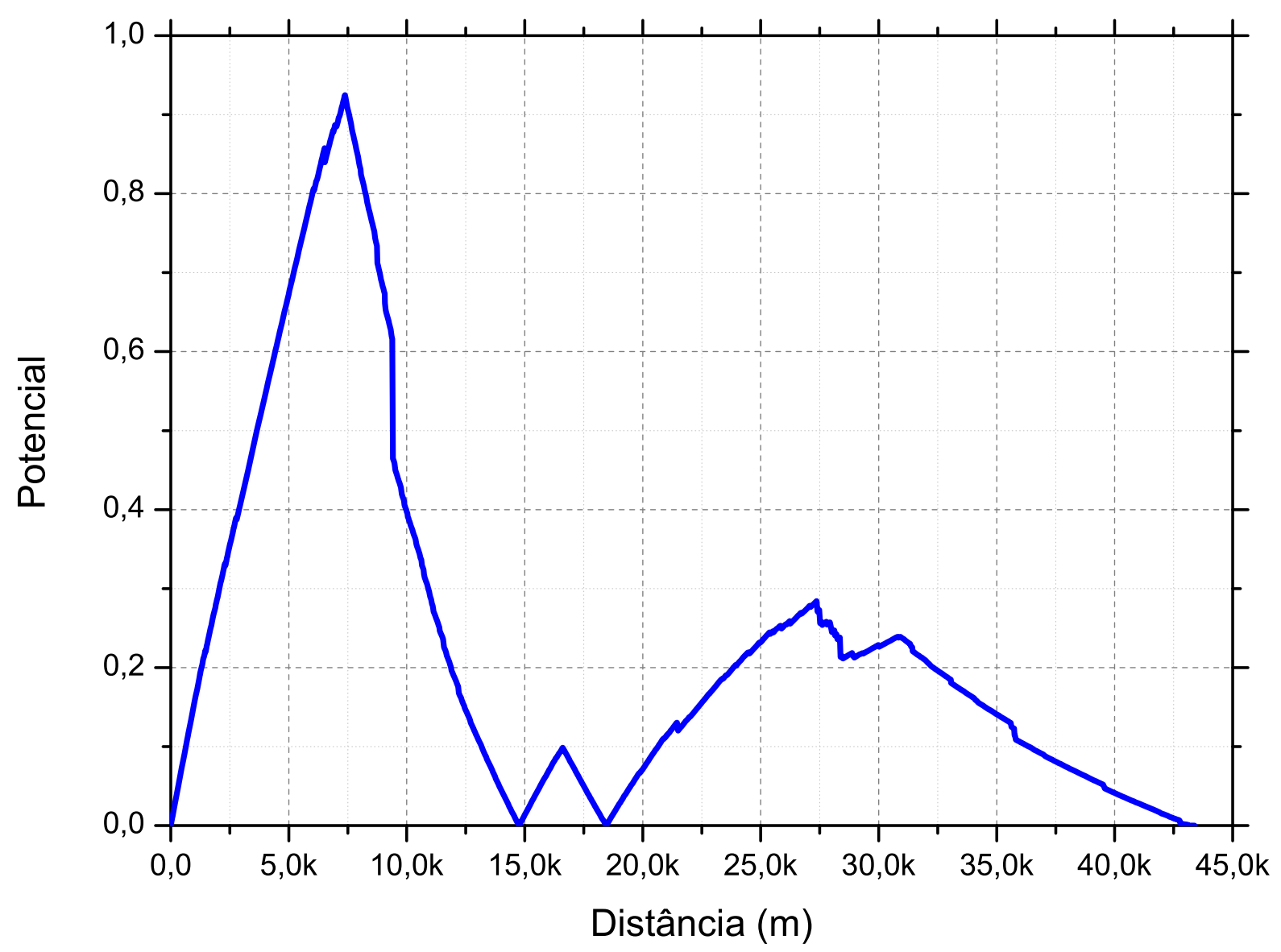

FIGURA 5.6 - Potencial para instalação de dispositivos indicadores de faltas ao longo do tronco principal do alimentador IGU04.

É possível observar que, devido a maior parte da carga desse alimentador se encontrar na área urbana, posicionadas no início e final do alimentador, os principais pontos para a referida instalação se encontram também em torno das regiões caracterizadas como urbana do alimentador IGU04.

Considerando todas as variáveis analisadas, carga, clientes, distância entre os dispositivos e corrente de curto-circuito mínima, os principais potenciais pontos de instalação estão a uma distância aproximada entre 7,5 e 27,5 km da subestação. (Figura 5.6). 


\subsection{Resultados Para Alimentador TTD18}

O segundo estudo de caso será realizado sobre o Alimentador TTD18, o qual está situado na cidade de Tatuí (Subestação Tatuí 02). O alimentador é derivado de um transformador de 15/18,75 MVA, com tensão 138/13,8 kV, esquema de ligação $\mathrm{D} / \mathrm{Y}$ aterrado.

Este alimentador é caracterizado tipicamente por atender 4400 clientes, dos quais $75 \%$ caracterizados como residenciais. Atende a localidade de Tatuí, tanto em sua área urbana quanto rural, com uma extensão de aproximadamente 30,8 km no tronco principal. Do total de 27,5 MVA de carga suprida por esse alimentador, 4,9 MVA é atendida na área urbana e 22,6 MVA na área rural. A Figura 5.7 apresenta a representação gráfica da disposição geográfica deste alimentador. 


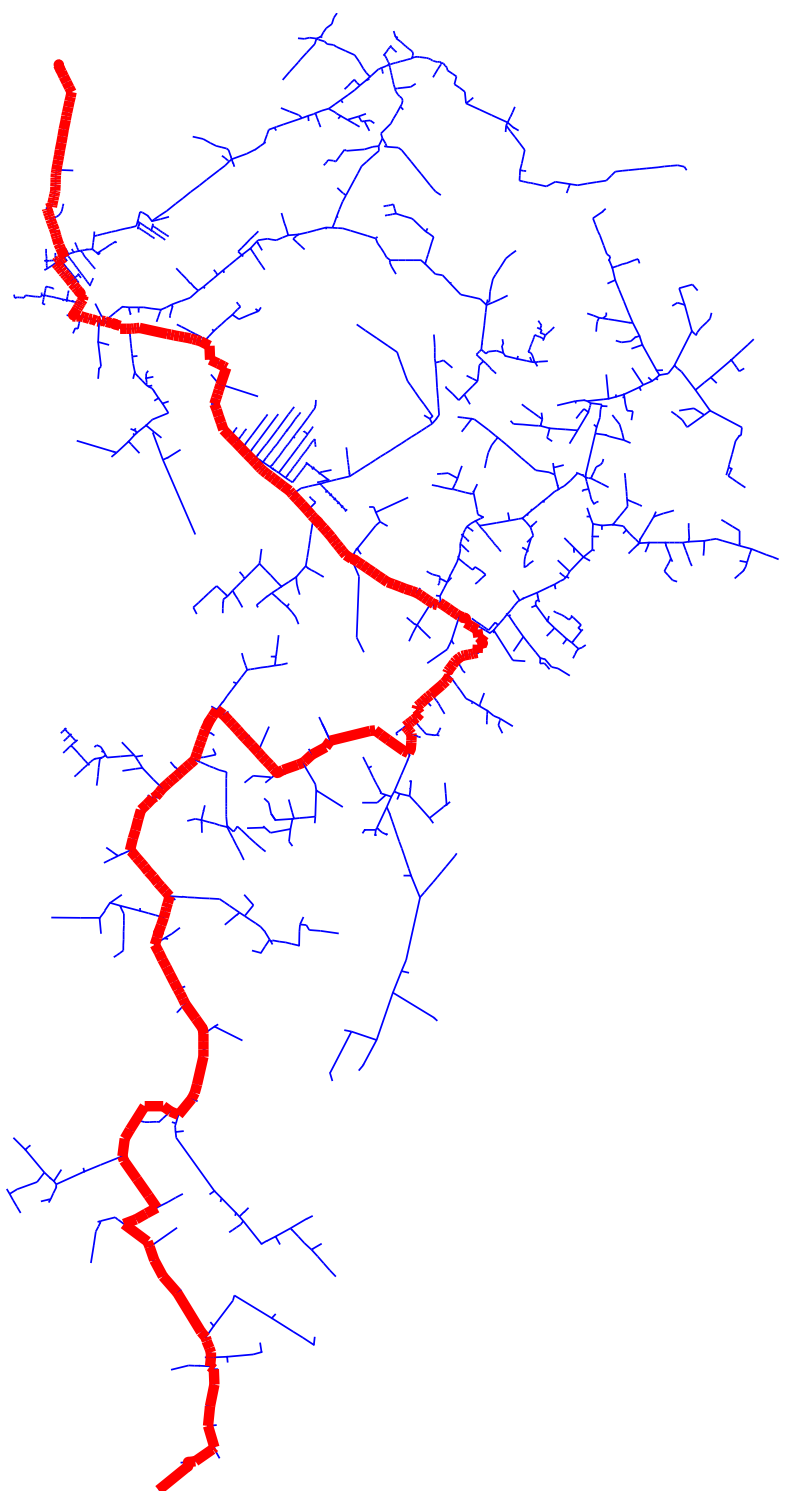

FIGURA 5.7 - Alimentador TTD18 com destaque para o tronco principal.

Assim, por meio da Figura 5.8, apresenta-se como a carga e o número de clientes se comportam ao longo da extensão do tronco principal do alimentador TTD18. 


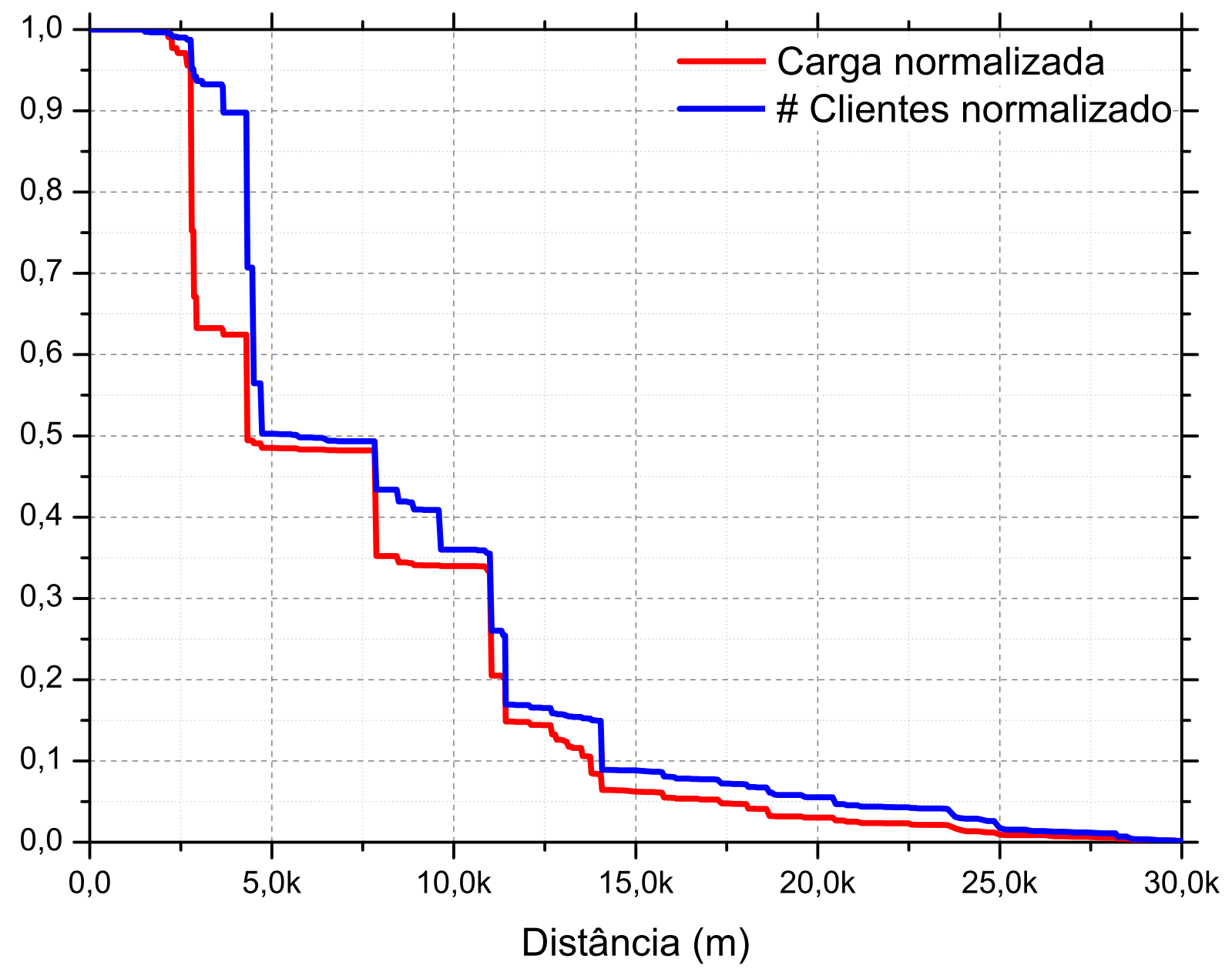

FIGURA 5.8 - Comportamento da carga e do número de clientes ao longo do tronco principal do alimentador TTD18.

Por meio dos gráficos da Figura 5.8 é possível verificar que o alimentador apresenta uma sensível mudança da carga e do número de clientes à jusante do ponto, com distância de $3 \mathrm{~km}$ contados da subestação, e vai decaindo até $15 \mathrm{~km}$, quando essa queda torna-se menos acentuada. Em termos reais, tem-se que esse alimentador possui seus primeiros $5 \mathrm{~km}$, aproximadamente, destinados à alimentação de cargas urbanas e o restante (mais de $25 \mathrm{~km}$ ) destinado à alimentação de cargas rurais.

Pode-se observar a mesma variação para a corrente de curto-circuito mínima ao longo do tronco principal. Essa observação se justifica em função da uniformidade dos cabos empregados para constituição do tronco principal de 
alimentadores de distribuição. A Figura 5.9 ilustra o comportamento da corrente de curto-circuito mínima ao longo do tronco principal do alimentador TTD18.

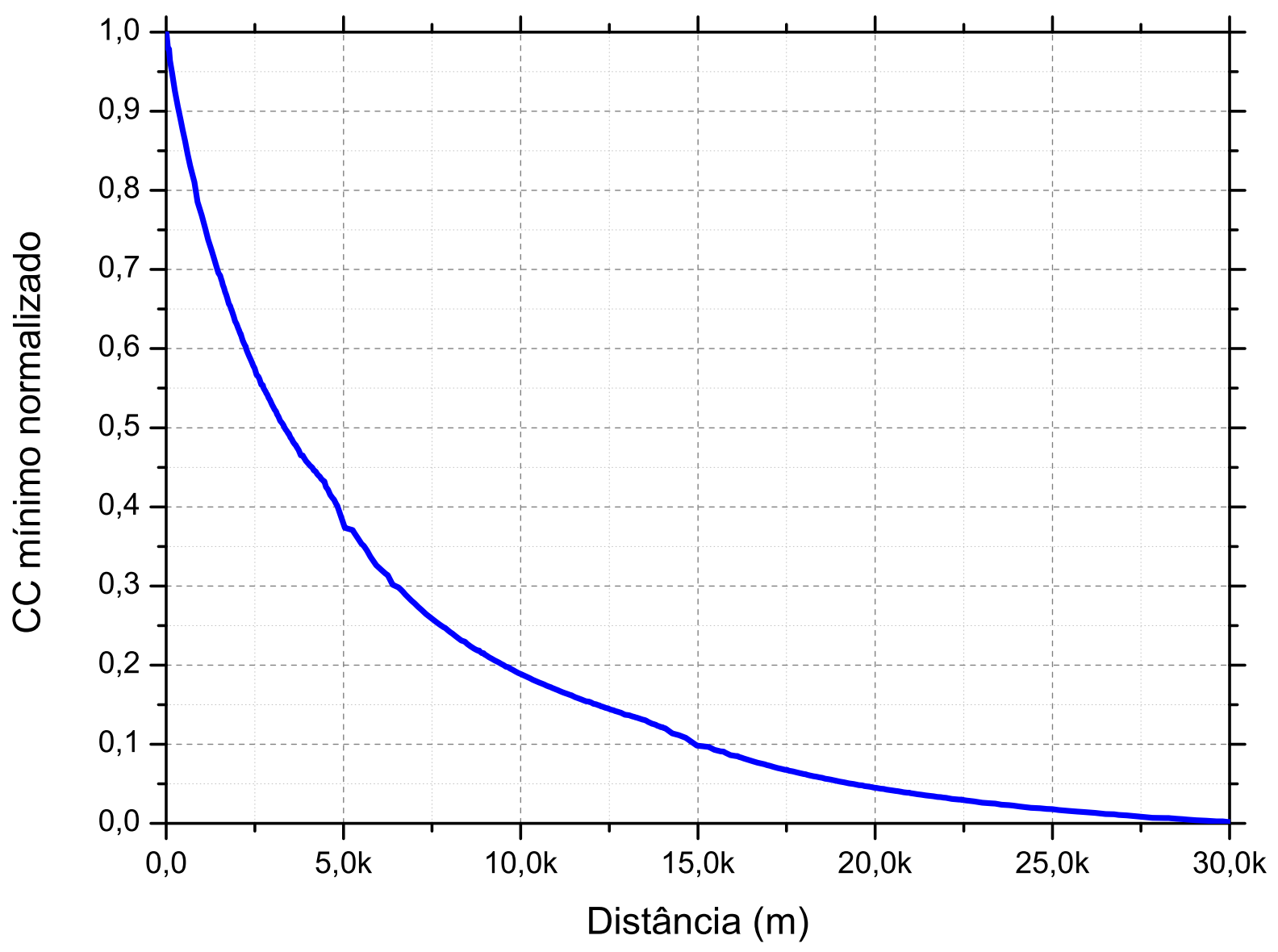

FIGURA 5.9 - Comportamento da corrente de curto-circuito mínima ao longo do tronco principal do alimentador TTD18.

A Figura 5.10 ilustra como a distância até os dispositivos adjacentes mais próximos tem se comportado ao longo do tronco principal do alimentador TTD18. 


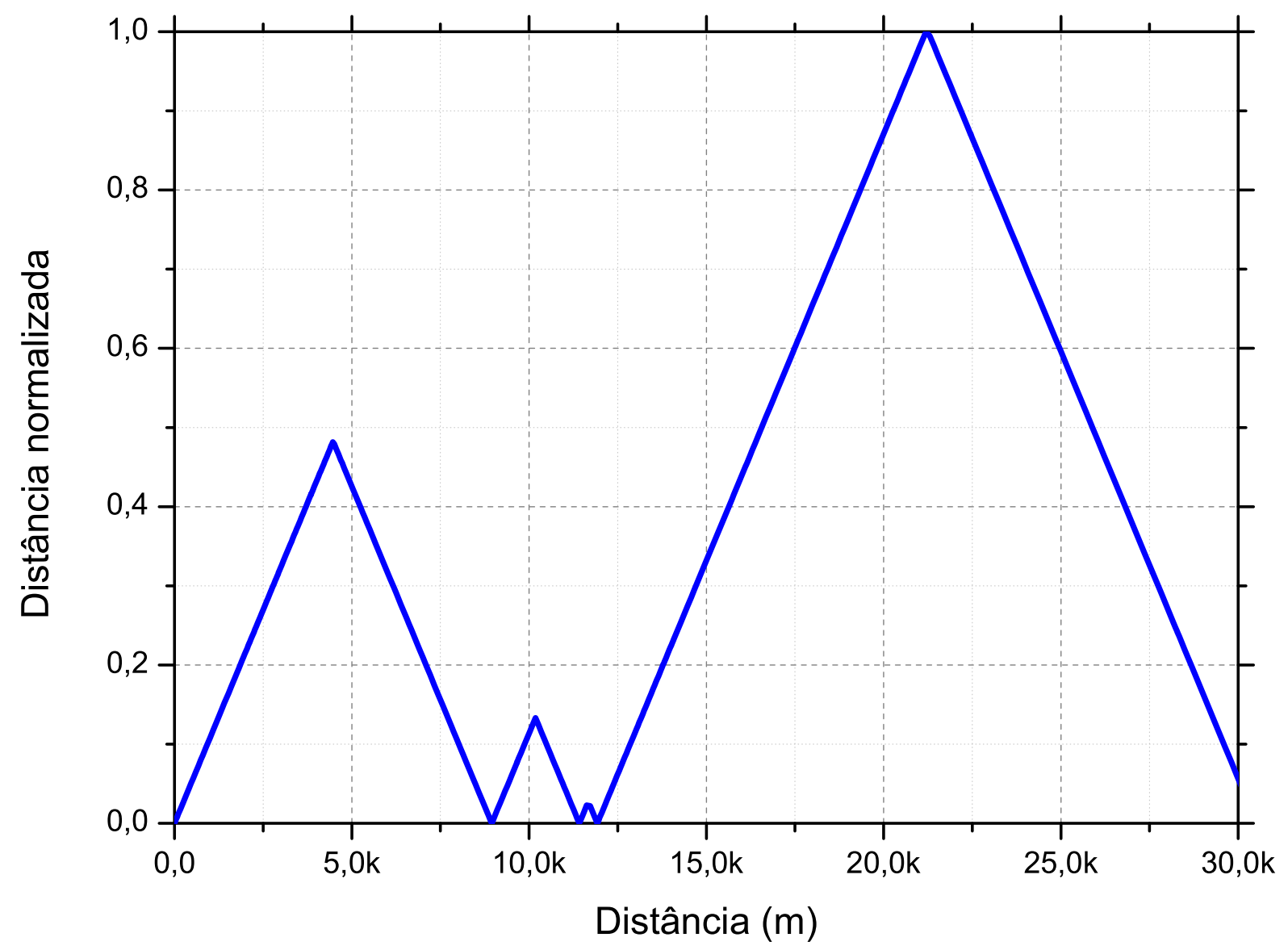

FIGURA 5.10 - Distância normalizada até os dispositivos indicadores de faltas ao longo do tronco principal do alimentador TTD18.

Por meio da Figura 5.10 verifica-se que, aproximadamente, nos pontos distantes em torno de 5 e 22 km do tronco principal do alimentador TTD18 em relação a SE, a distância entre dispositivos IFs e as proteções tripolares apresentam seus maiores valores.

Assim, a partir da aplicação do sistema de inferência fuzzy apresentado na Seção 4.3, ilustra-se por meio da Figura 5.11 como o potencial para instalação de dispositivos IFs se comporta ao longo do tronco principal do alimentador TTD18. 


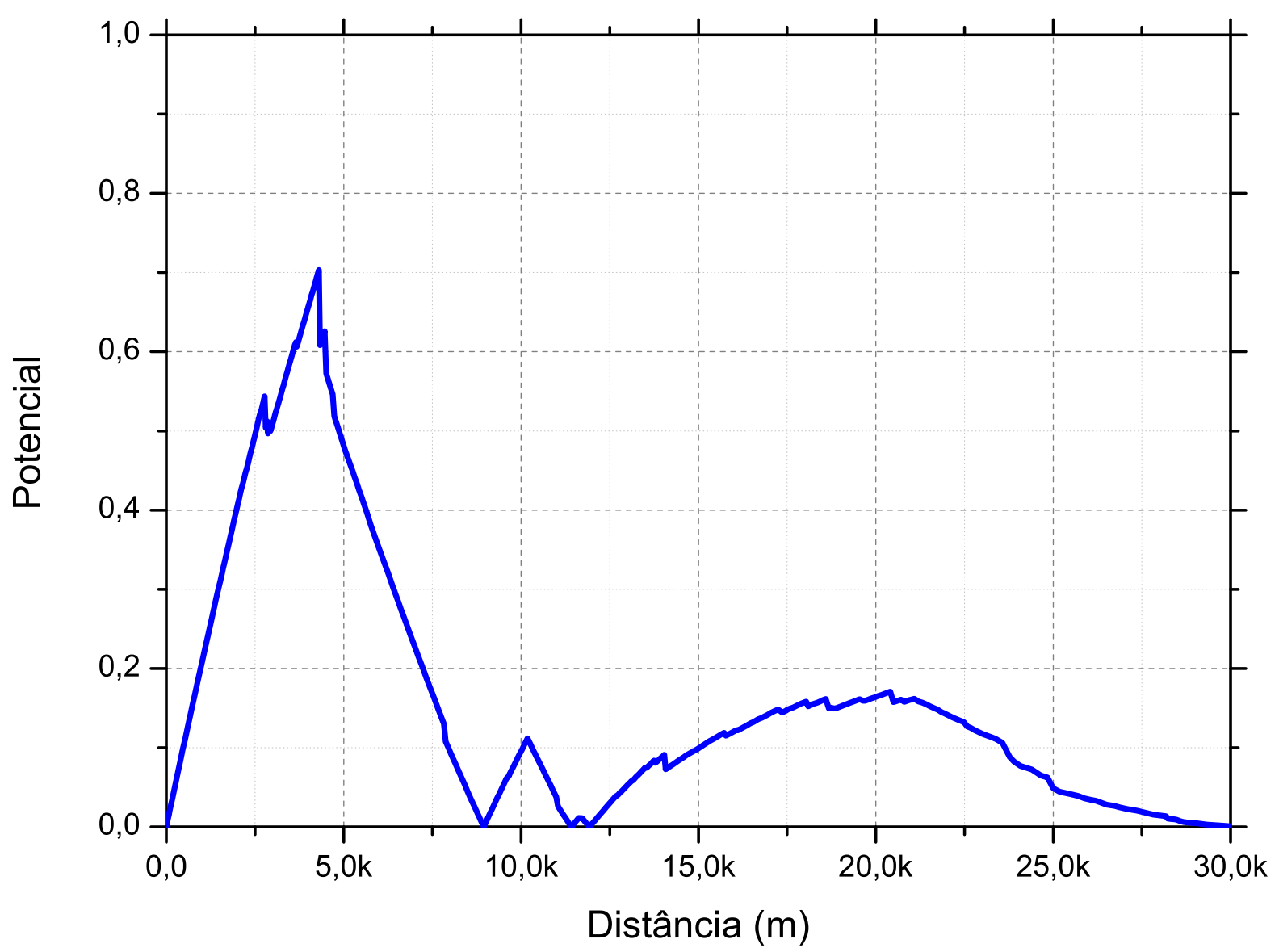

FIGURA 5.11 - Potencial para instalação de dispositivos indicadores de faltas ao longo do tronco principal do alimentador TTD18.

É possível observar que, devido a maior parte dos clientes desse alimentador também se encontrar na área urbana, os principais pontos para a referida instalação se encontram também na região urbana do alimentador TTD18. Considerando todas as variáveis analisadas, carga, clientes, distância entre os dispositivos e corrente de curto-circuito mínima, os principais potenciais pontos de instalação estão a uma distância aproximada entre 4,5 e 20 km da subestação.

\subsection{Resultados Para Alimentador RCA42}

O terceiro estudo de caso será realizado sobre o Alimentador RCA42, que é suprido pela Subestação Rio Claro 02, mas que atende cargas da localidade de 
Itirapina. O alimentador é derivado do Transformador 3 da referida SE, com potência de 30/40 MVA, tensão 138/34,5 kV e esquema de ligação $Y$ aterrado $/ Y$ aterrado.

Este alimentador é caracterizado tipicamente por atender 5700 clientes, dos quais $86 \%$ caracterizados como residenciais. Atende a localidade de Itirapina, tanto em sua área urbana quanto rural. Atende ainda uma carga urbana de 10,3 MVA e de 18,4 MVA na área rural, com uma extensão de aproximadamente 49,5 km no tronco principal. Este alimentador possui como característica um fluxo de potência gerado pela Usina do Lobo, o que dificulta a sinalização correta do IF, pois a geração da usina pode contribuir para a corrente de curto-circuito, fazendo-se com que 0 indicador não sinalize a falta. A Figura 5.12 apresenta a representação gráfica da

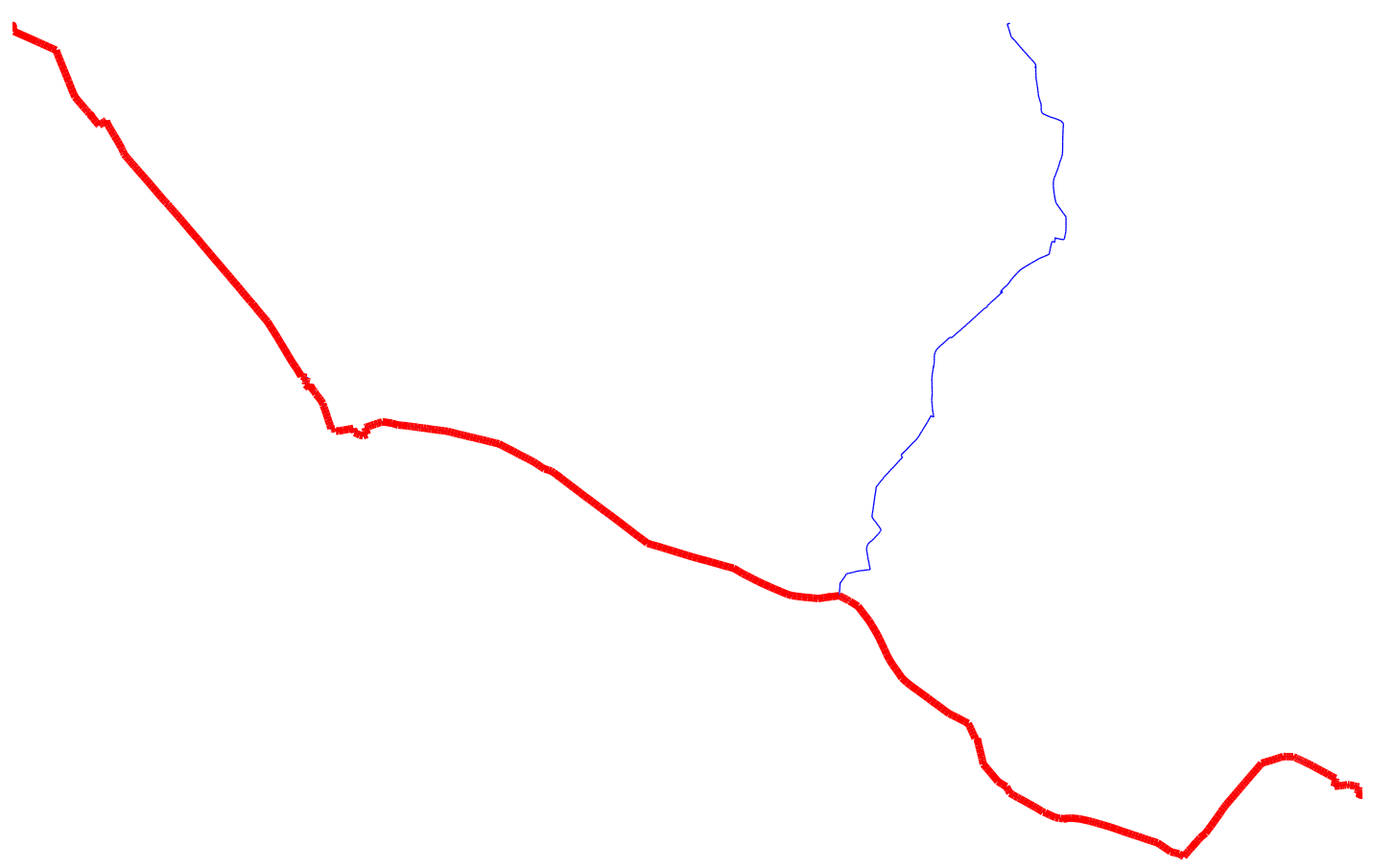

FIGURA 5.12 - Alimentador RCA42 com destaque para o tronco principal. 
Assim, por meio da Figura 5.13, apresenta-se como a carga e o número de clientes se comportam ao longo da extensão do tronco principal do alimentador RCA42.

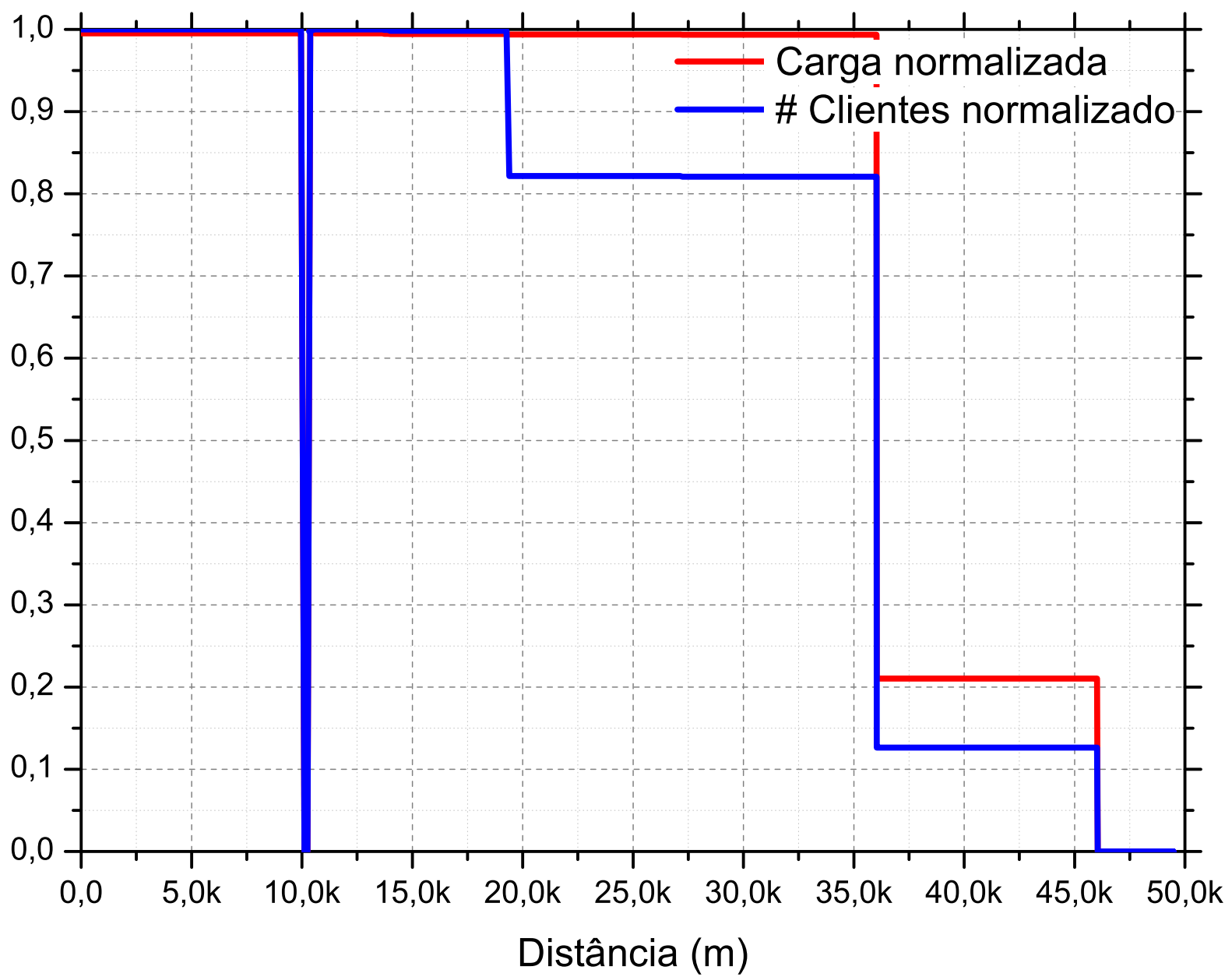

FIGURA 5.13 - Comportamento da carga e do número de clientes ao longo do tronco principal do alimentador RCA42.

Por meio dos gráficos da Figura 5.13, é possível verificar que o alimentador apresenta uma sensível mudança da carga e do número de clientes à jusante do ponto com distância de $20 \mathrm{~km}$ contados da subestação, e vai decaindo até $45 \mathrm{~km}$ quando essa caída torna-se menos acentuada. Em termos reais, tem-se que esse alimentador possui seus primeiros $25 \mathrm{~km}$, aproximadamente, destinados à alimentação de cargas urbanas e o restante (mais de $20 \mathrm{~km}$ ) destinado à 
alimentação de cargas rurais. A descontinuidade ocorrida no ponto com distância de aproximadamente $10 \mathrm{~km}$ tem como causa falha de cadastro de ativos na base de dados.

Pode-se observar a mesma variação para a corrente de curto-circuito mínima ao longo do tronco principal. Essa observação se justifica em função da uniformidade dos cabos empregados para constituição do tronco principal de alimentadores de distribuição. A Figura 5.14 ilustra o comportamento da corrente de curto-circuito mínima ao longo do tronco principal do alimentador RCA42.

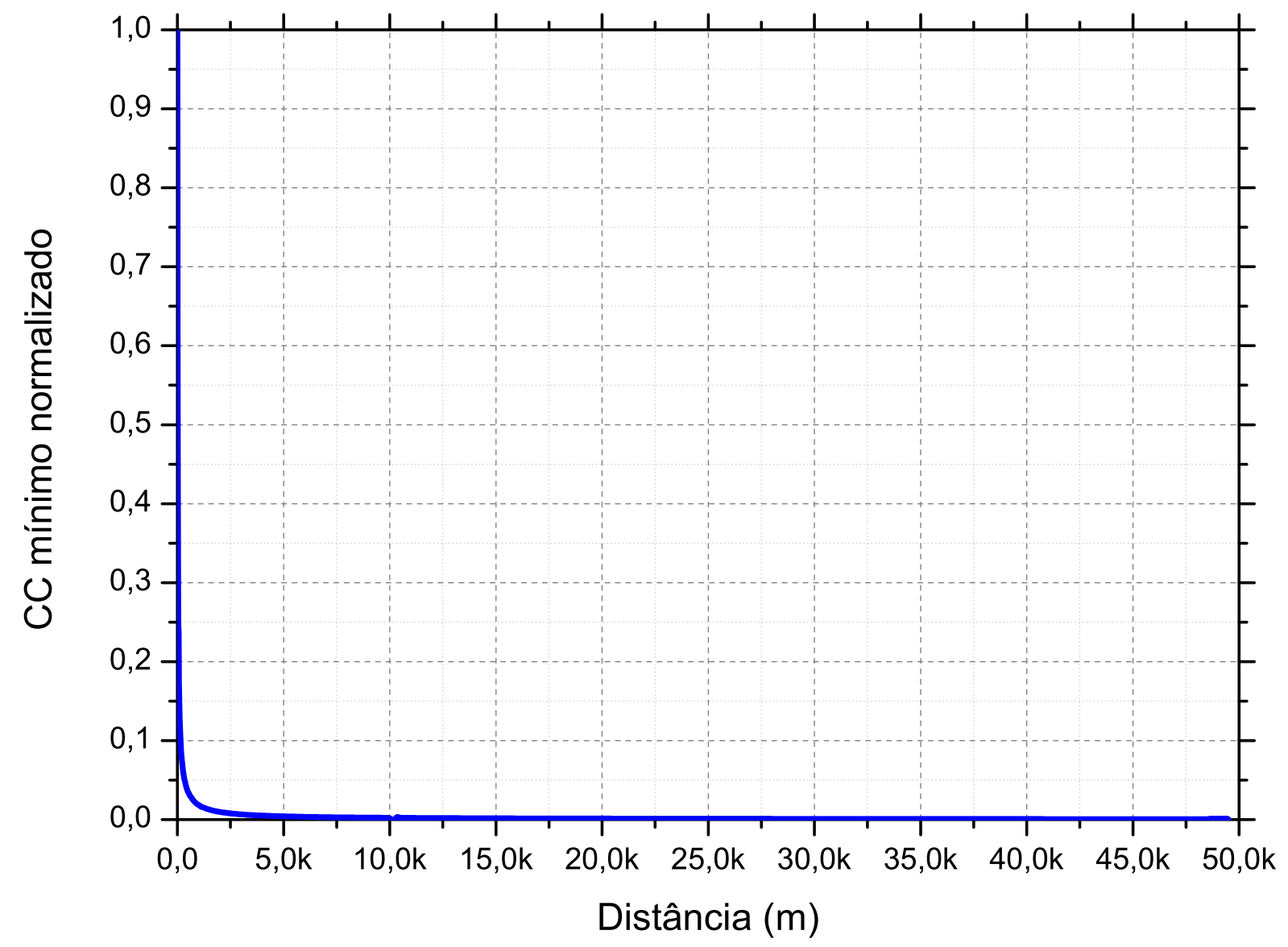

FIGURA 5.14 - Comportamento da corrente de curto-circuito mínima ao longo do tronco principal do alimentador RCA42.

A Figura 5.15 lustra como a distância até os dispositivos adjacentes mais próximos tem se procedido ao longo do tronco principal do alimentador RCA42. 


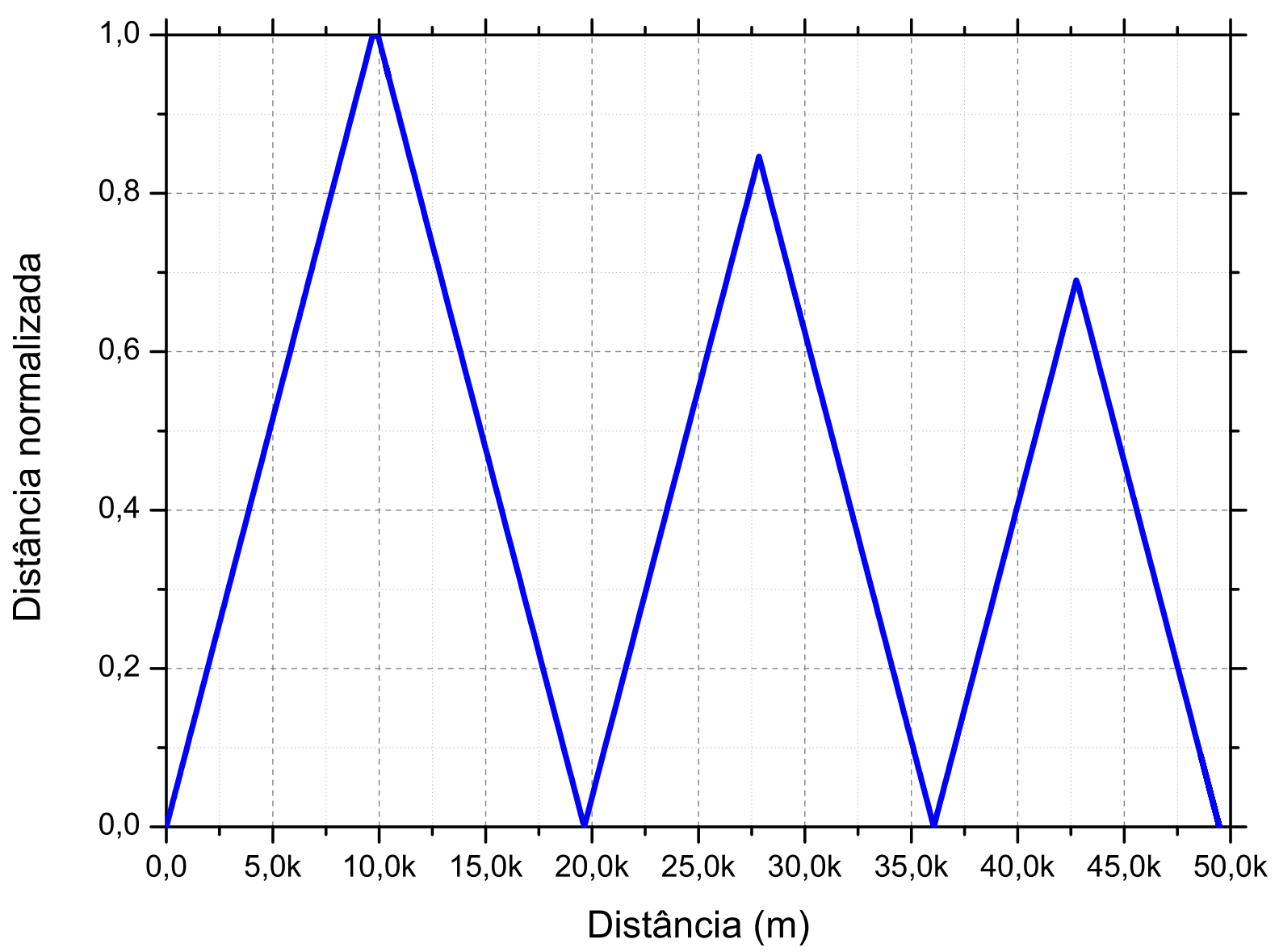

FIGURA 5.15 - Distância normalizada até os dispositivos indicadores de faltas ao longo do tronco principal do alimentador RCA42.

Por meio da Figura 5.15 verifica-se que, aproximadamente, nos pontos distantes em torno de 10, 28 e $43 \mathrm{~km}$ do tronco principal do alimentador RCA42 em relação a SE, a distância entre dispositivos IFs apresentam seus maiores valores.

Assim, a partir da aplicação do sistema de inferência fuzzy apresentado na Seção 4.3, ilustra-se por meio da Figura 5.16 como o potencial para instalação de dispositivos IFs se comporta ao longo do tronco principal do alimentador RCA42. 


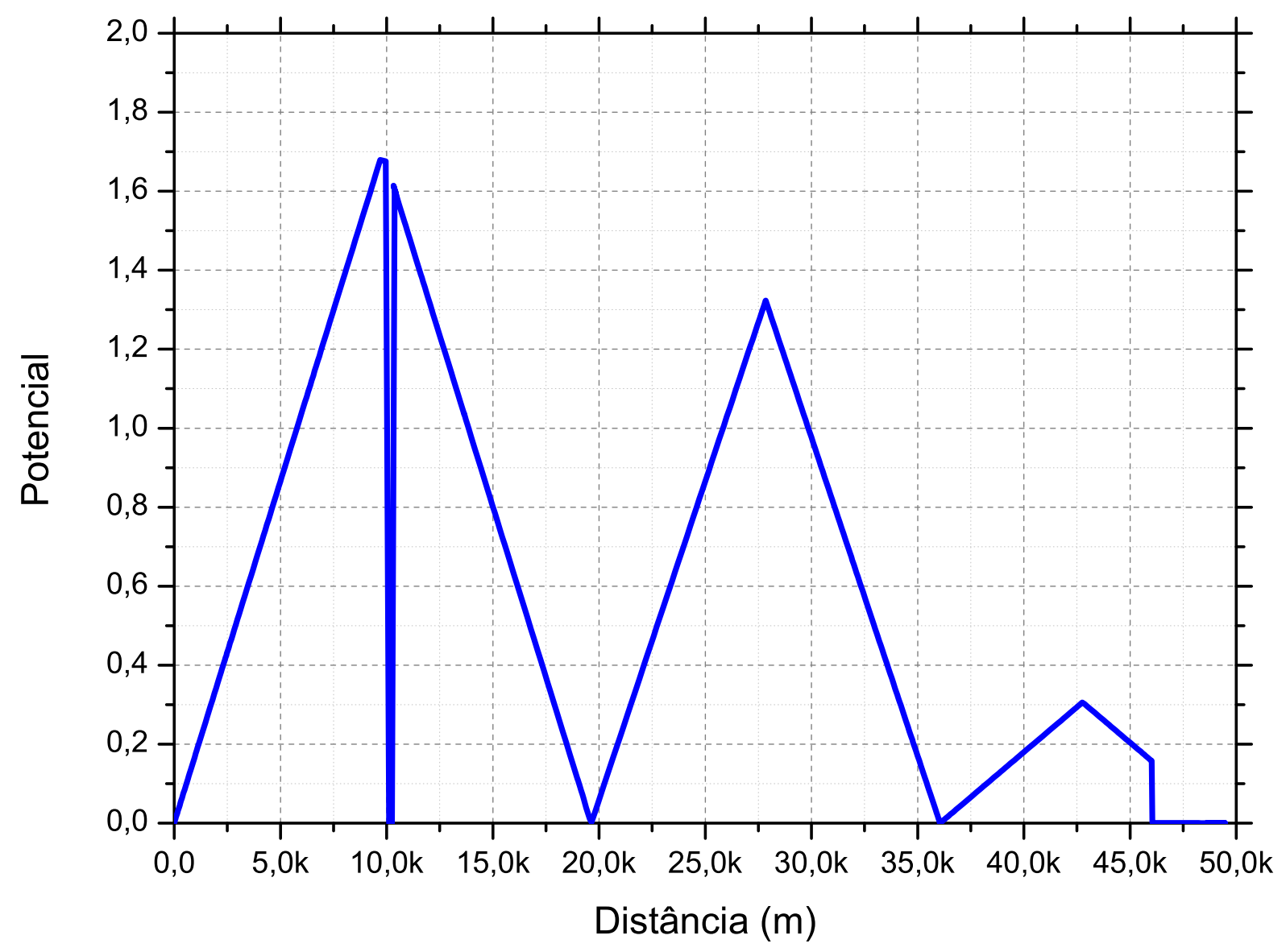

FIGURA 5.16 - Potencial para instalação de dispositivos indicadores de faltas ao longo do tronco principal do alimentador RCA42.

É possível observar que, devido a carga se concentrar na área urbana próxima à SE e alimentar a localidade de Itirapina, distante aproximadamente $28 \mathrm{~km}$ da SE, os principais pontos para a referida instalação se encontram também nessas regiões do alimentador RCA42. Em função do maior espaçamento entre dispositivos IFs se encontrar na região distante 10 e $27,5 \mathrm{~km}$ da SE (Figura 5.15), tem-se que esses seriam inicialmente os principais pontos para instalação. Entretanto, devido a presença de geração no alimentador, o restabelecimento da energia ocorre antes do tempo de sensibilização do IF para faltas permanentes, fazendo-se com que ocorra o reset do IF. Para este caso, é recomendada a utilização do indicador bidirecional. A descontinuidade ocorrida no ponto com distância de aproximadamente $10 \mathrm{~km}$ tem como causa falha de cadastro de ativos na base de dados. 


\subsection{Resultados Para Alimentador IGU05}

O quarto estudo de caso será realizado sobre o Alimentador IGU05, o qual está situado na cidade de Iguape, Subestação Iguape 01 . O alimentador é derivado do Transformador 1 da referida SE, com potência de 10/12,5 MVA, com tensão de transformação de 69/13,8 kV, esquema de ligação $D / Y$ aterrado

Este alimentador é caracterizado tipicamente por atender cargas residenciais com $90 \%$ do total de 5.850 clientes. Do total de 17,4 MVA de carga suprida por esse alimentador, 6,8 MVA é atendida na área urbana e 10,6 MVA na área rural. O alimentador possui uma extensão de aproximadamente $63 \mathrm{~km}$ no tronco principal. A Figura 5.17 apresenta a representação gráfica da disposição geográfica deste alimentador. 


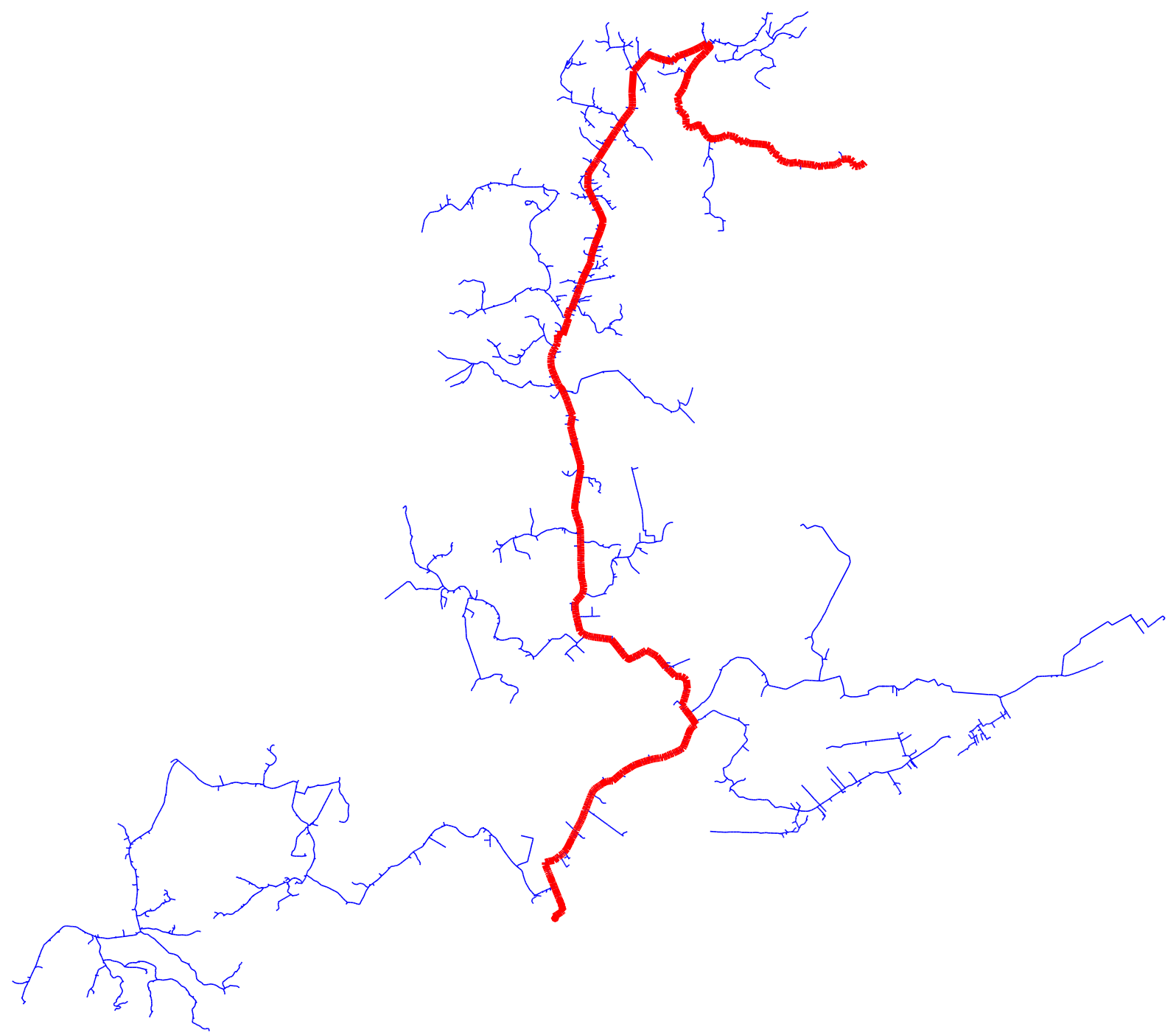

FIGURA 5.17 - Alimentador IGU05 com destaque para o tronco principal.

Assim, por meio da Figura 5.18, apresenta-se como a carga e o número de clientes se comportam ao longo da extensão do tronco principal do alimentador IGU05. 


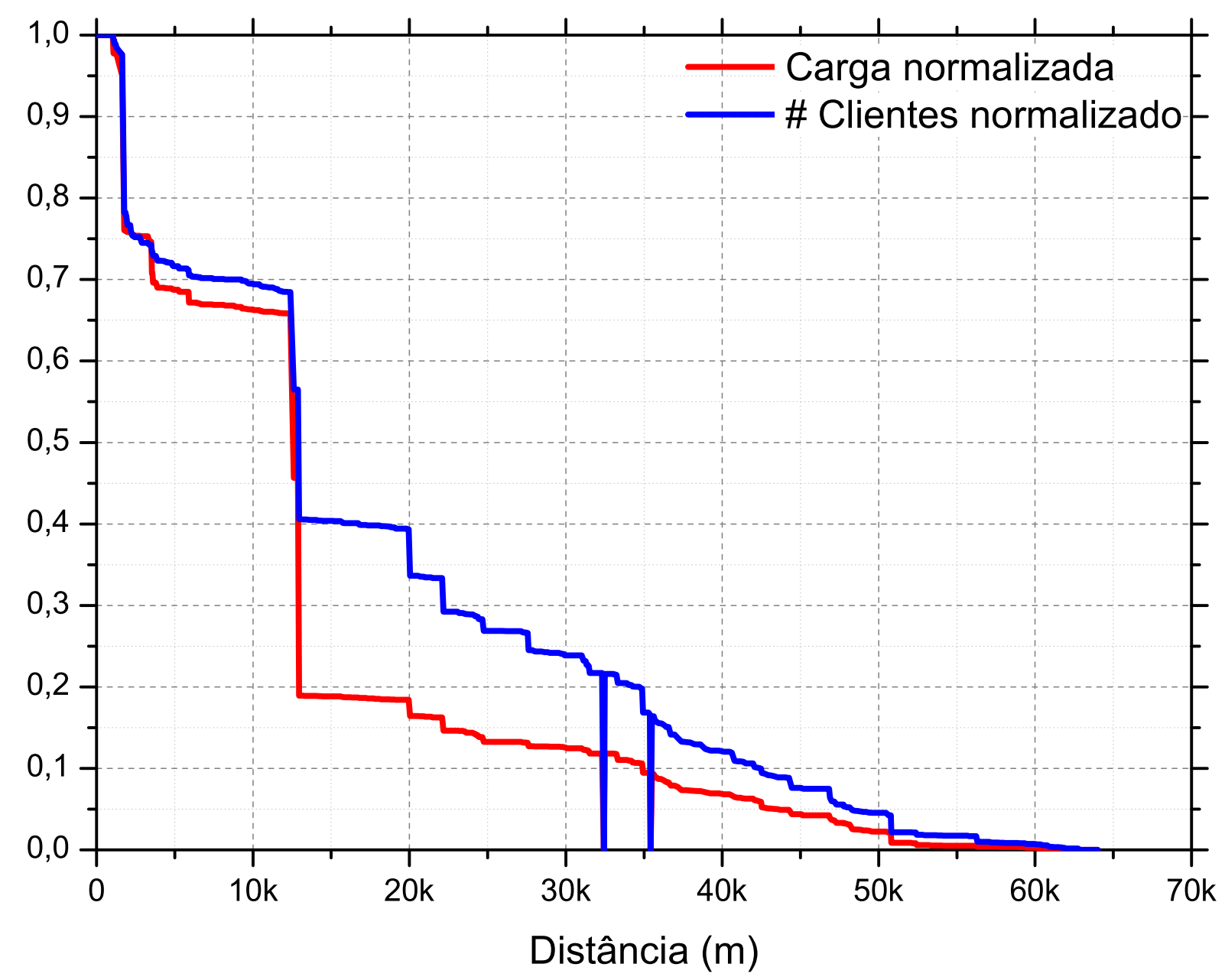

FIGURA 5.18 - Comportamento da carga e do número de clientes ao longo do tronco principal do alimentador IGU05.

Por meio dos gráficos da Figura 5.18, é possível verificar que o alimentador apresenta uma sensível mudança da carga e do número de clientes logo na saída da SE, à jusante do ponto com distância de $2 \mathrm{~km}$ contados da subestação. Em termos reais, tem-se que esse alimentador possui seus primeiros $20 \mathrm{~km}$, aproximadamente, destinados à alimentação de cargas urbanas e o restante (mais de 40 km) destinado à alimentação de cargas rurais. A descontinuidade ocorrida nos pontos com distância de aproximadamente 32 e $36 \mathrm{~km}$ tem como causa falha de cadastro de ativos na base de dados.

Pode-se observar a mesma variação para a corrente de curto-circuito mínima ao longo do tronco principal. Essa observação se justifica em função da 
uniformidade dos cabos empregados para constituição do tronco principal de alimentadores de distribuição. A Figura 5.19 ilustra o comportamento da corrente de curto-circuito mínima ao longo do tronco principal do alimentador IGU05.

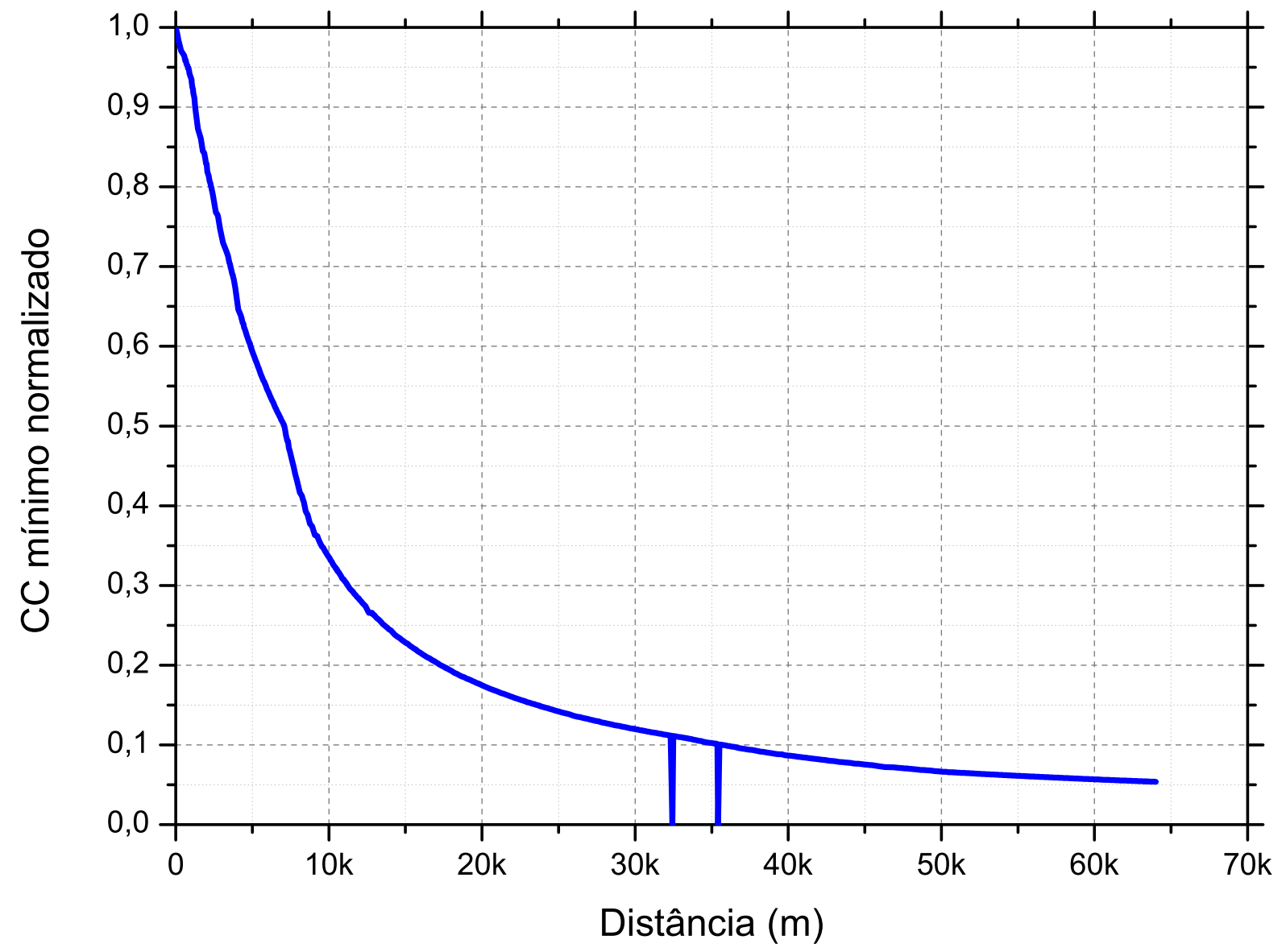

FIGURA 5.19 - Comportamento da corrente de curto-circuito mínima ao longo do tronco principal do alimentador IGU05.

A Figura 5.20 ilustra como a distância até os dispositivos adjacentes mais próximos tem se comportado ao longo do tronco principal do alimentador IGU05. A descontinuidade ocorrida nos pontos com distância de aproximadamente 32 e $36 \mathrm{~km}$ tem como causa falha de cadastro de ativos na base de dados. 


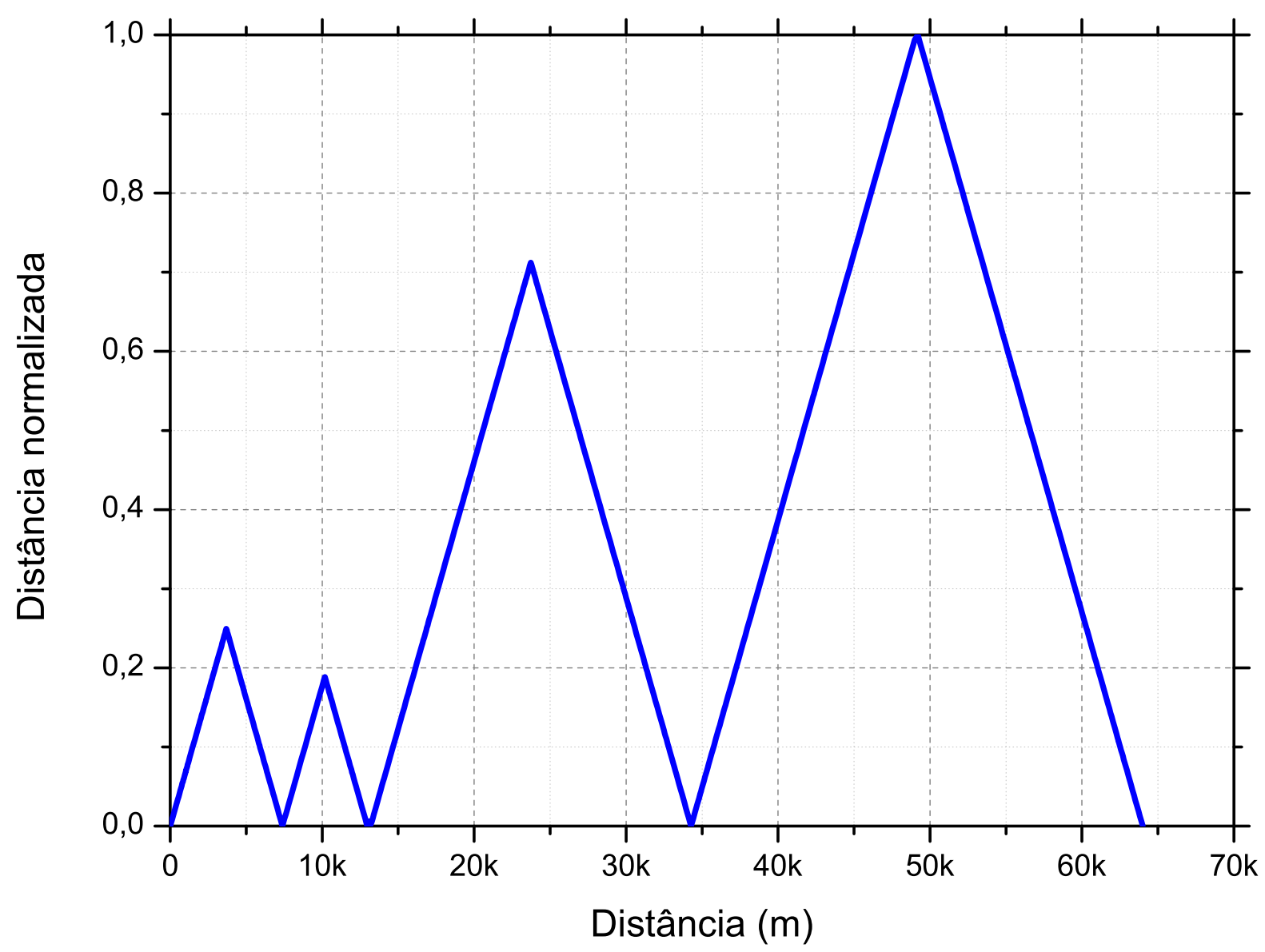

FIGURA 5.20 - Distância normalizada até os dispositivos indicadores de faltas ao longo do tronco principal do alimentador IGU05.

Por meio da Figura 5.20 verifica-se que, aproximadamente, nos pontos distantes em torno de 25 e $50 \mathrm{~km}$ do tronco principal do alimentador IGU05, a distância entre dispositivos IFs apresentam seus maiores valores.

Assim, a partir da aplicação do sistema de inferência fuzzy apresentado na Seção 4.3, ilustra-se por meio da Figura 5.21 como o potencial para instalação de dispositivos IFs se comporta ao longo do tronco principal do alimentador IGU05. 


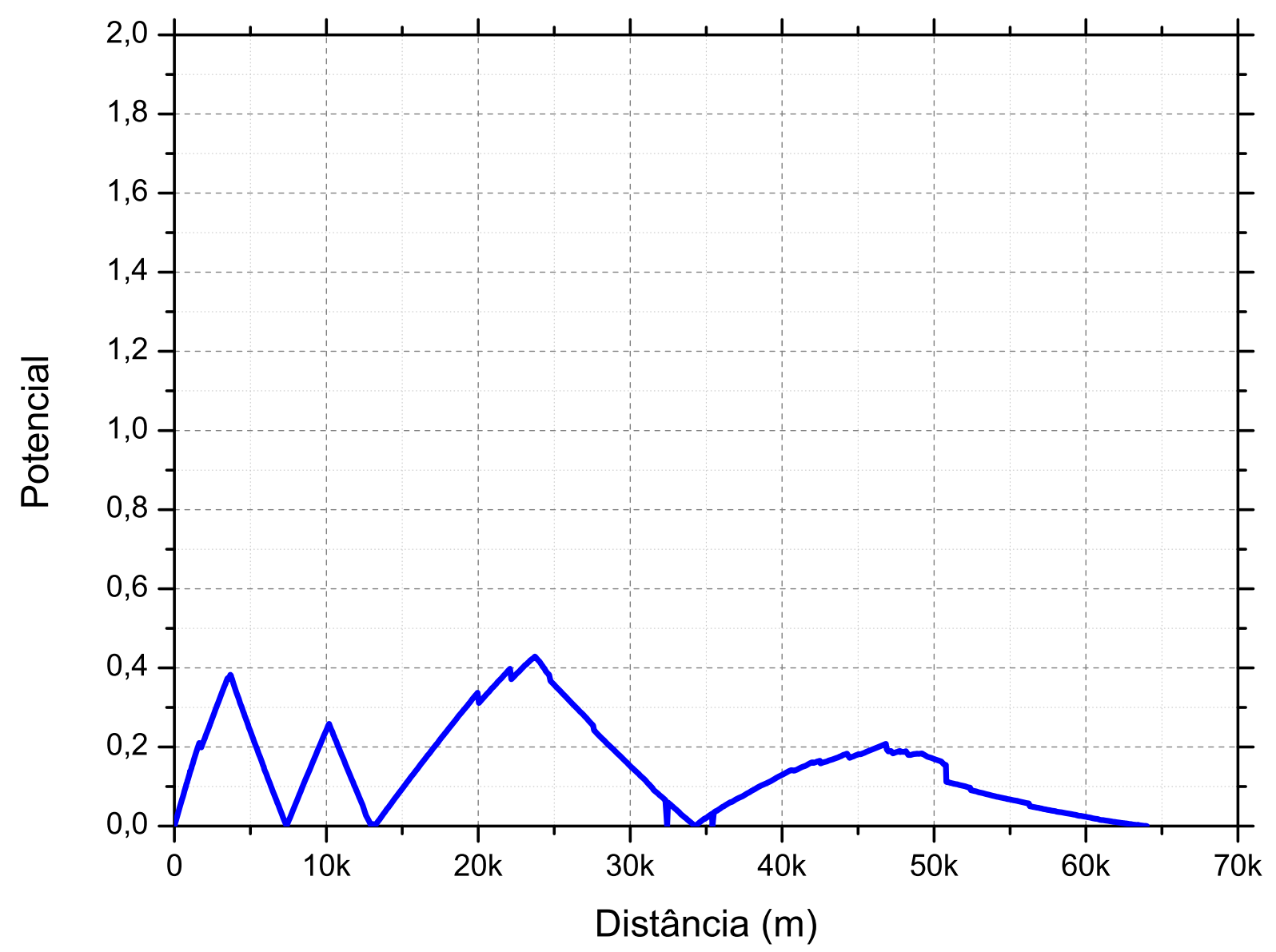

FIGURA 5.21 - Potencial para instalação de dispositivos indicadores de faltas ao longo do tronco principal do alimentador IGU05.

É possível observar que, devido à maior parte da carga desse alimentador se encontrar na área rural, os principais pontos para a referida instalação se encontram também na região rural do alimentador IGU05, a uma distância aproximada entre 24 e $47 \mathrm{~km}$ da subestação (Figura 5.21). Em função do maior espaçamento entre dispositivos IFs se encontrar nas áreas caracterizadas como rurais (Figura 5.20), tem-se que esses seriam inicialmente os principais pontos para instalação. Observamos também dois pontos na área urbana situados a 3 e $10 \mathrm{~km}$ respectivamente. Esses pontos apresentam grande potencial devido à presença de grande concentração de clientes. 


\subsection{Resultados Para Alimentador IGU03}

O quinto estudo de caso será realizado sobre o Alimentador IGU03, o qual está situado na cidade de Iguape, Subestação Iguape 01.0 alimentador é derivado do Transformador 2 da referida SE com potência de 10/12,5 MVA, com tensão de transformação de 69/13,8 kV, esquema de ligação D/Y aterrado

Este alimentador é caracterizado tipicamente por atender cargas residenciais, com $92 \%$ do total de 5.450 clientes. Do total de 7,5 MVA de carga suprida por esse alimentador, 5,4 MVA é atendida na área urbana e 2,1 MVA na área rural. O alimentador possui uma extensão de aproximadamente $37,5 \mathrm{~km}$ no

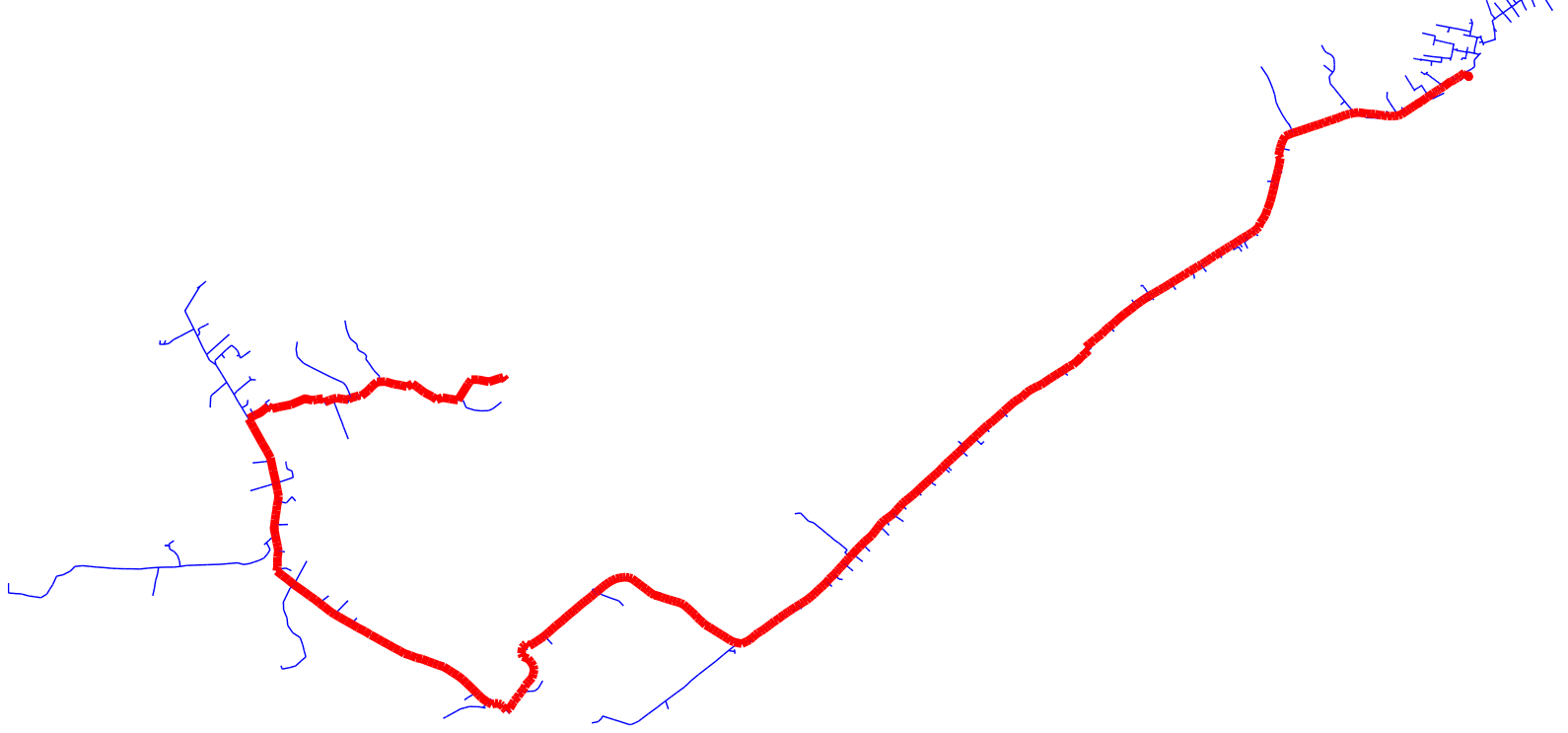

FIGURA 5.22 - Alimentador IGU03 com destaque para o tronco principal.

Assim, por meio da Figura 5.23, apresenta-se como a carga e o número de clientes se comportam ao longo da extensão do tronco principal do alimentador IGU03. 


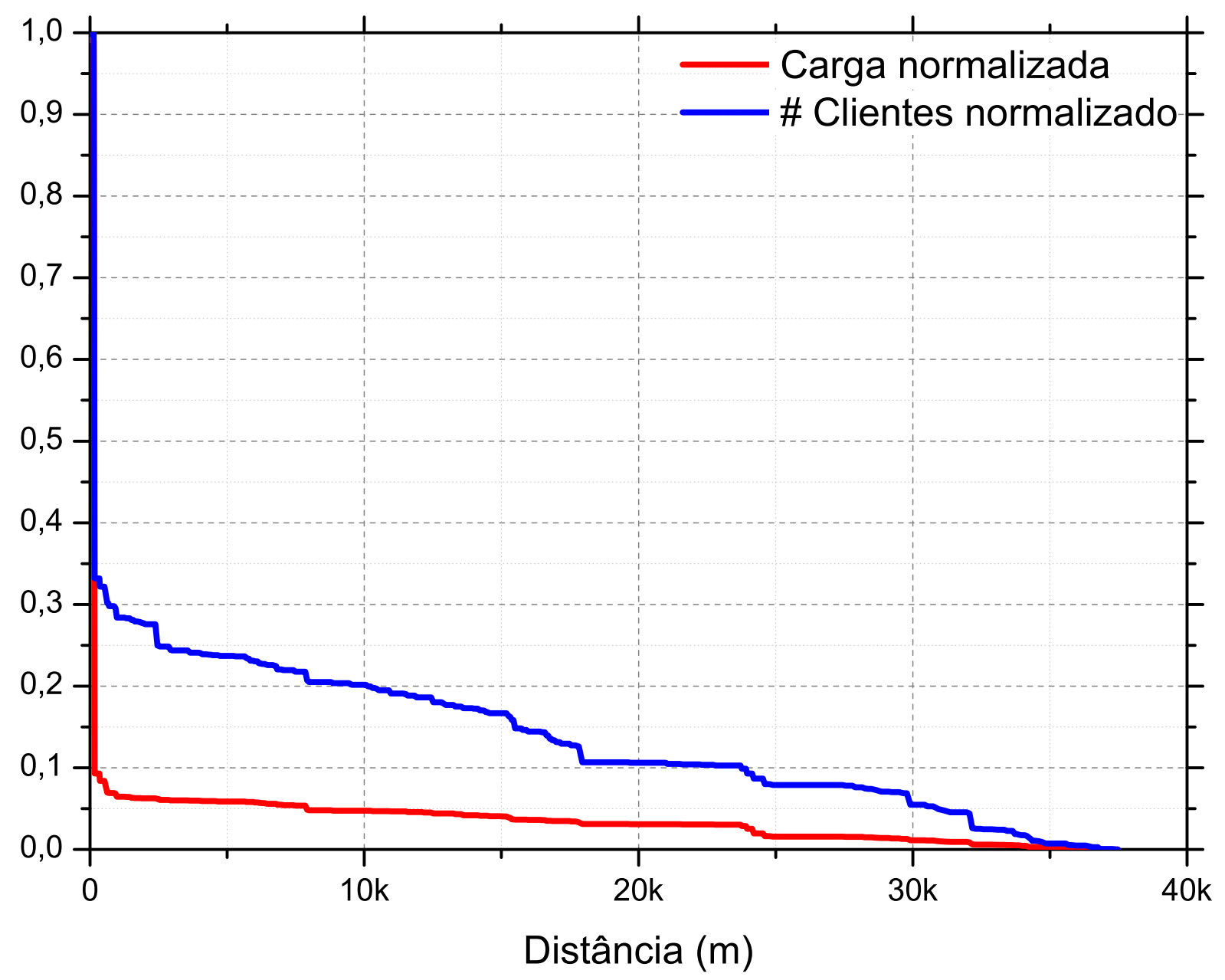

FIGURA 5.23 - Comportamento da carga e do número de clientes ao longo do tronco principal do alimentador IGU03.

Por meio dos gráficos da Figura 5.23 é possível verificar que o alimentador apresenta uma sensível mudança da carga e do número de clientes logo na saída da SE, à jusante do ponto com distância de $1 \mathrm{~km}$ contado da subestação. Em termos reais, tem-se que esse alimentador possui quase que a totalidade de sua extensão localizada na área urbana.

Pode-se observar a mesma variação para a corrente de curto-circuito mínima ao longo do tronco principal. Essa observação se justifica em função da uniformidade dos cabos empregados para constituição do tronco principal de 
alimentadores de distribuição. A Figura 5.24 ilustra o comportamento da corrente de curto-circuito mínima ao longo do tronco principal do alimentador IGU03.

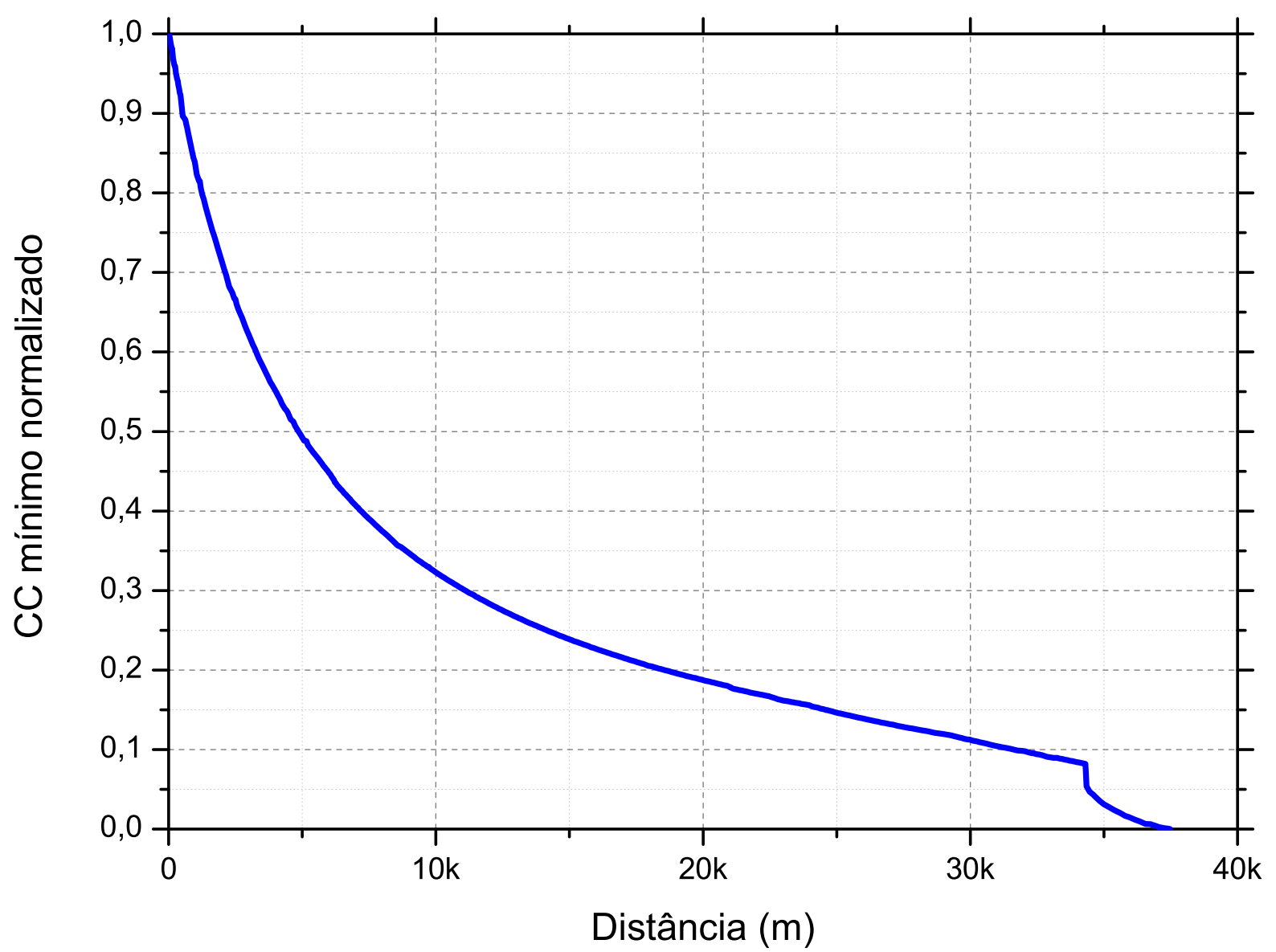

FIGURA 5.24 - Comportamento da corrente de curto-circuito mínima ao longo do tronco principal do alimentador IGU03.

A Figura 5.25 ilustra como a distância até os dispositivos adjacentes mais próximos tem se comportado ao longo do tronco principal do alimentador IGU03. 


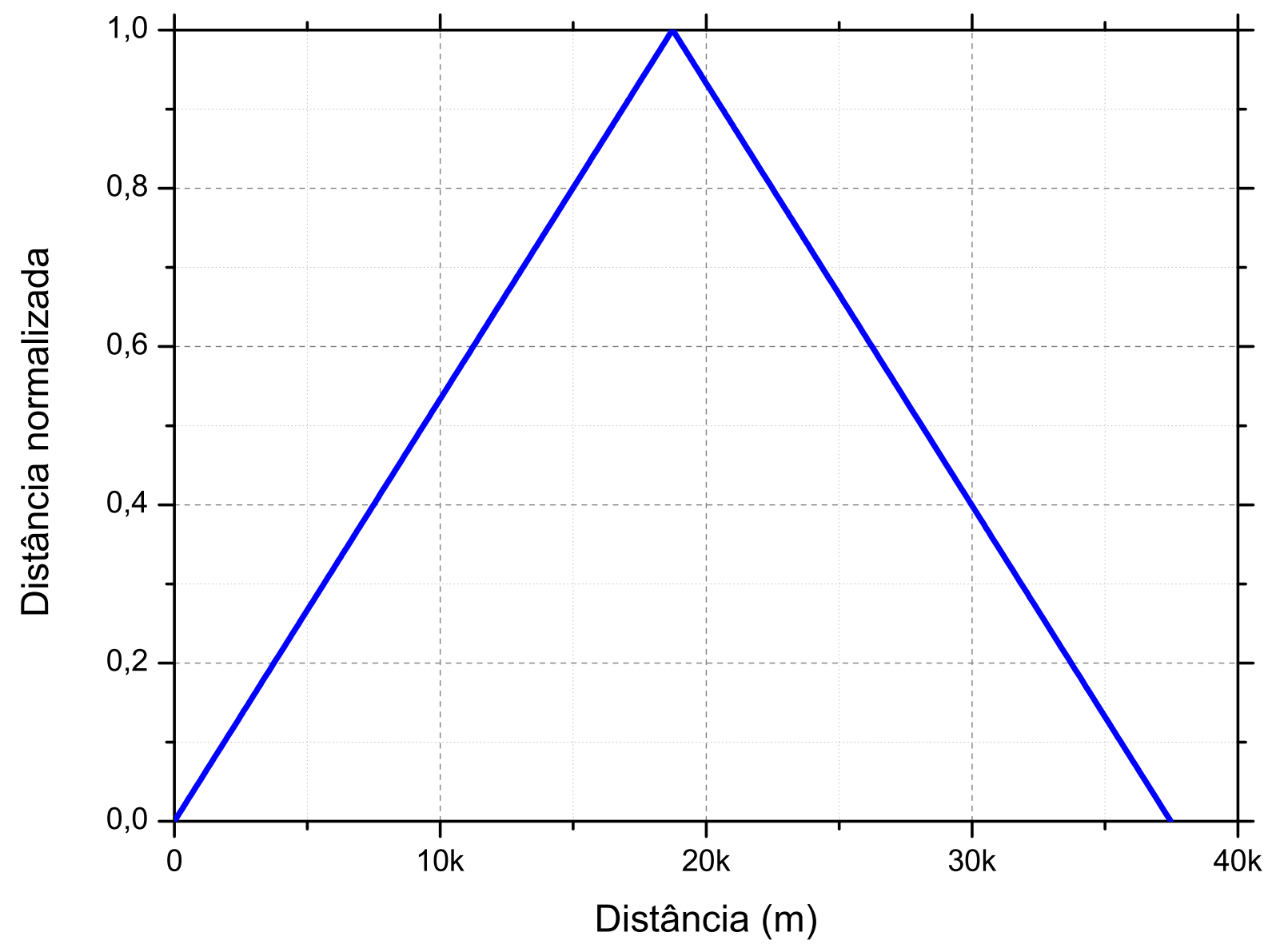

FIGURA 5.25 - Distância normalizada até os dispositivos indicadores de faltas ao longo do tronco principal do alimentador IGU03.

Por meio da Figura 5.25 verifica-se que, em um único ponto distante em torno de 18 km, a distância entre dispositivos IFs apresentam seu maior valor.

Assim, a partir da aplicação do sistema de inferência fuzzy apresentado na Seção 4.3, ilustra-se por meio da Figura 5.26 como o potencial para instalação de dispositivos IFs se comporta ao longo do tronco principal do alimentador IGU03. 


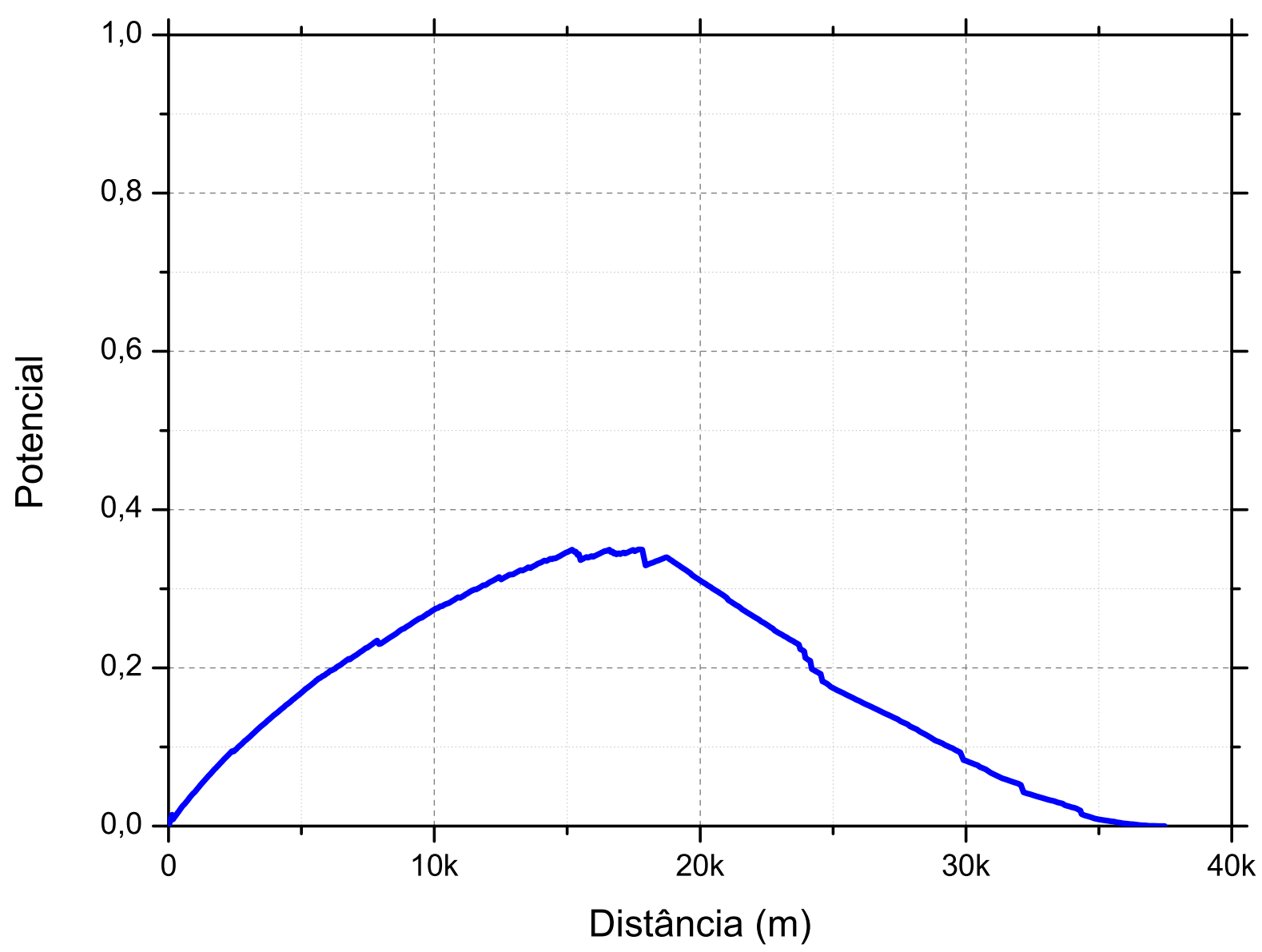

FIGURA 5.26 - Potencial para instalação de dispositivos indicadores de faltas ao longo do tronco principal do alimentador IGU03.

É possível observar que, devido a maior parte da carga desse alimentador se encontrar na área urbana, os principais pontos para a referida instalação se encontram também na região urbana do alimentador IGU03. Devido a essa característica, tem-se que o maior espaçamento entre dispositivos IFs se encontram nessa área (Figura 5.26), sendo considerado o principal ponto para instalação, com uma distância aproximada de $18 \mathrm{~km}$ da subestação. 



\section{Conclusões e Trabalhos Futuros}

Ao longo dessa dissertação foram apresentados como determinadas variáveis pertinentes à quantificação do potencial para instalação de dispositivos indicadores de faltas se comportam ao longo de trechos primários de sistemas de distribuição reais. Além disso, apresentou-se uma arquitetura de sistema inteligente baseada em inferência fuzzy para realizar essa quantificação a partir das variáveis abordadas. Além de se calcular o potencial para instalação de novos IF, os resultados destacados denotam também a potencialidade da ferramenta para avaliar a atual rede de dispositivos IFs já instalados.

A técnica desenvolvida foi também utilizada em campo visando à análise de 5 alimentadores pilotos. O processo de validação foi então elaborado, averiguandose em campo, se as posições sugeridas pela técnica proposta estão condizentes com os pontos instalados.

Como resultado, foi constatado que o sistema fuzzy de alocação dos dispositivos IFs posicionou os mesmos em pontos estratégicos, que facilitam em muito as atividades de restabelecimento do sistema. Algumas poucas alterações nos posicionamentos sugeridos pelo sistema fuzzy foram efetuadas devido à topografia do ponto de instalação e à facilidade de acesso para as equipes.

Destaca-se o caráter prático deste trabalho com aplicação imediata na análise dos pontos de IF existentes. Também, esses estudos serão considerados no planejamento de novos pontos de instalação de IF proporcionando uma maior efetividade na aplicação dos recursos financeiros da empresa.

Como continuidade ao trabalho desenvolvido, pode-se citar o desenvolvimento de outras ferramentas que indicassem, de forma automática, em 
que ponto específico (poste) do alimentador poderia ser inserido o IF a fim de otimizar os requisitos envolvidos com o restabelecimento do sistema. Para tanto, abordagens baseadas em algoritmos genéticos e/ou enxame de partículas (particle swarm) poderiam ser utilizadas para tais propósitos. 


\section{Referências Bibliográficas}

ANEEL - AGÊNCIA NACIONAL DE ENERGIA ELÉTRICA, Resolução no. 024 de 27 de janeiro de 2000 .

ANGERER, F., "OH and UG fault indication via radio networks", IEEE/PES Transmission and Distribution Conference and Exposition, vol. 2, pp. 991-992, 2001.

ARAVENA, J.L.; CHOWDHURY, F.N., "A new approach to fast fault detection in power systems", Proceedings of International Conference on Intelligent Systems Applications to Power Systems - ISAP'96, pp. 328-332, 1996.

BAKER, G.; STEINER, J. P.; ROCKWELL, D., "Performance of on-line fault distance monitor for distribution cable circuits", IEEE Transmission and Distribution Conf. and Exposition, vol. 2, pp. 979-981, 2001.

BALDWIN, T.; RENOVICH Jr, F.; SAUDERS, L.F., "Directional ground-fault indicator for high-resistance grounded systems", IEEE Transactions on Industry Applications, vol. 39, no. 2, pp. 325-332, 2003.

$\mathrm{CHO}, \mathrm{N}$.; HA, B., "The results of the field test in distribution automation system for the Korea Utility", Proceedings of Power System Technology - POWERCON, vol.1, pp. 48-52, 1998.

CHOI, T.; KOH, I.-S.; KIM, B.-H.;SONG, W.-S.;JANG, W.-S., "PC-based remote control and fault location system for distribution line", IEEE Power Engineering Society Winter Meeting, vol. 2, pp. 1085-1090, 1999. 
CONG, D.P.; RAISON B.; ROGNON, J.P.; BONNOIT, S.; MANJAL, B., "Optimization of fault indicators placement with dispersed generation insertion", IEEE Power Engineering Society - General Meeting, pp. 1530-1537, 2005.

DUC-PHAM, C.; RAISON, B.; ROGNON, J.-P.; BONNOIT, S.; MANJAL, B., "Optimization of fault indicators placement with dispersed generation insertion", IEEE Power Engineering Society - General Meeting, pp. 1530-1537, 2005.

FALAGHI, H.; HAGHIFAM, M.R.; OSOULI TABRIZI, M.R., "Fault indicators effects on distribution reliability indices", $18^{\text {th }}$ International Conference on Electricity Distribution - CIRED2005, pp. 1-4, 2005.

GOMIDE, F.A.C.; GUDWIN, R. R. "Modelagem, controle, sistemas e lógica fuzzy", Revista Controle e Automação, vol. 4, no. 3, pp. 97-115, 1994.

HIROTA, K. Industrial Applications of Fuzzy Technology, Springer Verlag, New York, 1993

KIM, C.H.; KIM, H.; KO, Y.H.; BYUN, S.H.; AGGARWAL, R.K.; JOHNS, A.T., "A novel fault-detection technique of high-impedance arcing faults in transmission lines using the wavelet transform", IEEE Transactions on Power Delivery, vol. 17, no. 4, pp. 921-929, 2002.

KRAJNAK, D. J., "Faulted circuit indicators and system reliability", Rural Electric Power Conference, pp. A4/1 - A4/4, 2000.

LEE, C.C., "Fuzzy logic in control systems: fuzzy logic controllers - part I and II", IEEE Transactions on Systems, Man and Cybernetics, vol. 20, pp. 404-435, 1990.

LEHTONEN, M., MATSINEN, A.; ANTILA, E.; KURU, E.J., "An advanced model for automatic fault management in distribution networks", IEEE Power Engineering Society Winter Meeting, vol. 3, pp. 1900-1904, 2000. 
PEDRYCZ, W; GOMIDE, F. An Introduction to Fuzzy Sets - Analysis and Design, MIT Press, 1998.

SANTOS, N.R.; SILVA, I.N.; FLAUZINO, R.A.; SPATTI, D.H., "Optimized Selection Approach of Transformer Protection Devices against Atmospheric Discharges Using Expert System", IEEE Power Engineering Society - General Meeting, Calgary (Canadá), 6p., 2009.

SILVA, I.N.; ARRUDA, A.; FLAUZINO, R.A., "Sistema especialista para obtenção da matriz de admitância de transformadores de potência visando estudos de transitórios de alta freqüência", VI Congreso Latino-Americano Generación y Transporte de Energía Eléctrica (CLAGTEE), Paper No. A-257, 8 p., 2005.

SILVA, I.N.; FLAUZINO, R.A.; RODRIGUES, J.F., "Uma aplicação de redes neurais artificiais em projetos de aterramento elétrico", IV Simpósio Brasileiro de Automação Inteligente, pp. 692-697, 1999.

SOUDI, F.; TOMSOVIC K., "Optimized distribution protection using binary programming", IEEE Transactions on Power Delivery, vol. 13, no. 1, pp 218-224, 1998.

SOUDI, F.; TOMSOVIC, K., "Optimal distribution protection design: quality of solution and computational analysis", International Journal on Electric Power and Energy Systems, vol. 21, pp. 327-335, 1999.

SOUDI, F.; TOMSOVIC, K., "Optimal trade-offs in distribution protection design", IEEE Transactions on Power Delivery, pp. 292-296, 2001.

TANG, Y.; WANG, H.F.; AGGARWAL, R.K.; JOHNS, A.T., "Fault indicators in transmission and distribution systems", Proceedings of Electric Utility Deregulation and Restructuring and Power Technologies, pp. 238-243, 2000. 
TANNLUND, P.; BJORKMAN, G., "An advanced distribution automation system experience from application development and project implementation", Proceedings of Power System Technology, pp. 127-132, 2000.

WANG H.; THORP, J.S., "Optimal locations for protection system enhancement: a simulation of cascading outages", IEEE Transactions on Power Delivery, vol. 16, no. 4, pp. 528-533, 2001.

ZADEH, L. A. "Fuzzy sets", Information and Control, vol. 8, p. 29-44, 1965.

ZADEH, L. A. "Outline of new approach to the analysis of Complex systems and decision", IEEE Transactions on Systems, Man and Cybernetics, vol. 3, pp. 2844, 1973.

ZAHRA, F.; JEYASURYA, B.; QUAICOE, J. E., "High-speed transmission line relaying using artificial neural networks", Electric Power Systems Research, no. 53, pp. 173-179, 2000.

ZHANG, H.F.; PAN, Z.C.; SANG, Z.Z., "Fault locating in ungrounded and compensated systems", Eighth IEE International Conference on Developments in Power System Protection, vol. 2, pp. 469-472, 2004. 